\title{
INCORPORAÇÃO DE RESÍDUOS URBANOS E AS PROPRIEDADES FÍSICO-HÍDRICAS DE UM LATOSSOLO VERMELHO AMARELO
}

\author{
CLÁUDIO ROBERTO MARCIANO
}

\begin{abstract}
Tese apresentada à Escola Superior de Agricultura "Luiz de Queiroz", Universidade de São Paulo, para obtenção do título de Doutor em Agronomia. Área de Concentração: Solos e Nutrição de Plantas.
\end{abstract}

P I R A C I C A B A

Estado de São Paulo - Brasil

Março - 1999 


\title{
INCORPORAÇÃO DE RESÍDUOS URBANOS E AS PROPRIEDADES FÍSICO-HÍDRICAS DE UM LATOSSOLO VERMELHO AMARELO
}

\author{
CLÁUDIO ROBERTO MARCIANO
}

Engenheiro Agrônomo

Orientador: Prof. Dr. SERGIO OLIVEIRA MORAES

Tese apresentada à Escola Superior de Agricultura "Luiz de Queiroz", Universidade de São Paulo, para obtenção do título de Doutor em Agronomia. Área de concentração: Solos e Nutrição de Plantas.

P I R A C I C A B A

Estado de São Paulo - Brasil

Março - 1999 
Dados Internacionais de Catalogação na Publicação (CIP)

DIVISÃO DE BIBLIOTECA E DOCUMENTAÇÃO - Campus "Luiz de Queiroz"/USP

\section{Marciano, Cláudio Roberto}

Incorporação de resíduos urbanos e as propriedades fisico-hídricas de um latossolo vermelho amarelo / Cláudio Roberto Marciano. - - Piracicaba, 1999.

93 p. : il.

Tese (doutorado) - - Escola Superior de Agricultura Luiz de Queiroz, 1999. Bibliografia.

1. Condutividade hidráulica do solo 2. Curva de retenção 3. Densidade do solo 4. Infliltrômetro 5. Latossolo vermelho-amarelo 6. Porosidade do solo 7. Propriedade fisica do solo 8 . Relação solo-água 9. Resíduo urbano I. Título 


\section{AGRADECIMENTOS}

- ao Conselho do Curso de Pós-Graduação em Solos e Nutrição de Plantas da ESALQ/USP, pela oportunidade de realização deste programa;

- ao CNPq, Conselho de Desenvolvimento Científico e Tecnológico, pela bolsa de estudos concedida;

- ao Prof. Dr. Sergio Oliveira Moraes, exemplo de ser humano e orientador no sentido mais amplo da palavra, pela orientação, dedicação e amizade;

- ao amigo Fernando Carvalho Oliveira, colega nos cursos de mestrado e doutorado e parceiro na condução deste trabalho, pela rica troca de informações em todos os momentos;

- à Profa. Dra. Maria Emilia Mattiazzo, pelo suporte dado a este trabalho;

- ao Dr. Léo Zimbach e à Dra. Raffaella Rossetto, pequisadores da Estação Experimental do IAC em Piracicaba, pela concessão da área experimental

- aos funcionários da Estação Experimental do IAC em Piracicaba, particularmente o técnico Marcelo, pelo inestimável apoio nas atividades de campo;

- ao Prof. Dr. Quirijn de Jong van Lier, pela colaboração no tratamento matemático dos dados e pela revisão desta tese;

- aos Profs. Dr. Paulo Leonel Libardi e Dr. Klaus Reichardt, pelos ensinamentos e pelos exemplos de trabalho e dedicação à vida acadêmica;

- aos técnicos Luiz Fernando Novello e Francisco Bernardo Dias, do Laboratório de Física do Solo do Depto. de Ciêcias Exatas, pelos apoio em todas as etapas deste trabalho, e aos demais funcionários do Depto. de Ciêcias Exatas, Anamaria, Robinson, Edivaldo e Vanderlino, pelo convívio; 
- ao Prof. Dr. Álvaro Pires da Silva, pela concessão de uso do Laboratório de Física do Solo do Depto. de Ciêcia do Solo e Nutrição de Plantas, onde parte das análises foram realizadas;

- aos técnicos Vladimir e Luciano, do Laboratório de Física do Solo do Depto. de Ciêcia do Solo e Nutrição de Plantas, pelo apoio nas análises;

- aos funcionários da DIBD da ESALQ/USP, pela atensioso atendimento de sempre;

- a todos os colegas da pós-graduação da ESALQ/USP, pelo agradável convívio;

- aos professores do Curso de Agronomia da Faculdade de Engenharia de Ilha Solteira/UNESP, por ser a fonte inicial de meu conhecimento agronômico;

A todos que direta ou indiretamente colaboraram para a realização deste trabalho, sinceramente agradeço.

Agradeço ainda, em especial:

- a Deus, pela vida e pela saúde;

- à minha esposa Lia e ao Murilo, que são minha nova família, pela convivência, amor, compreensão e apoio em todos os momentos;

- aos meus pais, Aparecida e Valdemar, por se superarem na educação de seus filhos, e aos meus irmãos, pelo convívio;

- aos demais familiares, pelo constante apoio. 


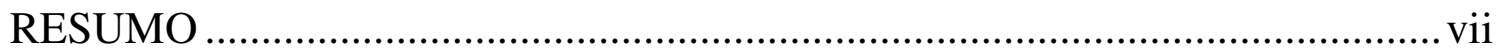

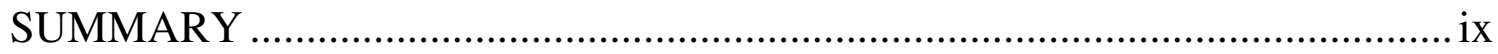

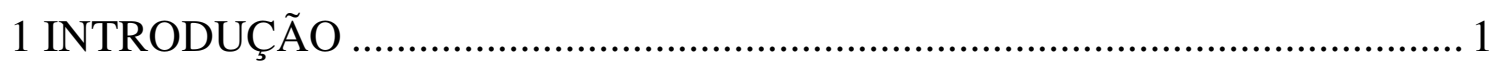

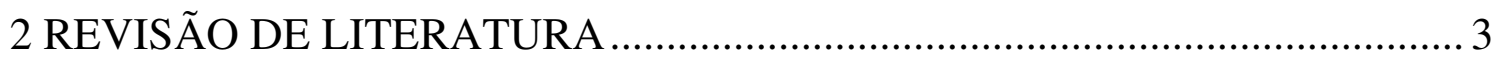

2.1 Geração e disposição de resíduos urbanos ................................................................ 3

2.2 Influência do revolvimento sobre a estrutura do solo e sobre sua estabilidade......... 4

2.3 Alterações de propriedades físicas do solo por materiais orgânicos ........................... 6

2.4 Persistência da matéria orgânica adicionada ao solo por resíduos urbanos e

sua importância para as propriedades físicas .......................................................... 9

2.5 Alterações de propriedades físicas "estáticas" do solo............................................. 11

2.6 Alterações de propriedades físicas "dinâmicas" do solo............................................. 16

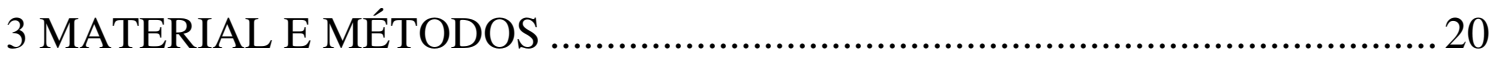

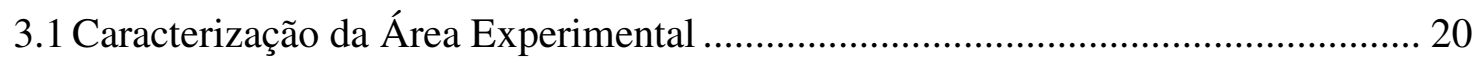

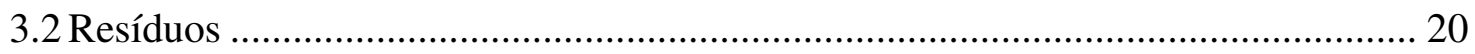

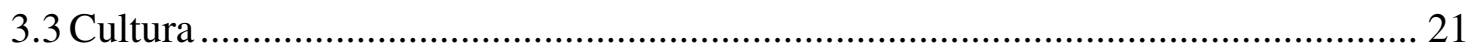

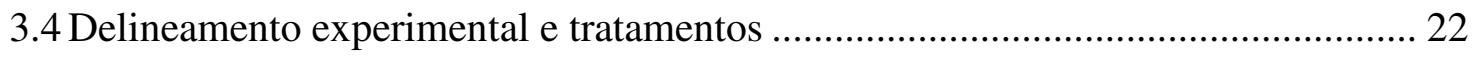

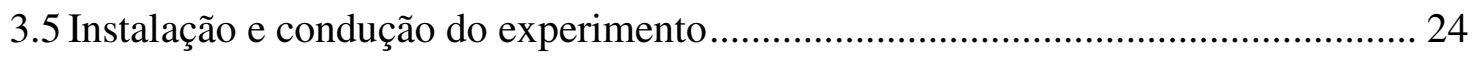

3.6 Dificuldades durante a instalação e condução do experimento................................. 25

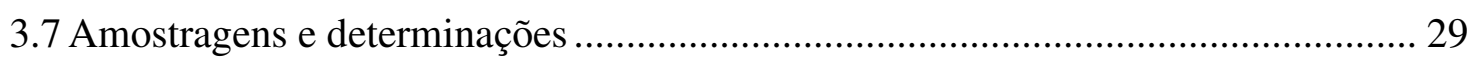

3.7.1 Análise granulométrica e densidade dos sólidos............................................ 29

3.7.2 Conteúdo de carbono orgânico do solo ........................................................... 30

3.7.3 Avaliação físico-hídrica do solo.................................................................. 30

3.7.3.1 Coleta e preparo das amostras de solo ....................................................... 30

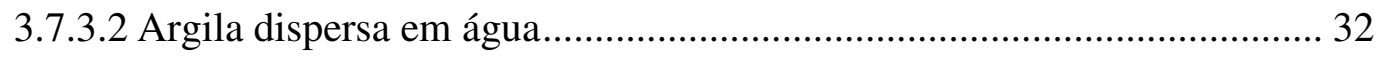


3.7.3.3 Condutividade hidráulica do solo saturado......................................... 32

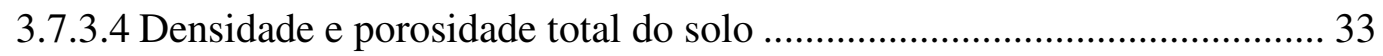

3.7.3.5 Curva de retenção da água no solo ..................................................... 34

3.7.3.6 Condutividade hidráulica obtida pelo método do infiltrômetro

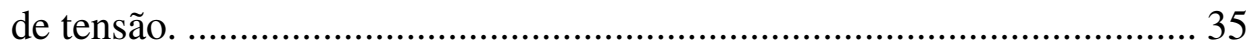

3.7.3.7 Condutividade hidráulica pelo método de Van Genuchten (1980).......... 37

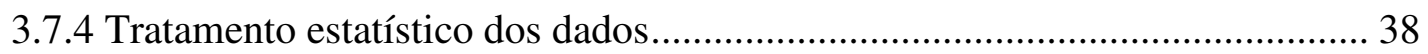

4 RESULTADOS E DISCUSSÃO ......................................................... 41

4.1 Composição granulométrica e densidade dos sólidos do solo .............................. 42

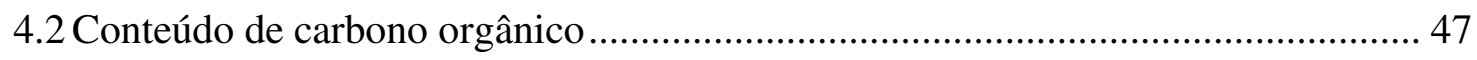

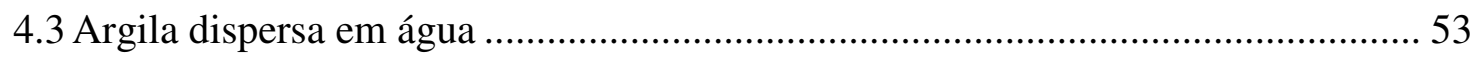

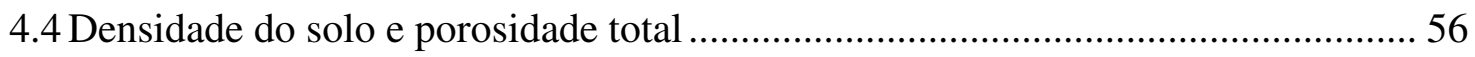

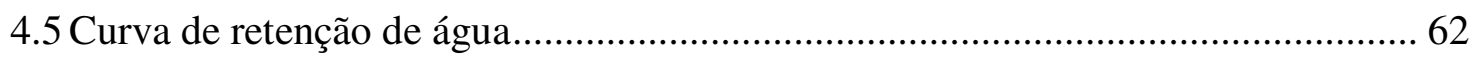

4.6 Condutividade hidráulica em amostras de solo saturadas ................................... 71

4.7 Condutividade hidráulica pelo método do infiltrômetro de tensão ........................ 73

4.8 Condutividade hidráulica pelo método de Van Genuchten (1980) ........................ 80

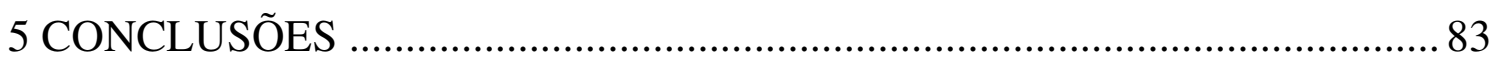

\section{REFERÊNCIAS BIBLIOGRÁFICAS}

APÊNDICE: Determinação da condutividade hidráulica a partir de medidas com infiltrômetro de tensão, pelo método de Ankeny et al. (1991) 


\title{
INCORPORAÇÃO DE RESÍDUOS URBANOS E AS PROPRIEDADES FÍSICO-HÍDRICAS DE UM LATOSSOLO VERMELHO AMARELO
}

\author{
Autor: CLÁUDIO ROBERTO MARCIANO \\ Orientador: PROF. DR. SERGIO OLIVEIRA MORAES
}

\begin{abstract}
RESUMO
Conduziu-se durante dois anos, em um Latossolo Vermelho Amarelo, em Piracicaba-SP (22 $41^{\prime} 00^{\prime \prime} \mathrm{S} ; 4^{\circ} 39^{\prime} 00^{\prime \prime} \mathrm{O} ; 554 \mathrm{~m}$ de altitude), um experimento com a cultura da cana-de-açúcar. Foram utilizados 9 tratamentos com 4 repetições, implantados num delineamento em blocos ao acaso. Os tratamentos foram: tr1 - adubação mineral + calagem; tr2, tr3; tr4 e tr5 - doses de lodo de esgoto (respectivamente, 0; 33; 66 e $99 \mathrm{Mg} \mathrm{ha}^{-1}$, no primeiro ano, e 0; 37; 74 e $112 \mathrm{Mg} \mathrm{ha}^{-1}$, no segundo ano); tr6, tr7; tr8 e tr9 - doses de composto de lixo (respectivamente, 0; 20; 40 e $60 \mathrm{Mg} \mathrm{ha}^{-1}$, no primeiro ano, e $0 ; 24 ; 48$ e $72 \mathrm{Mg} \mathrm{ha}^{-1}$, no segundo ano). Os resíduos foram aplicados manualmente na superfície do solo e incorporados com enxada rotativa, no primeiro ano em área total e no segundo apenas na entrelinha. Foram determinados, em cada parcela, os seguintes parâmetros do solo: composição granulométrica (amostras coletadas antes da implantação do experimento); o conteúdo de carbono orgânico (amostras coletadas em 15 datas durante os dois anos); conteúdo de argila dispersa em água, densidade e porosidade total (amostras coletadas ao final do primeiro e do segundo ano do ciclo da cultura); curva de retenção de água, condutividade hidráulica do solo saturado e condutividade hidráulica relativa (amostras coletadas ao final do primeiro ano do ciclo da cultura); e condutividade hidráulica do solo saturado e não saturado (determinada no campo ao final de dois anos do ciclo da cultura, utilizando o infiltrômetro de tensão).
\end{abstract}


Os resultados obtidos mostraram que houve redução da densidade do solo e aumento da porosidade total com o aumento das doses dos resíduos, para a camada de 0 a 0,15 m de profundidade, no segundo ano de aplicação. Nas parcelas que receberam aplicações de ambos os resíduos, houve aumento da condutividade hidráulica do solo próximo à saturação e redução à medida que o solo se afasta da saturação, para a faixa de potencial mátrico estudada $(0$ a $1 \mathrm{kPa})$. O decaimento da condutividade hidráulica relativa, a partir da saturação, foi inicialmente mais acentuado nas parcelas que receberam aplicações de ambos os resíduos, quando comparadas às que não receberam resíduos. Verificou-se também, através de análises de regressão múltipla, que diferenças na retenção de água e no conteúdo de argila dispersa em água, que pela análise de variância convencional seriam atribuídas exclusivamente aos tratamentos, de fato eram parcial ou totalmente devidas a variações não casuais na composição granulométrica do solo.

Pelos resultados pôde-se concluir que a aplicação de resíduos urbanos ao solo leva a modificações de propriedades como a densidade e porosidade total do solo, a condutividade hidráulica do solo saturado e a condutividade hidráulica do solo não saturado. Pôde-se concluir também que a casualização dos tratamentos na área experimental não garante a ausência de covariação entre os tratamentos e outras variáveis independentes, as quais podem interferir nas propriedades de interesse (variáveis dependentes) e, conseqüentemente, na eficiência da análise de variância feita de maneira convencional, sendo recomendado a realização de um "ensaio em branco" para verificar a eficiência desta casualização. 


\title{
URBAN RESIDUES INCORPORATION AND SOIL PHYSICO-HIDRIC PROPERTIES OF A RED YELLOW LATOSOL
}

\author{
Author: CLÁUDIO ROBERTO MARCIANO \\ Adviser: PROF. DR. SERGIO OLIVEIRA MORAES
}

\begin{abstract}
SUMMARY
An experiment was carried out during two years on a Red Yellow Latosol cropped with sugar-cane, located in the country of Piracicaba-SP $\left(22^{\circ} 41^{\prime} 00^{\prime \prime} \mathrm{S}\right.$; $47^{\circ} 39^{\prime} 00^{\prime \prime} \mathrm{W} ; 554 \mathrm{~m}$ high). Nine treatments with 4 replications were used in a random-block experimental design. The treatments were: $\operatorname{tr} 1-$ mineral fertilization + $\mathrm{CaCO}_{3} ; \operatorname{tr} 2, \operatorname{tr} 3 ; \operatorname{tr} 4$ and tr5 - levels of sewage sludge (respectively, 0; 33; 66 and $99 \mathrm{Mg}$ $\mathrm{ha}^{-1}$, in the first year, and $0 ; 37 ; 74$ and $112 \mathrm{Mg} \mathrm{ha}^{-1}$, in the second year); tr6, tr7; tr8 and tr9 - levels of composed of garbage (respectively, 0; 20; 40 and $60 \mathrm{Mg} \mathrm{ha}^{-1}$, in the first year, and 0; 24; 48 and $72 \mathrm{Mg} \mathrm{ha}^{-1}$, in the second year). The residues were manually applied on the soil surface and incorporated with a rotative plough. In the first year, the incorporation was done on the total area; in the second year only in inter-rows. The following soil parameters were determinated in each plot: particle size distribution (samples collected before the installation of the experiment); organic carbon content (15 samplings along the two years); natural clay content, soil bulk density and total soil porosity (sampling at the end of the first and second years of the growing cycle); water retention curves, saturated hydraulic conductivity and relative unsaturated hydraulic conductivity (samples collected at the end of the first year of the growing cycle); and saturated and unsaturated hydraulic conductivity (determined in situ at the end of the first and second years of the growing cycle, using tension infiltrometer).
\end{abstract}


Results show a decrease the soil bulk density and increase of total porosity as the levels of residue application increased, for the 0 to $0.15 \mathrm{~m}$ soil layer, in the second year of application. On the plots that received applications of both residues, there was increase of the hydraulic conductivity near the soil saturation and decrease for the 0 to $1 \mathrm{kPa}$ matric potential range. The decline of the relative hydraulic conductivity starting from the saturation, was initially more accentuated in the plots that received applications of both residues as compared with the ones that did not. It was also verified, through analyses of multiple regression, that differences in the water retention and in the natural clay content, that they would be attributed exclusively to the treatments by the conventional variance analysis, they were partially or totally owed to non casual variations in the particle size distribution of the soil.

It could be concluded that the soil application of urban residues causes modifications of soil physical properties as saturated and unsaturated soil hydraulic conductivity. It could also be concluded that the randomization of the treatments in the experimental area does not guarantee the covariance absence between the treatments and other independent variables, which can interfere in the properties of interest (dependent variables) and, consequently, in the efficiency of the variance analysis done in a conventional way. 


\section{INTRODUÇÃO}

Um dos grandes problemas ambientais da atualidade é a alta produção de resíduos urbanos. A maior parte dos esgotos é lançada "in natura" nos cursos d'água e o lixo urbano depositado a céu aberto ou, em alguns casos, em aterros sanitários. Ambos causam odores desagradáveis, atraem animais e insetos transmissores de doenças e comprometem a qualidade dos recursos hídricos de determinadas regiões, podendo inclusive contaminar águas de abastecimento urbano. Os esgotos podem ser tratados, o que resolve apenas parte do problema, pois este processo gera uma grande quantidade de lodo de esgoto, um resíduo de consistência pastosa e composição predominantemente orgânica. Se a destinação final deste novo resíduo não for adequada, a eficiência ambiental do tratamento dos esgotos passa a ser reduzida. Neste sentido, o uso agrícola do lodo de esgoto é uma possibilidade. Quanto ao lixo, uma das alternativas para a redução do volume a ser descartado é a produção de composto orgânico, também com destinação agrícola.

Entretanto, a utilização de resíduos dessa natureza em solos pode ser limitada por diversos fatores, destacando-se a presença de patógenos, de compostos orgânicos persistentes e tóxicos, de compostos nitrogenados e, principalmente, de metais pesados. Como conseqüência, os organismos do solo podem ser afetados, as plantas podem manifestar sintomas de toxidez e os metais pesados adicionados podem ser transferidos para a cadeia alimentar através do consumo dos vegetais ou mesmo da água contaminada de aqüíferos superficiais ou subterrâneos. Por outro lado, desde que utilizados dentro de certos limites a serem definidos pela pesquisa, a possibilidade do uso agrícola desses resíduos mostra-se promissora, pois além de sua eliminação ser uma necessidade econômica e social, eles podem eventualmente trazer efeitos benéficos ao solo. 
Tendo em vista que o uso agrícola do lodo de esgoto é uma possibilidade iminente e que o uso de composto de lixo já é um fato, principalmente nas proximidades das grandes cidades, o descarte desses resíduos em solos de áreas tropicais requer mais estudos, principalmente objetivando uma avaliação mais detalhada das possíveis alterações tanto benéficas quanto maléficas que venham a ocorrer. Neste contexto, o presente trabalho fez parte de um projeto mais abrangente, o qual incluiu o projeto intitulado "Metais pesados e formas nitrogenadas em um Latossolo Vermelho Amarelo tratado com resíduos urbanos durante anos sucessivos", em que se estudou a degradação da carga orgânica adicionada, a lixiviação de formas nitrogenadas e metais pesados e a fitodisponibilidade desses metais no solo. Outro objetivo do referido projeto foi verificar a aplicabilidade em condições tropicais dos critérios ditados pela EPA (Agência de Proteção Ambiental dos EUA), os quais são definidos em termos de quantidades máximas de metais pesados possíveis de serem aplicadas anualmente ao solo.

Reconhecendo que os principais fatores que devem limitar o descarte desses resíduos sejam os químicos, e que a contaminação das águas superficiais e subterrâneas está intimamente ligada às propriedades de retenção e transmissão de água e de solutos no solo, o presente trabalho objetivou estudar os efeitos do descarte desses materiais nas propriedades físico-hídricas do solo, contribuindo com o projeto citado anteriormente. Neste sentido, esse estudo assenta-se na hipótese de que a aplicação dos resíduos levará a modificações nas propriedades físico-hídricas do solo, tal como a retenção de água e a condutividade hidráulica do solo saturado e não saturado. 


\section{REVISÃo DE LITERATURA}

\subsection{Geração e disposição de resíduos urbanos}

A produção de lixo nas áreas urbanas brasileiras está em trono de 0,7 e $0,9 \mathrm{~kg} \mathrm{dia}^{-1}$, de acordo com estudos citados por Lima et al. (1998). Estes autores mostram ainda uma estimativa de que a população brasileira, hoje em torno de 150 milhões, crescerá até se estabilizar nos 265,5 milhões, no ano de 2075. Considerando que a quantidade de lixo per capita se mantenha estável, e que $80 \%$ desta população resida em cidades, o cálculo da quantidade de lixo que seria gerada em 2075 leva a um resultado assustador: cerca de $170.000 \mathrm{Mg}$ de lixo por dia. A reciclagem do lixo urbano é uma das melhores formas de se evitar o acúmulo desse material em lixões ou aterros sanitários (Berton \& Valadares, 1991). A compostagem, passível de ser realizada devido ao alto teor de matéria orgânica do lixo, é uma boa opção para a diminuição da quantidade a ser descartada e ainda ajudar na produção agrícola (Lima et al., 1998). Para efeito de cálculo, Berton (1996) assumiu que metade da quantidade do lixo que é processado em usinas de reciclagem é transformada em composto orgânico, o que representa uma redução considerável. Em sua estimativa, presumindo ainda que os 29 milhões de habitantes que vivem em regiões urbanas do Estado de São Paulo produzam por habitante $0,5 \mathrm{~kg} \mathrm{dia}^{-1}$, teríamos uma oferta potencial de composto de lixo de 2,6 milhões $\mathrm{Mg}$ ano $^{-1}$. Considerando uma aplicação média de composto de $30 \mathrm{Mg} \mathrm{ha}^{-1}$, essa quantidade potencial a ser produzida daria apenas para cerca de $1 \%$ da área explorada com culturas comerciais no Estado, o que permitiu ao autor concluir que há demanda suficiente para suprir a oferta.

No Brasil, apenas uma fração muito pequena dos esgotos é hoje tratada. Deste tratamento resulta o lodo de esgoto, cuja disposição final é problemática e chega a 
representar $60 \%$ do custo de operação das estações de tratamento (Centro Nacional de Referência em Gestão Ambiental Urbana, 1998). No entanto, inúmeros projetos de tratamento têm sido implantados, e a produção deste resíduo deve crescer acentuadamente a curto prazo. Alternativas para seu descarte são apresentadas por Mattiazzo-Prezzotto (1992), sendo que uma das consideradas mais vantajosas e ambientalmente corretas é a disposição de lodo de esgoto em solos agrícolas, pois além do efeito fertilizante, este resíduo melhora as condições físicas do solo. Neste sentido, segundo o Centro Nacional de Referência em Gestão Ambiental Urbana (1998), a Companhia de Saneamento do Paraná (SANEPAR) está coordenando a implantação do projeto “Utilização agrícola do lodo de esgoto como fertilizante”. Além disso, segundo a própria Companhia de Saneamento do Paraná (1998), o projeto promoveu a publicação do “Manual técnico para utilização agrícola do lodo de esgoto no Paraná”, que já está sendo comercializado.

A aplicação de resíduos ao solo, que a nível internacional já era tradicional do ponto de vista agronômico, onde o objetivo básico é o fornecimento de nutrientes às plantas, mudou de enfoque já na década de 70, passando a existir um interesse cada vez maior em dispor desses resíduos em doses muito além daquelas de tradição agronômica (Khaleel et al., 1981). O uso do solo agrícola como sistema receptor da matéria orgânica presente no lixo urbano e nos esgotos, através do composto de lixo e do lodo de esgoto, apresenta-se como uma alternativa natural e racional para a reciclagem desses resíduos, uma vez que são em sua maioria originários do próprio solo. O Centro Nacional de Referência em Gestão Ambiental Urbana, órgão vinculado ao Ministério do Meio Ambiente, dos Recursos Hídricos e da Amazônia Legal e à Universidade Livre do Meio Ambiente, tem uma página na Internet (http://www.bsi.com.br/unilivre/centro) que divulga boa parte dos planos, programas, pesquisas e experiências bem sucedidas desta área desenvolvidos no Brasil.

\subsection{Influência do revolvimento sobre a estrutura do solo e sobre sua estabilidade}

Eventualmente resíduos orgânicos podem ser aplicados ao solo sem que haja incorporação, entretanto na maioria das vezes esta é feita por ocasião do preparo do 
solo. Neste caso, as alterações físicas não podem ser atribuídas exclusivamente à adição do resíduo, uma vez que o simples revolvimento do solo durante o preparo reconhecidamente altera a densidade, a porosidade total e a distribuição dos diâmetros de poros (Camargo, 1983; Castro, 1989). Pelo revolvimento, a densidade diminui e a porosidade total aumenta, principalmente pelo incremento do volume de macroporos. Como conseqüência, as propriedades físico-hídricas do solo também são alteradas. A retenção de água aumenta para potenciais mátricos próximos à zero, mas sofre um diminuição acentuada à medida que o solo se afasta da saturação, de forma que já para potenciais mátricos da ordem de $-10 \mathrm{kPa}$ (um dos valores normalmente aceitos para capacidade de campo) a retenção passa a ser menor que aquela para um solo não revolvido. Para o potencial mátrico correspondente ao ponto de murcha permanente (-1500 kPa), esta diminuição na retenção pode ser menos acentuada ou mesmo não ocorrer, de forma que a água retida na faixa disponível às plantas (entre $-10 \mathrm{e}$ -1500 kPa) pode não se alterar ou mesmo diminuir. A condutividade hidráulica do solo próximo à saturação pode ser incrementada devido ao aumento da proporção de macroporos. Para umidades mais baixas, a condutividade pode diminuir, seja devido à redução da proporção de microporos, seja devido ao aumento na tortuosidade do filme de água que recobre as partículas do solo.

Embora no presente trabalho não tenham sido encontradas referências na literatura sobre os fatores que determinam a condição estrutural de um solo imediatamente após o seu revolvimento (ou seja, o arranjamento tridimensional de suas partículas), pode-se supor que estes fatores devem ser, basicamente, as características das partículas primárias e secundárias, como tamanho, densidade e formato. No entanto esta estrutura inicial é extremamente instável, e o solo se consolidará com o tempo após o revolvimento (Brown et al., 1990). Por exemplo, Klein (1996), trabalhando em uma área conduzida sob sistema plantio direto por 3 anos, implantou 5 tipos de manejo de solo: arado de discos; escarificador protótipo modelo "paraplow"; escarificador com hastes parabólicas; grade de discos e plantio direto (testemunha). Após estes tratamentos, toda a área voltou a ser manejada no sistema de plantio direto, e amostragens para avaliar a densidade do solo foram realizadas 8, 20 e 28 meses após. 
Nos tratamentos com escarificador e arado de discos, o autor verificou redução significativa da densidade do solo na primeira amostragem, porém nenhum efeito persistiu para a segunda e terceira amostragens. West et al. (1992), para três áreas cultivadas convencionalmente com soja e sorgo granífero, verificaram que a erodibilidade do solo consolidado (9 meses após o preparo, após um ciclo cultural) foi apenas $23 \%$ daquela observada para o solo não consolidado (recém preparado). Segundo os autores, isto ocorre devido à maior estabilidade estrutural deste último, confirmada pelos maiores índices de resistência à fratura (cisalhador) e à penetração (penetrômetro de bolso).

Devido à instabilidade da estrutura do solo após o revolvimento, os efeitos imediatos do preparo também podem ser revertidos muito rapidamente. Diversos fatores levam à reacomodação das partículas do solo, fazendo com que estas atinjam uma condição estrutural mais estável. O tráfego de máquinas e implementos, o impacto das gotas de chuva, a movimentação da água no solo e os ciclos de umedecimento e secagem são alguns destes fatores (Gerard, 1965; Brown et al., 1990, Dias Júnior \& Pierce, 1996). A intensidade dessa reacomodação, no entanto, pode ser diferente dependendo, por exemplo, da classe textural ou da presença de agentes cimentantes. Se durante o revolvimento é feita a incorporação de resíduos orgânicos, o solo pode se tornar menos susceptível aos fatores que induzem a reacomodação das partículas do que aquele onde nenhum resíduo foi incorporado. Isto ocorre porque a matéria orgânica é um dos principais agentes cimentantes dos agregados do solo, e a elevação de seu conteúdo pode levar, ainda que parcialmente, à manutenção das alterações estruturais induzidas pelo revolvimento do solo.

\subsection{Alterações de propriedades físicas do solo por materiais orgânicos}

Diversos são os trabalhos que mostram as alterações no solo provocadas pela aplicação de materiais orgânicos. Do ponto de vista químico, segundo Glória (1992), esta aplicação pode provocar alterações no $\mathrm{pH}$ (que dependem do tipo de material orgânico) e aumento das cargas negativas do solo (e, consequentemente, da CTC). Além disso, o autor afirma que a utilização de resíduos permite a reciclagem de nutrientes e 
contribui para o solo em termos de matéria orgânica, que está presente em elevada concentração nesses materiais. Comumente ocorrem também alterações em propriedades físicas do solo associadas ao aumento do conteúdo de matéria orgânica proporcionada pela aplicação dos resíduos (Hill \& James, 1995). Diversos autores revisaram na literatura os resultados de pesquisa sobre os efeitos de resíduos orgânicos nas propriedades físicas do solo (Khaleel et al., 1981; Clapp et al., 1986; Gallardo-Lara \& Nogales, 1987; Metzger \& Yaron, 1987; Hill \& James, 1995). A partir dos dados disponíveis na literatura, Khaleel et al. (1981) conseguiram estabelecer correlações entre alterações na capacidade de retenção de água e na densidade do solo e o incremento no conteúdo de carbono orgânico do solo.

Trabalhos mais antigos, como o de Bouyoucos (1939), também já evidenciavam efeitos de materiais orgânicos em propriedades físicas do solo. Utilizando $100 \mathrm{~g}$ de 7 solos e adicionando a cada um deles as quantidades $0,2,4,6,8,10$ e $12 \mathrm{~g}$ de solo orgânico, turfa ou esterco de curral, Bouyoucos (1939) verificou aumento na água disponível às plantas com o aumento da dose do material aplicado. O efeito foi proporcionalmente maior quanto mais arenoso era o solo, ou seja, quanto menor a sua capacidade de retenção original. Neste caso, onde do ponto de vista agrícola as quantidades aplicadas foram elevadíssimas e a determinação foi feita imediatamente após a mistura dos materiais, mediu-se apenas a transferência da capacidade de retenção de água dos resíduos, que é elevada, para o solo.

Pode-se, portanto, evidenciar duas maneiras pelas quais a matéria orgânica age sobre as propriedades físico-hídricas do solo. A primeira é pela sua ação cimentante, a qual leva à manutenção das alterações estruturais induzidas pelo revolvimento do solo durante o preparo. A segunda é pela transferência ao solo de suas propriedades intrínsecas, que aqui denominaremos efeito mistura. Neste sentido, Logan \& Harrison (1995) estudaram, em um solo de textura siltosa, os efeitos da aplicação de $500 \mathrm{Mg} \mathrm{ha}^{-1}$ de um resíduo denominado ' $\mathrm{N}$-viro soil", formado pela mistura entre lodo de esgoto e um ou mais subprodutos industriais alcalinos (que promovem a estabilização do lodo). Inicialmente no trabalho o resíduo é caracterizado fisicamente quanto ao seu conteúdo de sólidos, conteúdo de material orgânico, densidade e porosidade total, densidade dos 
sólidos, retenção de água, condutividade hidráulica do solo saturado em amostras normais e compactadas, limites de Atterberg, índice de retração com a secagem, estabilidade de agregados e composição granulométrica. Um ano após a aplicação do resíduo ao solo, determinou-se, no campo, a resistência à penetração, e em amostras de solo coletadas na camada $0-0,15 \mathrm{~m}$ de profundidade, as mesmas propriedades físicas enumeradas anteriormente para o 'N-viro soil". Para cada uma destas propriedades foram obtidos valores previstos considerando-se somente o efeito da mistura volumétrica entre o "N-viro soil" e o solo. Este valor previsto geralmente permaneceu dentro de uma faixa de $40 \%$ de variação em torno do valor observado. Na maioria dos casos, o valor previsto subestimou o efeito do "N -viro soil" (mesmo as medidas tendo sido feitas um ano após a aplicação). Segundo os autores, isto sugere que as reações químicas, físicas e biológicas entre o "N-viro soil" e o solo devem ter influenciado as propriedades físicas mais do que seria esperado aplicando-se um modelo de simples mistura para prever as alterações.

Pelo exposto, conclui-se que podem ocorrer alterações em propriedades físicas do solo ainda que quantidades não muito elevadas de resíduos sejam utilizadas, pois estas alterações não ocorrem somente em função do efeito direto da matéria orgânica, mas de suas reações no solo, as quais intensificam este efeito. Conclui-se também que a ação da matéria orgânica sobre a estrutura do solo não pode ser avaliada por determinações realizadas imediatamente após a incorporação, uma vez que as reações químicas, físicas e biológicas sugeridas por Logan \& Harrison (1995) não teriam ainda ocorrido. Outro aspecto a se considerar é que, embora esta ação cimentante e o efeito mistura sempre ocorram concomitantemente, eles eventualmente podem alterar as propriedades físico-hídricas de maneira inversa. Por exemplo, quanto à retenção de água na capacidade de campo, verifica-se que a ação conjunta do revolvimento do solo e da presença da matéria orgânica como agente cimentante levaria à sua redução, conforme discutido anteriormente. Já o efeito da simples mistura levaria ao seu aumento, seja porque a matéria orgânica tem elevada capacidade de retenção de água, seja porque suas partículas coloidais podem se interpor nos macroporos, transformando-os em microporos. Quanto à condutividade hidráulica, Metzger \& Yaron (1987) salientam, 
para a aplicação de lodo de esgoto, que o efeito dos componentes orgânicos sobre esta propriedade é indireto, através da modificação na condição de agregação e na porosidade do solo, levando ao seu aumento para umidades próximas à saturação e à sua redução para umidades menores. No entanto, quando se aplica material orgânico na superfície sem posterior incorporação, efeito inverso a este eventualmente pode ocorrer. Neste caso, partículas orgânicas coloidais podem ser carreadas e se interporem nos macroporos, reduzindo a condutividade hidráulica para umidades próximas à saturação (devido à diminuição dos macroporos), e aumentando-a para umidades menores (devido à elevação da proporção de microporos ou à diminuição na tortuosidade do filme de água que recobre as partículas do solo).

O resultado final da incorporação de um resíduo ao solo será devido ao balanço entre a ação cimentante e o efeito mistura. A predominância de um ou outro será basicamente função da quantidade aplicada. Se a quantidade aplicada for pequena, pode-se esperar a predominância da ação cimentante, afetando a estrutura do solo. Caso a quantidade aplicada seja mais elevada, a transferência das propriedades do resíduo para o solo pelo efeito mistura pode ter um significado mais pronunciado.

\subsection{Persistência da matéria orgânica adicionada ao solo por resíduos urbanos e sua importância para as propriedades físicas}

Metzger \& Yaron (1987), revisando na literatura a influência da matéria orgânica do lodo nas propriedades físicas do solo, afirmam que a persistência destes efeitos está diretamente relacionada à persistência do carbono orgânico do lodo no solo. Se parte do carbono orgânico é resistente à degradação, o seu conteúdo no solo aumentará sob aplicações repetidas de lodo e alterações irreversíveis das propriedades físicas poderão ocorrer. Assim, o mais importante efeito da adição de resíduos sobre propriedades físicas do solo seria conseqüência da permanência de certas frações da matéria orgânica adicionada (ou de certas frações neoformadas a partir de sua transformação), permanência esta que pode provocar alterações estruturais e na estabilidade dos agregados do solo.

Ressalta-se, portanto, a importância de estudos sobre a dinâmica do carbono orgânico adicionado ao solo. Apesar das substâncias orgânicas adicionadas se 
envolverem em diversas interações com a fração mineral do solo, a extensão de sua mineralização depende de vários fatores. Em seu trabalho, Metzger \& Yaron (1987) enumeram como fatores as características do resíduo (naquele caso, características do lodo de esgoto, como origem, técnica de estabilização, composição), os parâmetros do solo (textura, $\mathrm{pH}$ ), as condições ambientais (temperatura, umidade) e as condições de aplicação (dose e método de aplicação). Por exemplo, quanto às características do resíduo, os autores diferenciam claramente dois tipos de lodo de esgoto: os digeridos anaerobicamente, que apresentam uma fração relativamente elevada de carbono orgânico resistente à degradação, e os não digeridos, em que as quantidades de carbono orgânico mineralizável são muito maiores. Quanto ao método de aplicação, informações a respeito da influência da incorporação ou não dos resíduos ao solo sobre a dinâmica da mineralização da matéria orgânica são raras e contraditórias. Em casa de vegetação, Terry et al. (1979) observaram mineralização mais rápida do carbono orgânico quando o lodo de esgoto foi aplicado à superfície do que quando foi incorporado ao solo. No campo, Kladivko \& Nelson (1979) compararam a dinâmica do conteúdo de carbono orgânico do solo, ao qual lodo líquido foi aplicado por três diferentes métodos (aplicação em superfície, grade de discos e grade rotativa), e observaram que não houve diferenças significativas entre os tratamentos. Aqui consideraremos somente o caso da incorporação dos resíduos à camada arável.

Diversos autores verificaram que boa parte da matéria orgânica adicionada é resistente à decomposição ou converte-se rapidamente em formas mais estáveis de materiais húmicos. Gupta et al. (1977), por exemplo, em um experimento de campo onde foram aplicadas $0,112,225$ e $450 \mathrm{Mg} \mathrm{ha}^{-1}$ de lodo de esgoto, observaram que 58\% da matéria orgânica aplicada não foi decomposta até 1 ano após a aplicação. Feita uma segunda aplicação das mesmas doses e decorrido mais um ano, os autores observaram que 50\% da matéria orgânica aplicada nos dois anos não havia sido decomposta. Hernandez et al. (1988), no entanto, aplicaram ao solo restos de videira, esterco de porco, esterco de curral, lixo urbano e lodo de esgoto e verificaram que, para os três últimos, o teor de carbono orgânico das parcelas apresentou-se menor que na testemunha. Os autores concluíram, portanto, que as interações do resíduo com a fração 
mineral mudaram a dinâmica da transformação do carbono orgânico no solo, alterando inclusive o comportamento do carbono nativo. Ou seja, a extensão da mineralização do carbono orgânico depende realmente dos vários fatores enumerados por Metzger $\&$ Yaron (1987).

No Brasil ainda são poucos os trabalhos que avaliam a velocidade da degradação de resíduos orgânicos em solos. Entre eles pode-se citar o trabalho de Oliveira (1995), que num experimento em casa de vegetação utilizando solos tratados com 50, 100 e $150 \mathrm{Mg} \mathrm{ha}^{-1}$ de lodo de esgoto úmido (respectivamente correspondentes a 13,5; 27 e 40,5 $\mathrm{Mg} \mathrm{ha}^{-1}$ do material seco), evidenciou que a maior parte da carga orgânica de lodos de esgoto não permanece nos solos por mais de 60 dias. Também trabalhando em casa de vegetação, Barreto (1995) aplicou a dois solos (um arenoso, com apenas $68 \mathrm{~g} \mathrm{~kg}^{-1}$ de argila, e outro de textura média, com $235 \mathrm{~g} \mathrm{~kg}^{-1}$ de argila) quantidades correspondentes a 0; 3,6 e 7,2 $\mathrm{Mg} \mathrm{ha}^{-1}$ de carbono orgânico, a partir de quatro resíduos (torta de filtro, composto de lixo, lodo petroquímico e lodo de esgoto). Num período de incubação de 60 dias, o autor observou que 52 a $66 \%$ das perdas ocorreram nos primeiros 20 dias. Ao final do período, já havia sido degradado cerca de $80 \%$ do carbono aplicado ao solo arenoso e $60 \%$ do aplicado ao solo de textura média.

Observa-se que, no Brasil, a maior parte dos resultados disponíveis é proveniente de trabalhos de incubação em vasos conduzidos em casa de vegetação. Mesmo a nível internacional, Metzger \& Yaron (1987) salientam que, na maioria dos casos, o potencial de mineralização para a matéria orgânica do lodo foi obtido a partir de resultados de incubação de misturas solo-lodo sob condições controladas. No campo os fatores que determinam a dinâmica de mineralização do carbono orgânico adicionado se equacionam de maneira distinta daquela da casa de vegetação, e a evolução da condição física do solo obtido em uma condição não pode ser transferida para outra.

\subsection{Alterações de propriedades físicas "estáticas" do solo}

Há cerca de 50 anos, Klute \& Jacob (1949) já relatavam que a adição de materiais ricos em matéria orgânica levava a alterações físicas do solo, como a diminuição de sua densidade. Isto vem sendo constantemente reafirmado para os novos 
resíduos que hoje são gerados e que necessitam ser descartados. Por exemplo, Berton (1996) afirma que, devido à presença de matéria orgânica em sua composição, o composto de lixo urbano diminui a densidade do solo. Khaleel et al. (1981), analisando dados de 12 estudos sobre efeitos a curto e longo prazo da aplicação de resíduos, deduziram uma equação de regressão linear $(\Delta \rho=3,99+6,99 \Delta \mathrm{CO})$ entre a redução percentual relativa na densidade do solo $(\Delta \rho)$ e o incremento percentual relativo no carbono orgânico do solo $(\Delta \mathrm{CO})$.

Gupta et al. (1977), após dois anos de aplicação de lodo de esgoto em solo arenoso, resultando em doses acumuladas de 0, 225, 450 e $900 \mathrm{Mg} \mathrm{ha}^{-1}$, verificaram uma diminuição linear da densidade do solo $\left(\rho, \mathrm{em} \mathrm{Mg} \mathrm{m}^{-3}\right)$ em função do conteúdo de matéria orgânica do solo ( $\mathrm{MO}$, em \% a base de massa), segundo a equação $\rho=1,4975$ - 0,0875 MO. Como consequiência, também verificaram aumento na porosidade total. Wei et al. (1985) aplicaram doses de 0;11,2; 22,4; 48,8 e $112 \mathrm{Mg} \mathrm{ha}^{-1}$ de lodo de esgoto em um solo argiloso. Além destes, um tratamento adicional foi a aplicação de seis doses anuais de $22,4 \mathrm{Mg} \mathrm{ha}^{-1}$, totalizando $134,4 \mathrm{Mg} \mathrm{ha}^{-1}$. Após 5,5 anos, tendo sido cultivados sorgo granífero $\left(1^{\circ}\right.$ ciclo cultural) e milho (demais 5 ciclos), os autores verificaram reduções na densidade do solo em relação à testemunha de $0,0,7 ; 3,5 ; 8,3$ e 6,3\%, respectivamente para as doses 11,$2 ; 22,4 ; 48,8 ; 112$ e $134,4 \mathrm{Mg} \mathrm{ha}^{-1}$.

Felton (1995) aplicou e incorporou a um solo de mina duas doses de composto de lixo urbano (14 e $28 \mathrm{Mg} \mathrm{ha}^{-1}$ ). Ao longo de 34 meses, o valor médio da densidade do solo nas parcelas testemunha foi da ordem de $1,74 \mathrm{Mg} \mathrm{m}^{-3}$, enquanto que nas parcelas tratadas o autor verificou que esta se reduziu para $1,49 \mathrm{Mg} \mathrm{m}^{-3}$. No entanto, diferenças significativas entre os dois níveis de tratamentos não existiram, resultado este que o autor considera aceitável pelo fato de considerar que a dose $14 \mathrm{Mg} \mathrm{ha}^{-1}$ já é uma aplicação elevada, acima da qual uma aplicação adicional de material orgânico, como $28 \mathrm{Mg} \mathrm{ha}^{-1}$, tem pouco efeito. Logan \& Harrison (1995), em seu trabalho descrito no item 2.3, verificaram que tanto a densidade do solo $(\rho)$ quanto a densidade dos sólidos $\left(\rho_{\mathrm{s}}\right)$ foram significativamente diminuídas. Por outro lado, a porosidade total calculada 
$\left(\mathrm{PT}=1-\rho / \rho_{\mathrm{s}}\right)$ não sofreu efeito significativo, o que os autores atribuem à composição dos erros da densidade do solo e da densidade dos sólidos. Logan et al. (1996), conduzindo um trabalho que constou da aplicação de $25 \%$ (a base de massa) de lodo de esgoto puro e tratado com o resíduo gorduroso "Olestra" ( 5,7\% e 4,4\% a base de massa para "Olestra" nos estados líquido e sólido, respectivamente) em quatro solos de amplas diferenças físicas e químicas, também verificaram diminuições significativas na densidade do solo e na densidade dos sólidos com relação à testemunha, para amostras coletadas após 1, 6, 12 e 20 semanas de incubação em laboratório. A porosidade total calculada não foi obtida, mas para o solo arenoso (de características físicas originalmente mais pobres), o conteúdo de água na saturação mostrou-se maior nas parcelas tratadas.

Martens \& Frankenberger Jr. (1992), em um estudo com duração de 25 meses conduzido para avaliar os efeitos da incorporação de esterco de galinha, lodo de esgoto, palha de cevada e alfafa fresca sobre os parâmetros físicos de um solo de textura média, fizeram a aplicação de três doses destes materiais $\left(25 \mathrm{Mg} \mathrm{ha}^{-1}\right.$ cada, no início do experimento, após 10 meses e após 18 meses). Com relação à testemunha, os tratamentos diminuíram a densidade do solo e elevaram a estabilidade de agregados em água. Mbagwu \& Piccolo (1990), trabalhando com macro e microagregados coletados na camada de 0-0,20 m de solos que sofreram aplicação de esterco de porco, esterco de gado e lodo de esgoto, verificaram a diminuição da densidade do solo e aumento na estabilidade dos agregados e na capacidade de retenção de água a $33 \mathrm{kPa}$ de tensão, mas nenhum efeito significativo na porosidade interna e distribuição do tamanho dos agregados.

Epstein et al. (1976) estudaram, em solo de textura franco-siltosa, os efeitos da aplicação de doses de lodo de esgoto, digerido anaerobicamente ou compostado. Periodicamente determinavam a umidade do solo, e ao final do experimento, a curva de retenção de água. Os valores de umidade do solo foram mais elevados nas parcelas tratadas do que para as testemunhas, e as curvas de retenção foram diferentes entre elas. Considerando como água disponível aquela retida entre as tensões de 33 e $1500 \mathrm{kPa}$, foram determinados valores de $12,5 \%$ para a testemunha e $14,5 \%$ e $18,5 \%$, 
respectivamente para o lodo compostado e o de digestão anaeróbica na maior dose estudada $\left(240 \mathrm{Mg} \mathrm{ha}^{-1}\right)$. Epstein (1975) incorporou lodo de esgoto cru e digerido (5\% à base de massa) a um solo siltoso e, durante um período de 75 dias de incubação das misturas solo-lodo às temperaturas de 15,25 e $35^{\circ} \mathrm{C}$, fez medições periódicas da retenção de água, condutividade hidráulica e estabilidade de agregados. A adição de lodo de esgoto deslocou a curva de retenção de água, de tal forma que o conteúdo de água a um valor específico de potencial mátrico foi maior, mas a quantidade de água entre os potenciais -33 e $-1500 \mathrm{kPa}$ permaneceu essencialmente o mesma do solo original.

Além da densidade do solo, Felton (1995) avaliou também a retenção de água e verificou que a curva de retenção se alterou, sofrendo um deslocamento no sentido de se afastar daquela típica de um solo argiloso ou compactado e se aproximar mais de um solo de textura arenosa ou recentemente revolvido. Barreto (1995), trabalhando com amostras com estrutura indeformada, coletadas em vasos onde foi conduzido um experimento de degradação da matéria orgânica de 4 resíduos (lodo de esgoto, composto de lixo, lodo petroquímico e torta de filtro), determinou a capacidade de retenção de água nas tensões de 1, 2, 5, 10 e $15 \mathrm{kPa}$. Para o solo de textura média, o autor observou aumento na retenção de água nas tensões de 10 e $15 \mathrm{kPa}$ para todos os resíduos aplicados. Para o solo arenoso, no entanto, nenhum efeito evidente foi observado.

Gupta et al. (1977) não verificaram efeito para a água disponível, considerada entre $10 \mathrm{kPa}$ e $1500 \mathrm{kPa}$ de tensão, ou mesmo de água retida entre dois outros pontos, estejam eles situados na faixa intermediária ou na faixa "mais úmida" da curva. Verificaram, no entanto, que a curva de retenção sofreu um deslocamento no sentido de elevação da umidade correspondente a cada potencial mátrico, mantendo porém o mesmo formato. Para o potencial mátrico de $-1500 \mathrm{kPa}$, a umidade correspondente $\left(\theta_{1500,} \mathrm{em} \mathrm{m}^{3} \mathrm{~m}^{-3}\right)$ aumentou linearmente em função do conteúdo de matéria orgânica do solo (MO, em \%), segundo a equação $\theta_{1500}=0,0371+0,0257 \mathrm{MO}$, efeito este que os autores atribuíram à adsorção de água pela matéria orgânica. Obreza \& Reeder (1994), aplicando doses entre 13 e $112 \mathrm{Mg} / \mathrm{ha}$ de três tipos de composto urbano a um solo muito arenoso da Flórida, observaram aumento na retenção de água que, porém, não se 
traduziu em aumento de produtividade. Metzger \& Yaron (1987), analisando trabalhos com aplicação de lodo de esgoto, concluíram que deve haver aumento da água retida a tensões maiores que $1500 \mathrm{kPa}$, fora da faixa considerada disponível às plantas.

Kumar et al. (1985) aplicaram a um solo arenoso diferentes resíduos orgânicos (lodo de esgoto, lodo industrial prensado, adubo verde e esterco de curral), respectivamente nas quantidades de 827, 1043, 1370 e $542 \mathrm{Mg} / \mathrm{ha}$, e estudaram seus efeitos utilizando-se de amostras coletadas a $0,20 \mathrm{~m}$ de profundidade em pequenos cilindros metálicos. A incorporação de todos os resíduos orgânicos causou um apreciável aumento da água retida a um dado potencial, porém somente o lodo de esgoto e o lodo industrial provocaram aumento na água disponível. Rengasamy et al. (1980) misturaram lodo aluminoso a três solos de diferentes classes texturais (arenoso, argiloso e de textura média) nas taxas de aplicação de 2 e $20 \mathrm{Mg} \mathrm{ha}^{-1}$ (considerando-se uma profundidade de incorporação $0,10 \mathrm{~m}$ e densidade $1 \mathrm{Mg} \mathrm{m}^{-3}$ ). Após um período de dois meses da incubação em vasos, a adição do lodo levou à incrementos na estabilidade estrutural do solo e na água retida entre -10 e $1000 \mathrm{kPa}$. Tanto Logan \& Harrison (1995), trabalhando com a aplicação do "N -viro soil"' a um solo siltoso, quanto Logan et al. (1996), trabalhando com lodo de esgoto em quatro solos de diversas classes texturais, verificaram aumentos significativos na retenção de água aos potenciais mátricos $-5,9 ; 33$ e $1500 \mathrm{kPa}$. No entanto, somente Logan \& Harrison (1995) verificaram aumentos significativos na água disponível às plantas, considerada entre 33 e $1500 \mathrm{kPa}$.

No trabalho de Epstein (1975), a percentagem de agregados estáveis em água aumentou como resultado da adição de lodo. Depois de 6 meses, esta percentagem variava de 25 a $38 \%$ em média para o solo tratado com lodo, comparado com $17 \%$ do solo original. Em seus trabalhos, tanto Logan \& Harrison (1995) quanto Logan et al. (1996), verificaram que a aplicação de resíduos à base de lodo levaram a aumentos significativos na quantidade de agregados estáveis em água de tamanhos maiores (> $5 \mathrm{~mm}$, entre 2 e $5 \mathrm{~mm}$, entre 1 e $2 \mathrm{~mm}$ e entre 0,5 e $1 \mathrm{~mm}$ ) e reduções significativas na quantidade de agregados estáveis de tamanhos menores (entre 0,25 e 0,5 mm e $<0,25 \mathrm{~mm}$ ). Abu-Sarar (1993), trabalhando com um solo de estrutura instável, incubou-o durante 6 meses com as doses 2, 4 e $8 \%$ de lodo (à base de massa). Após este 
período, a estabilidade de agregados e a dispersão de argila foi avaliada em soluções de $\mathrm{NaCl} / \mathrm{CaCl}_{2}$ de concentrações eletrolíticas decrescentes combinadas com valores de RAS (razão de adsorção de sódio) de 5, 10, 15 e 20. Em concentrações eletrolíticas baixas, a estabilidade de agregados foi mais elevada e a dispersão de argila mais baixa nas amostras tratadas de $8 \%$ de lodo. Segundo o autor, os resultados por ele obtidos sustentam a hipótese de que a dispersão de argila ocorre no último estágio do enfraquecimento da estrutura do agregado. Abu-Sarar (1996) estudou durante 5 estações de inverno (87/88 a 91/92), os efeitos da incorporação anual de $20 \mathrm{Mg} \mathrm{ha}^{-1}$ de lodo de esgoto, além de outros três condicionadores químicos, sobre os volumes de enxurrada geradas de parcelas de $2 \mathrm{~m} \times 2 \mathrm{~m}$. Resultados de análise de regressão linear múltipla indicaram que os volumes de enxurrada dependem principalmente da altura da chuva e numa menor extensão da intensidade da chuva. A estabilidade estrutural da superfície do solo nas parcelas tratadas com lodo de esgoto foi maior que nas testemunhas. A melhoria estrutural das parcelas tratadas com lodo foi devido ao aumento tanto da salinidade do solo quanto do conteúdo de matéria orgânica. Embora a aplicação de resíduos provoque aumento na estabilidade da estrutura do solo, os efeitos na resistência à penetração geralmente sofre decréscimos, o que parece estar mais associado ao aumento da porosidade total. Em seu trabalho, Kumar et al. (1985) verificaram, em relação à testemunha, diminuição do coeficiente de penetração de $81 \%$ para o esterco de curral, $75 \%$ para o lodo industrial, $73 \%$ para o adubo verde e $70 \%$ para o lodo de esgoto.

\subsection{Alterações de propriedades físicas "dinâmicas" do solo}

Metzger \& Yaron (1987) salientam, para o lodo de esgoto, que o efeito dos componentes orgânicos nas propriedades de transmissão da água é indireto, através da modificação na condição de agregação e na porosidade do solo. Para a camada arável, na qual os resíduos são incorporados, o revolvimento do solo no preparo altera a porosidade e, conseqüentemente, as propriedades de transmissão da água. Se o solo “a priori” já possui propriedades favoráveis a um rápido caminhamento da água, seja devido a apresentar uma boa estrutura, seja devido a possuir uma textura arenosa, incrementos significativos podem de fato não ocorrer. Além disso, a alta variabilidade inerente a 
estas propriedades faz com que alterações significativas devido à aplicação de resíduos sejam escassos (Khaleel et al., 1981). Muitas vezes elevadas taxas de adição de lodo ou composto são necessárias para induzir mudanças estatisticamente significativas na condutividade hidráulica do solo saturado (Jacobowitz \& Steenhuis, 1984; Wei et al., 1985).

Kumar et al. (1985), trabalhando com amostras de solo coletadas num solo arenoso (que já possuía boas propriedades de transmissão da água), obtiveram diminuições marcantes no coeficiente de penetração, na infiltração horizontal acumulada e na condutividade hidráulica do solo saturado com a adição das doses desses materiais. A máxima diminuição da condutividade hidráulica foi verificada para a aplicação do lodo industrial (93\%), mas foram elevadas também para os outros resíduos (82\% para o esterco de curral, $78 \%$ para o adubo verde e $62 \%$ para o lodo de esgoto). Este comportamento foi justificado pelos autores pela provável diminuição do raio dos poros do solo, no entanto eles não esperariam o mesmo resultado para solos com textura fina, onde a matéria orgânica promove a formação de agregados. Logan et al. (1996), mesmo aplicando 25\% (a base de massa) de lodo de esgoto, puro ou tratado com o resíduo gorduroso 'Olestra", não obtiveram efeitos significativos sobre a condutividade hidráulica do solo saturado, independentemente da textura do solo utilizado.

Já Jacobowitz \& Steenhuis (1984), mesmo trabalhando com um solo arenoso, obtiveram aumentos tanto na condutividade hidráulica do solo saturado quanto na condutividade hidráulica do solo não saturado (faixa de potencial mátrico de 0 a $100 \mathrm{kPa}$ ) devido à adição de composto de lodo. Para solos numa ampla faixa de textura, a condutividade hidráulica do solo saturado nas parcelas tratadas com lodo normalmente é maior do que nas parcelas testemunhas (Epstein, 1975; Gupta et al., 1977; Morel et al., 1978; Chang et al., 1983; Wei et al., 1985). Em seu trabalho, Epstein (1975) verificou que a adição de lodo de esgoto inicialmente aumentou a condutividade hidráulica do solo saturado, embora após um período de 50 a 80 dias esta tenha retornado à valores estatisticamente iguais aos do solo original. Felton (1995) verificou que o logaritmo da condutividade hidráulica do solo saturado aumentou de $\log \left(8,45.10^{-8} \mathrm{~m} \mathrm{~s}^{-1}\right)$ para $\log \left(3,58 \cdot 10^{-6} \mathrm{~m} \mathrm{~s}^{-1}\right)$. Segundo o autor, a análise dos dados de condutividade hidráulica 
log-transformados permitiu reduzir a variabilidade e obter significância. Abu-Sarar (1993), no trabalho anteriormente citado, obteve condutividades hidráulicas maiores para as amostras tratadas com $8 \%$ de lodo em relação às demais taxas de aplicação, para qualquer combinação de RAS (razão de adsorção de sódio) e concentração eletrolítica da solução permeada através da amostra. Logan \& Harrison (1995) também verificaram aumentos significativos na condutividade hidráulica do solo saturado como resultado da aplicação de $500 \mathrm{Mg} \mathrm{ha}^{-1}$ de um resíduo denominado 'N -viro soil”, a um solo de textura siltosa.

Para o solo não saturado, a maioria dos relatos é que o efeito da aplicação de resíduos orgânicos sobre esta propriedade é depressivo. Por exemplo, Gupta et al. (1977), no mesmo trabalho citado anteriormente, verificaram que em qualquer conteúdo de água, a difusividade hidráulica diminuiu com o aumento da dose de lodo aplicada. A condutividade hidráulica do solo não saturado, determinada pela difusividade da água e pela inclinação da curva de retenção da água no solo, decresceu com o aumento da dose aplicada para qualquer conteúdo de água, exceto para a saturação. Uma rara exceção é o trabalho de Jacobowitz \& Steenhuis (1984), em que se obteve também aumentos na condutividade hidráulica do solo não saturado, provavelmente devido ao solo ser excessivamente arenoso.

Martens \& Frankenberger Jr. (1992) verificaram que as alterações em parâmetros físicos de um solo de textura média pela incorporação de esterco de galinha, lodo de esgoto, palha de cevada e alfafa fresca levaram a aumentos significativos na infiltração acumulada. Análises de regressão linear múltipla indicaram que a taxa de infiltração de água após a aplicação da primeira dose aumentou pelo estímulo à atividade microbiana no solo, a qual eleva a estabilidade dos agregados. Após a segunda e terceira aplicação dos condicionadores orgânicos, a elevação das taxas de infiltração estiveram mais correlacionadas à diminuição da densidade do solo na camada cultivada. As alterações nas propriedades físicas do solo resultaram também na elevação do conteúdo de água do solo durante o período experimental. Abu-Sarar (1996), estudando os efeitos da incorporação anual de $20 \mathrm{Mg} \mathrm{ha}^{-1}$ de lodo de esgoto e outros três condicionadores químicos sobre os volumes de enxurrada, verificaram que a maior estabilidade estrutural 
do solo nas parcelas tratadas com lodo proporcionou maiores taxas finais de infiltração (cerca de 10 vezes maior que na testemunha, que foi da ordem de 3,97 $\pm 0,68 \mathrm{~mm} \mathrm{~h}^{-1}$ ). Consequentemente, menores volumes de enxurrada final foram obtidos para as parcelas tratadas com lodo de esgoto e gesso.

Devido ao caráter hidrófobo de algumas frações da matéria orgânica adicionada ao solo via resíduos orgânicos, uma certa repelência à água tem sido documentada. Kumar et al. (1985), em um solo arenoso tratado com diferentes resíduos orgânicos (lodo de esgoto, lodo industrial prensado, adubo verde e esterco de curral), mediram o ângulo de contato da água $(\beta)$ com o solo. Os valores obtidos foram $\beta=33,7^{\circ}$ para a testemunha $(\cos \beta=0,832), \beta=79,2^{\circ}$ para o lodo de esgoto $(\cos \beta=0,188), \beta=82,0^{\circ}$ para o lodo industrial $(\cos \beta=0,140), \beta=84,4^{\circ}$ para o adubo verde $(\cos \beta=0,097) \mathrm{e}$ $\beta=85,1^{\circ}$ para o esterco de curral $(\cos \beta=0,086)$. Tratam-se de alterações consideráveis, uma vez que o ângulo de contato exerce uma importante função na penetração da água no material poroso. Constantini et al. (1995) também relatam o caráter hidrófobo de três solos tratados com lodo de esgoto. Segundo os autores, nos testes realizados utilizando-se um infiltrômetro de tensão, as taxas de infiltração iniciais (partindo-se do solo seco) eram menores nos solos que receberam lodo, o que os autores atribuíram não somente às frações hidrófobas da matéria orgânica, mas também à presença de micélio de fungos que se estendiam por todo o horizonte superficial. No entanto, para as taxas de infiltração em equilíbrio dinâmico, o comportamento inicial se invertia, passando a ser maiores para as parcelas que receberam lodo. Os autores atribuíram estas maiores taxas de infiltração final observadas para os solos tratados com lodo à presença de caminhos de fluxo preferencial da água. 


\section{MATERIAL E MÉTODOS}

\subsection{Caracterização da Área Experimental}

O experimento relacionado a esta tese foi conduzido nos anos agrícolas de 1996/1997 e 1997/1998, em condições de campo, na área da Estação Experimental do Instituto Agronômico de Campinas, em Piracicaba-SP. A localização geográfica é $22^{\circ} 41^{\prime} 00^{\prime \prime}$ de latitude sul e $47^{\circ} 39^{\prime} 00^{\prime}$ de longitude oeste, e a altitude, $554 \mathrm{~m}$ acima do nível do mar. O clima, segundo a classificação de Köppen, é do tipo Cwa: subtropical com inverno seco, com temperatura média do mês mais frio inferior a $18^{\circ} \mathrm{C}$ e do mês mais quente superior a $22^{\circ} \mathrm{C}$ (Setzer, 1966). Os parâmetros climáticos apresentam as seguintes médias anuais: (a) precipitação: $1253 \mathrm{~mm}$; (b) temperatura: $21,1^{\circ} \mathrm{C}$; (c) umidade relativa do ar: 74\%; (d) velocidade do vento: $2,2 \mathrm{~m} \mathrm{~s}^{-1}$. O relevo é suave ondulado, e o solo, um Latossolo Vermelho Amarelo, que tem algumas de suas propriedades apresentados na Tabela 1.

Tabela 1. Granulometria e propriedades químicas do solo da área experimental.

\begin{tabular}{|c|c|c|c|c|c|c|c|c|c|c|c|c|c|c|c|}
\hline \multirow{2}{*}{$\begin{array}{l}\text { Prof. } \\
\text { (m) }\end{array}$} & Areia grossa & Areia fina & Silte & Argila & \multirow{2}{*}{$\begin{array}{c}\mathrm{pH} \\
\left(\mathrm{CaCl}_{2}\right)\end{array}$} & \multirow{2}{*}{$\begin{array}{l}\text { M.O. } \\
\mathrm{g} \mathrm{dm}^{-3}\end{array}$} & \multirow{2}{*}{$\begin{array}{c}\mathrm{P} \\
\mathrm{mg} \mathrm{dm}^{-3}\end{array}$} & \multirow{2}{*}{\multicolumn{2}{|c|}{$\mathrm{K} \quad \mathrm{Ca}$}} & $\mathrm{Mg}$ & $\mathrm{H}+\mathrm{Al}$ & $\mathrm{Al}$ & SB & $\mathrm{T}$ & \multirow{2}{*}{$\begin{array}{l}\mathrm{V} \\
\%\end{array}$} \\
\hline & ------------ & $-\mathrm{g} \mathrm{kg}^{-1}$ & - & ----_* & & & & & & $---m$ & $\mathrm{~mol}_{\mathrm{c}} \mathrm{dm}^{-}$ & 3 & - & $\overline{------}$ & \\
\hline $0-0,20$ & 195 & 329 & 141 & 335 & 4,1 & 16 & 3 & 0,3 & 11 & 5 & 47 & 10 & 16,3 & 63,3 & 25,75 \\
\hline $0,20-0,40$ & 194 & 248 & 116 & 442 & 4,2 & 11 & 2 & 0,3 & 14 & 5 & 47 & 10 & 19,3 & 66,3 & 29,11 \\
\hline $0,40-0,60$ & 211 & 218 & 90 & 481 & 4,1 & 14 & 1 & 0,1 & 11 & 3 & 47 & 12 & 14,1 & 61,1 & 23,08 \\
\hline
\end{tabular}

* $2 \mathrm{~mm} \geq$ Areia grossa $>0,5 \mathrm{~mm} \geq$ areia fina $>0,05 \mathrm{~mm} \geq$ silte $>0,002 \mathrm{~mm} \geq$ argila

\subsection{Resíduos}

Foram utilizados dois diferentes resíduos de origem urbana: o lodo de esgoto e o composto de lixo. O lodo de esgoto anaerobicamente digerido foi proveniente da Estação de Tratamento de Esgotos de Barueri - SABESP, de Barueri-SP, e o composto 
de lixo da Usina de Tratamento de Lixo da Cidade de São Jorge - Prefeitura Municipal de Santo André, Santo André-SP. O conteúdo de água, bem como a composição química parcial de ambos os resíduos, são apresentados na Tabela 2.

Tabela 2. Conteúdo de água e composição química parcial dos resíduos.

\begin{tabular}{|c|c|c|c|c|}
\hline \multirow[b]{2}{*}{ Propriedades } & \multicolumn{2}{|c|}{ Lodo de esgoto } & \multicolumn{2}{|c|}{ Composto de lixo } \\
\hline & 1996 & 1997 & 1996 & 1997 \\
\hline Conteúdo de água $\left(\mathrm{g} \mathrm{kg}^{-1}\right)^{*}$ & 668,90 & 633,84 & 485,39 & 497,48 \\
\hline pH (em água, relação $1: 2,5)^{*}$ & 12,25 & 8,50 & 4,77 & 8,00 \\
\hline Alcalinidade $\left(\mathrm{mol} \mathrm{OH}^{-} \mathrm{kg}^{-1}\right)^{*}$ & 0,77 & 0,60 & 0,77 & 0,87 \\
\hline C-oxidável $\left(\mathrm{g} \mathrm{kg}^{-1}\right)^{* *}$ & 207,88 & 184,85 & 341,99 & 281,63 \\
\hline Matéria orgânica $\left(\mathrm{g} \mathrm{kg}^{-1}\right)^{* *}$ & 368,92 & 331,85 & 637,80 & 600,99 \\
\hline N-total $\left(\mathrm{g} \mathrm{kg}^{-1}\right)^{* *}$ & 25,58 & 21,71 & 10,12 & 12,71 \\
\hline Relação C/N** & 8,13 & 8,51 & 33,79 & 22,15 \\
\hline P-total $\left(\mathrm{g} \mathrm{kg}^{-1}\right)^{* *}$ & 11,20 & 11,16 & 1,63 & 4,46 \\
\hline $\mathrm{K}$-total $\left(\mathrm{g} \mathrm{kg}^{-1}\right)^{* *}$ & 1,06 & 0,97 & 5,28 & 4,90 \\
\hline Ca-total $\left(\mathrm{g} \mathrm{kg}^{-1}\right)^{* *}$ & 170,31 & 132,10 & 21,26 & 18,40 \\
\hline $\operatorname{Mg}$-total $\left(\mathrm{g} \mathrm{kg}^{-1}\right) * *$ & 10,63 & 2,70 & 2,66 & 1,60 \\
\hline S-total $\left(\mathrm{g} \mathrm{kg}^{-1}\right)^{* *}$ & 8,49 & 10,77 & 3,01 & 3,78 \\
\hline Na-total $\left(\mathrm{g} \mathrm{kg}^{-1}\right) * *$ & 0,76 & 0,71 & 5,46 & 5,20 \\
\hline Al-total $\left(\mathrm{g} \mathrm{kg}^{-1}\right)^{* *}$ & n.d. & n.d. & 12,8 & 5,7 \\
\hline Fe-total $\left(\mathrm{g} \mathrm{kg}^{-1}\right)^{* *}$ & n.d. & n.d. & 14,2 & 8,5 \\
\hline Cd-total $\left(\mathrm{mg} \mathrm{kg}^{-1}\right)^{* *}$ & 28 & 16 & 6 & 2 \\
\hline Cr-total $\left(\mathrm{mg} \mathrm{kg}^{-1}\right)^{* *}$ & 385 & 386 & 41 & 81 \\
\hline $\mathrm{Cu}$-total $\left(\mathrm{mg} \mathrm{kg}^{-1}\right)^{* *}$ & 784 & 534 & 123 & 403 \\
\hline Mn-total $\left(\mathrm{mg} \mathrm{kg}^{-1}\right)^{* *}$ & 253 & 273 & 188 & 180 \\
\hline Ni-total $\left(\mathrm{mg} \mathrm{kg}^{-1}\right)^{* *}$ & 239 & 268 & 26 & 34 \\
\hline $\mathrm{Pb}$-total $\left(\mathrm{mg} \mathrm{kg}^{-1}\right) * *$ & 153 & 171 & 91 & 196 \\
\hline Zn-total $\left(\mathrm{mg} \mathrm{kg}^{-1}\right)^{* *}$ & 1568 & 1649 & 387 & 496 \\
\hline
\end{tabular}

\subsection{Cultura}

Foi empregada, como planta-teste, a cana-de-açúcar (Saccharum officinarum) variedade RB-78-5148, implantada em ciclo anual no ano agrícola de 1996/1997 e 
cultivada como soqueira no ano agrícola de 1997/1998. Na escolha da cultura da cana-de-açúcar consideraram-se os seguintes fatores: a) não está necessariamente reservada ao consumo humano, podendo ser utilizada como combustível, evitando que metais pesados que porventura sejam absorvidos pelas plantas sejam incorporados à cadeia alimentar; b) tem alto interesse econômico pelo seu grande aproveitamento e pela extensa área ocupada no Estado de São Paulo; c) está próxima aos grandes centros urbanos potencialmente produtores de resíduos.

\subsection{Delineamento experimental e tratamentos}

$\mathrm{O}$ experimento foi conduzido num delineamento em blocos casualizados, com quatro repetições, onde foram estabelecidos 9 tratamentos: (1) Calagem + Adubação mineral; (2) Testemunha para o lodo; (3) Lodo de esgoto, dose A; (4) Lodo de esgoto, dose B; (5) Lodo de esgoto, dose C; (6) Testemunha para o composto; (7) Composto de lixo, dose A; (8) Composto de lixo, dose B; (9) Composto de lixo, dose C.

A calagem e a adubação do tratamento (1) seguiram as recomendações técnicas para a cultura da cana-de-açúcar apresentadas na $2^{\mathrm{a}}$ edição do Boletim Técnico $\mathrm{n}^{\mathrm{o}} 100$ do IAC (Spironello et al., 1996). Como um dos objetivos do projeto conduzido paralelamente a este foi verificar a aplicabilidade em nossas condições dos parâmetros de tolerância estabelecidos pela EPA (Environmental Protection Agency), citados em Wallace \& Wallace (1994), os quais levam em consideração a quantidade máxima de metais pesados possível de ser adicionada anualmente em solos agrícolas, as doses dos resíduos foram definidas com base na composição química dos resíduos (Tabela 2). Para o lodo de esgoto em 1996, verificou-se que por este critério a dose máxima seria $66 \mathrm{Mgha}^{-1}$ do material seco. Esta foi então chamada dose B, sendo a dose A correspondente a metade e a dose $\mathrm{C}$ a 1,5 vezes a dose $\mathrm{B}$. Portanto, as doses do lodo de esgoto foram: dose $\mathrm{A}=33 \mathrm{Mgha}^{-1}$, dose $\mathrm{B}=66 \mathrm{Mg} \mathrm{ha}^{-1}$ e dose $\mathrm{C}=99 \mathrm{Mg} \mathrm{ha}^{-1}$ do material seco (respectivamente $100 \mathrm{Mg} \mathrm{ha}^{-1}, \quad 200 \mathrm{Mgha}^{-1}$ e $300 \mathrm{Mg} \mathrm{ha}^{-1}$ do material úmido).

A adoção deste mesmo critério para a definição das doses do composto de lixo, que tem menores concentrações dos diversos metais pesados considerados contaminantes, levaria a doses elevadíssimas e operacionalmente inviáveis de serem transportadas, aplicadas e incorporadas ao solo. Estas doses seriam: 
dose $\mathrm{A}=300 \mathrm{Mg} \mathrm{ha}^{-1}$, dose $\mathrm{B}=600 \mathrm{Mg} \mathrm{ha}^{-1}$ e dose $\mathrm{C}=900 \mathrm{Mg} \mathrm{ha}^{-1}$ de material seco (respectivamente $600 \mathrm{Mg} \mathrm{ha}^{-1}, 1200 \mathrm{Mg} \mathrm{ha}^{-1}$ e $1800 \mathrm{Mg} \mathrm{ha}^{-1}$ do material úmido). Assim, optou-se por adotar como critério a aplicação de doses equivalentes, em termos de carbono orgânico, àquelas utilizadas nas respectivas doses de lodo de esgoto. Portanto, as doses A, B e C de composto de lixo foram $20 \mathrm{Mg} \mathrm{ha}^{-1}, 40 \mathrm{Mg} \mathrm{ha}^{-1}$ e $60 \mathrm{Mg} \mathrm{ha}^{-1}$ do material seco (respectivamente $39 \mathrm{Mgha}^{-1}, 78 \mathrm{Mg} \mathrm{ha}^{-1}$ e $117 \mathrm{Mg} \mathrm{ha}^{-1}$ do material úmido). Do ponto de vista das possíveis alterações físicas que viriam a ocorrer, este critério estabelecido possibilitou que comparações entre os resíduos fossem feitas de maneira mais coerente, pois é reconhecidamente o carbono orgânico o principal responsável por tais alterações.

Para o ano de 1997 foram adotados os mesmos critérios de 1996, ou seja, no caso do lodo de esgoto, a quantidade máxima de metais pesados possível de ser adicionada ao solo, e no caso do composto de lixo, a aplicação da mesma quantidade de carbono orgânico utilizada na dose de lodo de esgoto correspondente. Estes critérios levaram às seguintes doses de lodo de esgoto: dose $\mathrm{A}=37 \mathrm{Mg} \mathrm{ha}^{-1}$, dose $\mathrm{B}=74 \mathrm{Mg} \mathrm{ha}^{-1}$ e dose $\mathrm{C}=112 \mathrm{Mg} \mathrm{ha}^{-1}$ do material seco (respectivamente $101 \mathrm{Mg} \mathrm{ha}^{-1}, 202 \mathrm{Mg} \mathrm{ha}^{-1} \mathrm{e}$ $303 \mathrm{Mg} \mathrm{ha}^{-1}$ do material úmido), e às seguintes doses de composto de lixo: $24 \mathrm{Mg} \mathrm{ha}^{-1}$, $48 \mathrm{Mg} \mathrm{ha}^{-1}$ e $72 \mathrm{Mg} \mathrm{ha}^{-1}$ do material seco (respectivamente $48 \mathrm{Mg} \mathrm{ha}^{-1}, 96 \mathrm{Mg} \mathrm{ha}^{-1} \mathrm{e}$ $144 \mathrm{Mg} \mathrm{ha}^{-1}$ do material úmido). As doses dos resíduos utilizadas para cada tratamento, nos dois anos do experimento, são resumidamente apresentadas na Tabela 3.

Tabela 3. Doses dos resíduos utilizadas para cada tratamento, nos dois anos do experimento.

\begin{tabular}{lcc}
\hline \hline Tratamentos & \multicolumn{2}{c}{ Dose de resíduo utilizada $\left(\mathrm{Mg} \mathrm{ha}^{-1}\right)$} \\
\cline { 2 - 3 } & 1996 & 1997 \\
\hline tr1 (adubação mineral) & 0 (calagem + ad. & 0 \\
$\operatorname{tr}$ (testemunha p/ lodo) & plantio + ad. cobertura) & (adubação de cobertura) \\
tr3 (lodo dose A) & 33 & 0 \\
$\operatorname{tr}$ (lodo dose B) & 66 & 37 \\
$\operatorname{tr}$ (lodo dose C) & 99 & 74 \\
$\operatorname{tr}$ (testemunha p/ composto) & 0 & 112 \\
$\operatorname{tr}$ (composto dose A) & 20 & 0 \\
$\operatorname{tr}$ (composto dose B) & 40 & 24 \\
$\operatorname{tr}$ (composto dose C) & 60 & 48 \\
\hline \hline
\end{tabular}




\subsection{Instalação e condução do experimento}

O preparo da área para instalação do experimento inicialmente constou de uma sub-solagem para o rompimento de camada compactada localizada entre $0,20 \mathrm{~m}$ e 0,30 m de profundidade, realizada em julho de 1996. Após isto, no mês de agosto, uma aração seguida de gradagem de nivelamento foram realizadas. Cada parcela foi demarcada com 9,8 $\mathrm{m}$ de largura e $10 \mathrm{~m}$ de comprimento, onde seriam implantadas 7 linhas de cana-de-açúcar espaçadas $1,40 \mathrm{~m}$ entre si. A área total de cada parcela foi de $98 \mathrm{~m}^{2}$, sendo considerada área útil para amostragem os $25,2 \mathrm{~m}^{2}$ centrais $(6,0 \mathrm{x} 4,2 \mathrm{~m})$. A Figura 1 apresenta o esquema da área experimental.

No primeiro ano do experimento, os resíduos foram aplicados às parcelas na superfície do solo, com distribuição manual e em área total. Para o transporte do resíduo das pilhas até as parcelas utilizou-se uma carreta basculante tracionada por um trator. As quantidades estipuladas para cada parcela eram medidas, utilizando-se uma balança e um tambor com capacidade aproximada de $50 \mathrm{~kg}$. Primeiramente, às parcelas dos tratamentos (3), (4) e (5) aplicou-se o lodo de esgoto, que permaneceu na superfície do solo por alguns dias, ficando exposto às condições atmosféricas e sofrendo desidratação. Após este período, fez-se a aplicação do composto de lixo nas parcelas dos tratamentos (7), (8) e (9). Concomitantemente, calcário foi aplicado nas parcelas do tratamento (1), que receberiam adubação mineral. Logo após passou-se uma enxada rotativa em toda a área experimental, que revolveu a terra até uma profundidade aproximada de 0,20 m, promovendo uma incorporação bastante uniforme dos resíduos e do calcário. Detalhes da aplicação e incorporação dos resíduos neste primeiro ano podem ser observados nas Figura 2, 3 e 4 .

Após um período de incubação dos resíduos de aproximadamente 60 dias, foi realizado o plantio da cana-de-açúcar. Para as parcelas do tratamento (1), o fertilizante foi aplicado no sulco de plantio. No decorrer do período experimental foram realizados os tratos culturais necessários: cultivo e aplicação de herbicida, em todas as parcelas, e adubação de cobertura, para as parcelas do tratamento (1). Desde a implantação até a colheita da cana-de-açúcar, realizada em outubro de 1997, foram feitas diversas 


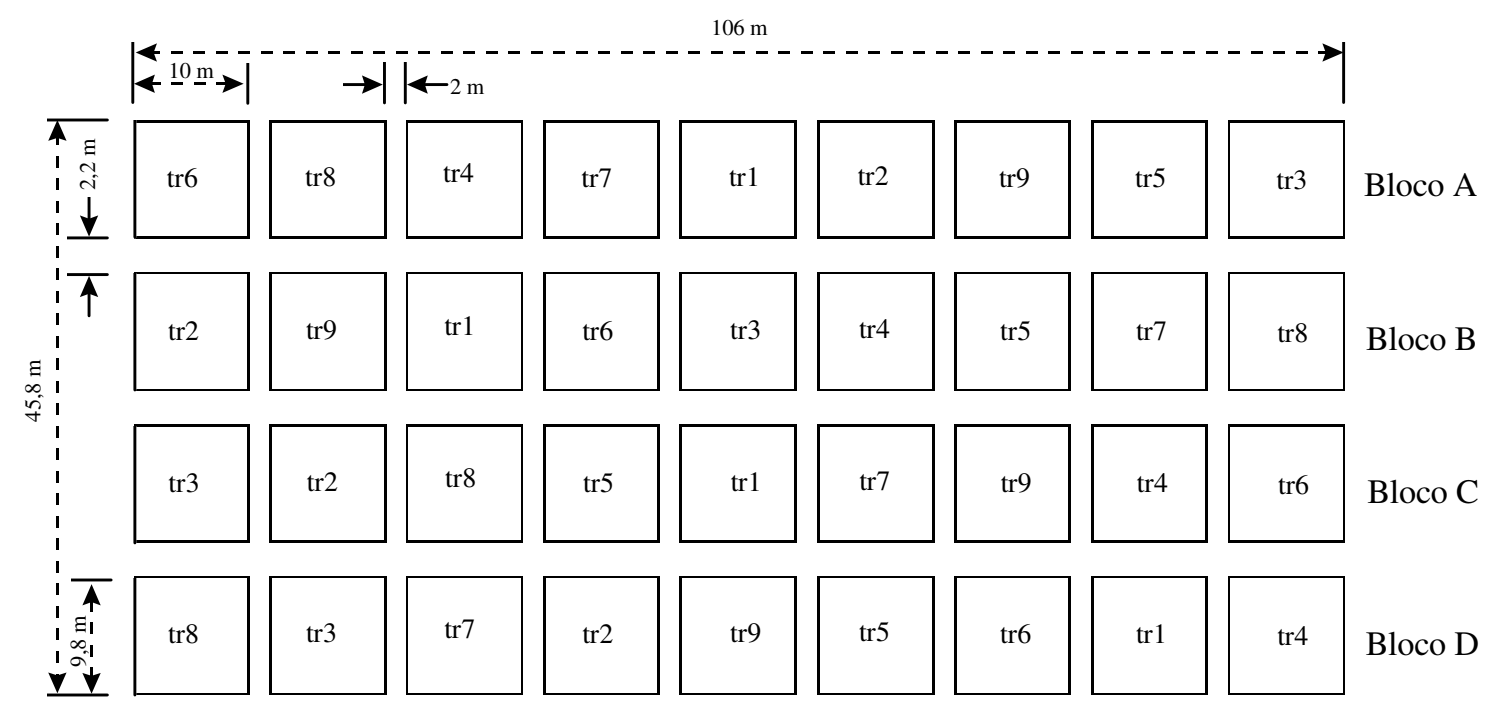

Figura 1: Esquema da área experimental

amostragens de solo e determinações de campo para obtenção das informações detalhadas nos itens subseqüentes.

No segundo ano do experimento, os resíduos foram novamente aplicados às parcelas na superfície do solo, com distribuição manual e em área total. Os mesmos procedimentos do primeiro ano foram utilizados. O lodo de esgoto foi reaplicado alguns dias antes do composto de lixo, sofrendo desidratação pela exposição atmosférica. Após a aplicação de ambos os resíduos, a incorporação foi feita somente na entrelinha, novamente por meio de uma enxada rotativa.

\subsection{Dificuldades durante a instalação e condução do experimento}

As quantidades totais de cada resíduo utilizadas no primeiro ano foram aproximadamente 23,5 $\mathrm{Mg}$ de lodo de esgoto e 9,2 $\mathrm{Mg}$ de composto de lixo. Para o segundo ano, estas quantidades foram aproximadamente $23,8 \mathrm{Mg}$ de lodo de esgoto e $11,3 \mathrm{Mg}$ de composto de lixo. Isto significou, para cada ano, o transporte de dois caminhões de lodo de esgoto e um caminhão de composto de lixo. Ressalta-se aqui a dificuldade para a realização do transporte dos resíduos de seu local de origem até o do experimento, tanto pelo receio das empresas quanto ao tipo de material a ser transportado, quanto pelo preço do frete cobrado para o transporte. 

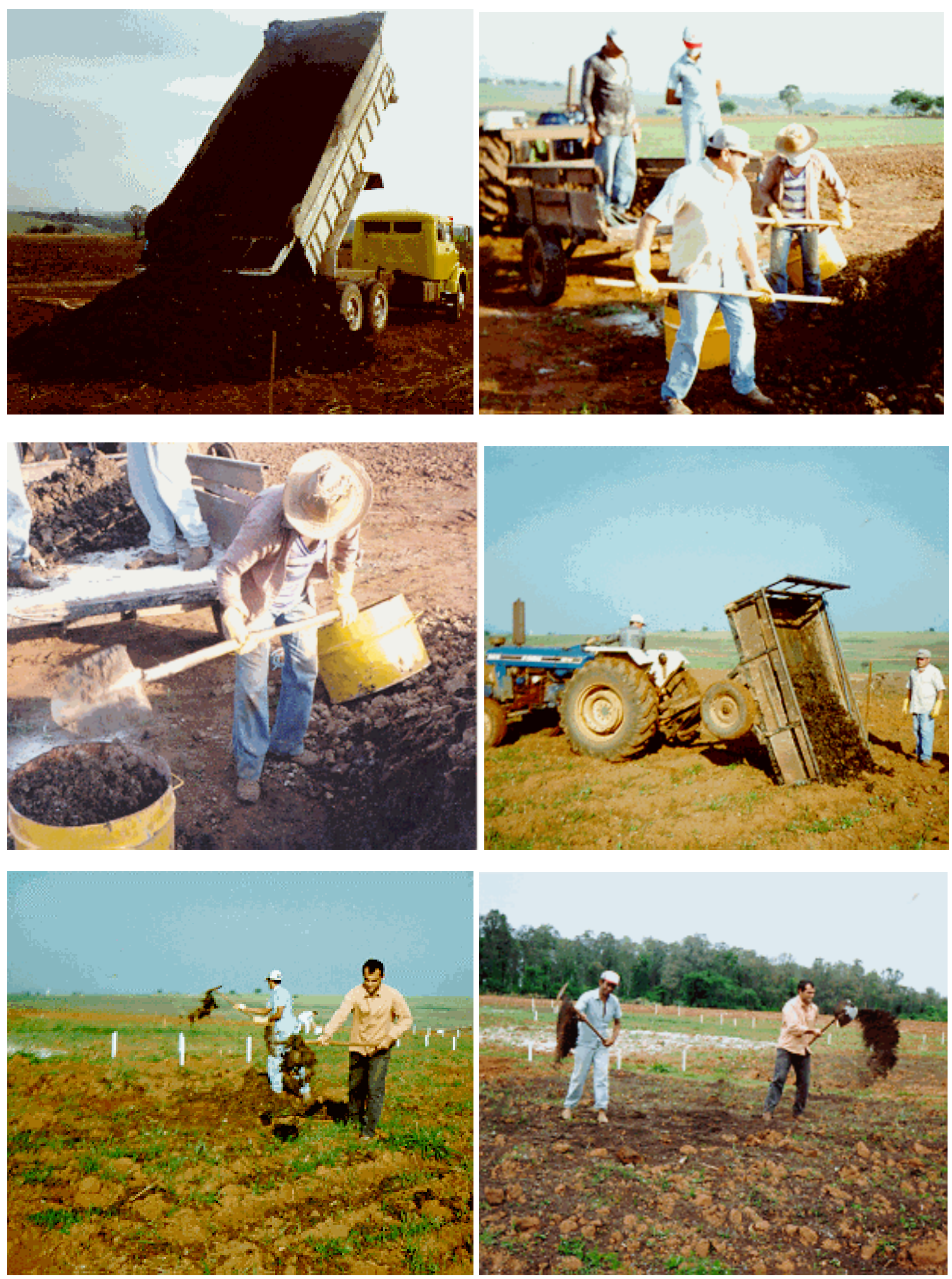

Figura 2: Transporte e aplicação dos resíduos nas parcelas, no ano agrícola de 1996/1997. 

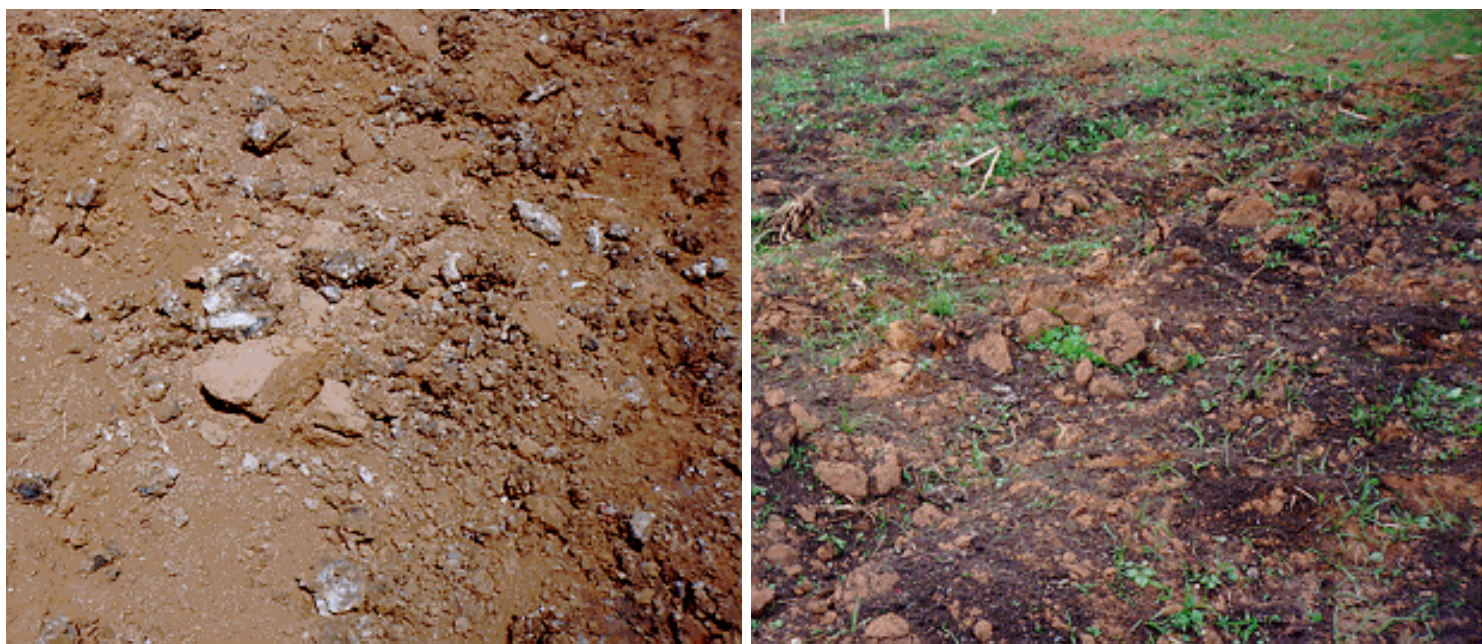

(lodo de esgoto - $33 \mathrm{Mg} \mathrm{ha}^{-1}$ )

(composto de lixo - $20 \mathrm{Mg} \mathrm{ha}^{-1}$ )
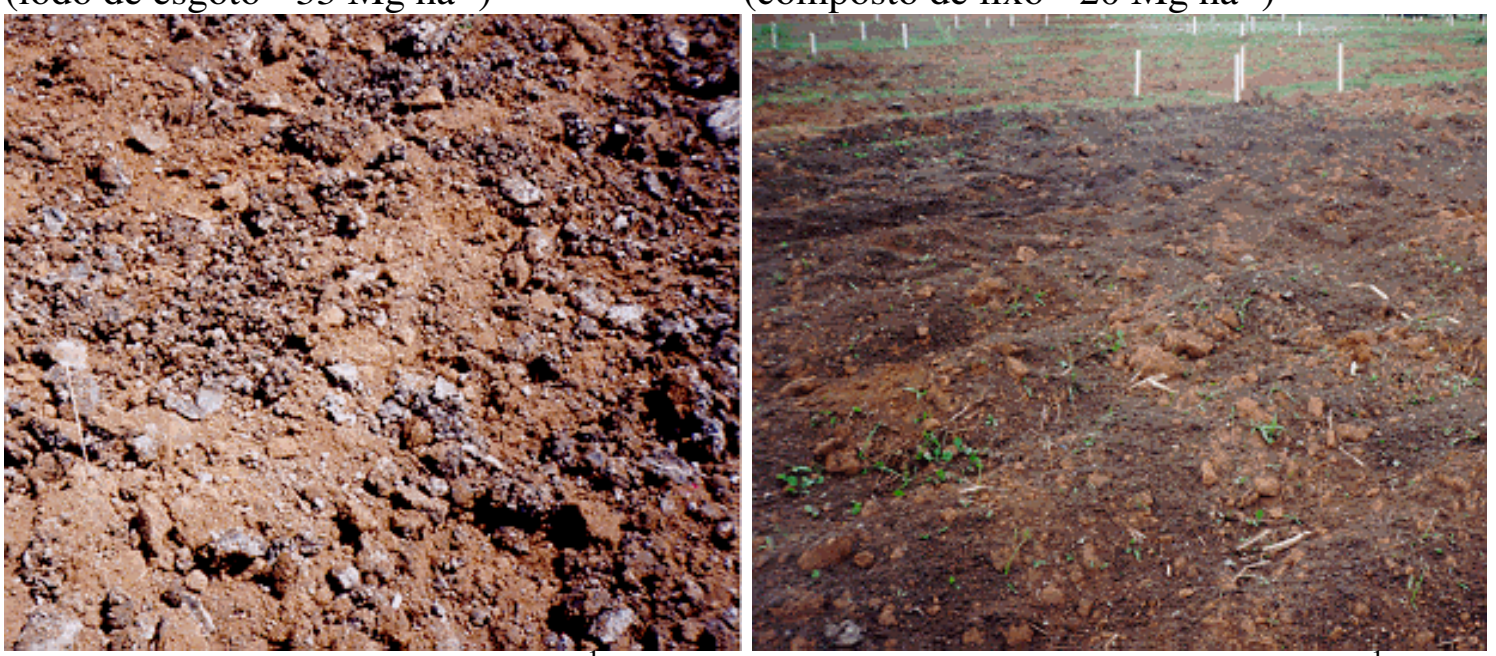

(lodo de esgoto - $66 \mathrm{Mg} \mathrm{ha}^{-1}$ )

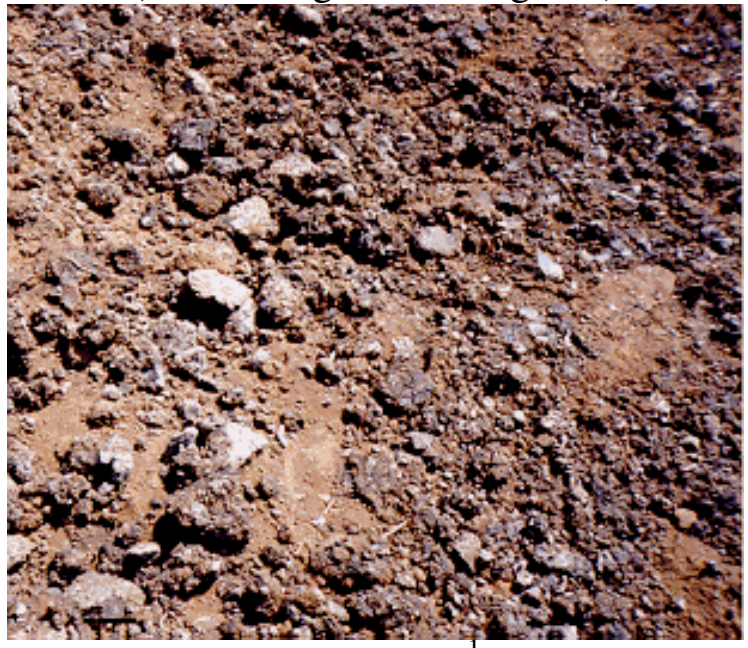

(lodo de esgoto - $99 \mathrm{Mg} \mathrm{ha}^{-1}$ )

(composto de lixo - $40 \mathrm{Mg} \mathrm{ha}^{-1}$ )

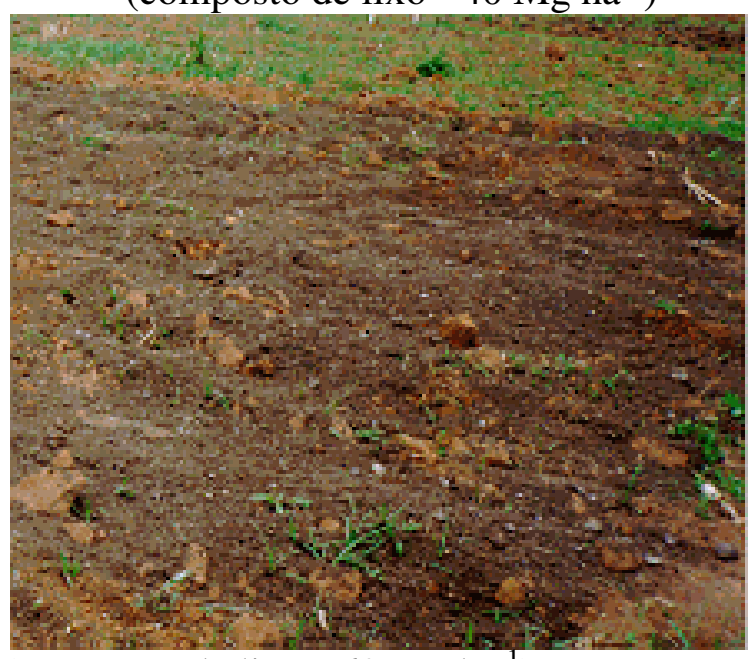

(composto de lixo - $60 \mathrm{Mg} \mathrm{ha}^{-1}$ )

Figura 3: Qualidade de distribuição dos resíduos nas parcelas, no ano agrícola de 1996/1997. 

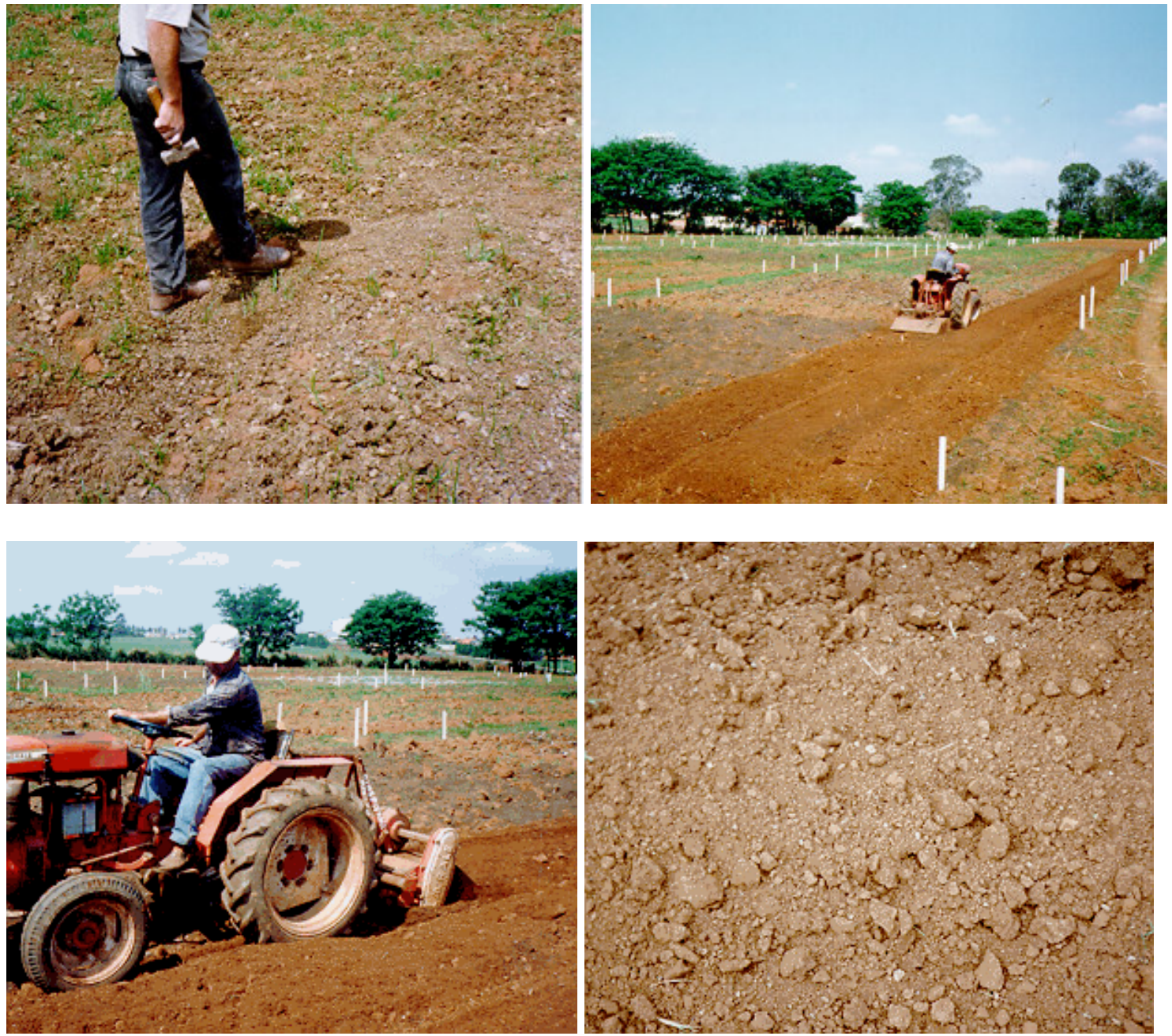

Figura 4: Aspecto do lodo após desidratação; incorporação dos resíduos e aspecto geral da área experimental, no ano agrícola de 1996/1997.

Outro fato é que o lodo de esgoto apresenta consistência pastosa e muito pegajosa. Desta forma, aderia-se às ferramentas, tornando muito difícil todo o processo de aplicação, desde o transporte até a distribuição nas parcelas. Como mão-de-obra para a aplicação dos resíduos, foram utilizados oito braçais durante três dias, sendo a maior parte deste tempo destinada à aplicação do lodo de esgoto. No primeiro ano, a ocorrência de chuvas intensas na época de aplicação tornou-a ainda mais difícil.

Quanto à incorporação do lodo de esgoto, a sua consistência, por si só, torná-la-ia difícil e desuniforme, visto que aderir-se-ia aos implementos e aos pneus do trator. Esta dificuldade intrínseca ao lodo, intensificada ainda mais pela ocorrência de chuvas intensas, impediram a sua incorporação imediata. Desta forma, o material 
permaneceu na superfície do solo por alguns dias, ficando exposto às condições atmosféricas. Ainda que não tenha sido planejada, esta exposição levou á desidratação do lodo, tornando a sua incorporação fácil e uniforme. Posteriormente tomou-se conhecimento que dificuldades na aplicação e incorporação de doses elevadas de lodo de esgoto já haviam sido relatadas por Epstein et al. (1976), que atribuíram estas dificuldades ao elevado conteúdo de água deste resíduo (naquele caso, apresentava apenas $23 \%$ de sólidos). Para a aplicação da maior dose $\left(240 \mathrm{Mg} \mathrm{ha}^{-1}\right)$, os autores fizeram uma aplicação inicial de $120 \mathrm{Mg} \mathrm{ha}^{-1}$, aguardaram secagem suficiente da superfície, e depois fizeram duas aplicações sucessivas de $60 \mathrm{Mg} \mathrm{ha}^{-1}$. Para a aplicação da mesma dose de lodo compostado com lixo urbano, os autores não relatam nenhum tipo de dificuldade, o que também se verificou no presente caso.

Principalmente nas parcelas que receberam as maiores doses de resíduos, a aplicação de herbicidas para controle de ervas daninhas em pré-emergência não foi muito eficiente, provavelmente pelo efeito de adsorção destes herbicidas à matéria orgânica adicionada. Neste sentido, houve necessidade de complementar o controle químico, realizando-se uma capina manual.

\subsection{Amostragens e determinações}

\subsubsection{Análise granulométrica e densidade dos sólidos}

Previamente à implantação do experimento foram coletadas amostras de solo da camada superficial ( 0 a $0,20 \mathrm{~m}$ de profundidade), aproximadamente no centro de cada parcela. Após secas ao ar, desagregadas e passadas por peneira de $2 \mathrm{~mm}$ de malha, as amostras foram utilizadas para a obtenção da densidade dos sólidos e da composição granulométrica do solo, seguindo a metodologia de rotina do Laboratório de Física do solo do Departamento de Ciência do Solo da ESALQ. A densidade dos sólidos $\rho_{\mathrm{s}}\left(\mathrm{kg} \mathrm{m}^{-3}\right)$ foi determinada pelo método do balão volumétrico, descrito em Kiehl (1979), utilizando-se álcool etílico para medição do volume de $20 \mathrm{~g}$ de solo.

Para a composição granulométrica, baseada na metodologia descrita em Gee \& Bauder (1986), $50 \mathrm{~g}$ de solo foram dispersas em solução aquosa de hexametafosfato de sódio puro $\left(6 \mathrm{~kg} \mathrm{~m}^{-3}\right)$ e hidróxido de sódio $\left(4 \mathrm{~kg} \mathrm{~m}^{-3}\right)$, por agitação durante 18 horas. A suspensão foi então transferida para provetas com capacidade para $1000 \cdot 10^{-6} \mathrm{~m}^{3}$, onde 
foram feitas duas leituras com densímetro de Bouyoucos. Na primeira leitura, realizada $40 \mathrm{~s}$ após agitação manual para uniformização da suspensão, determina-se a concentração de argila + silte. Na segunda, duas horas após a agitação, determina-se a concentração de argila. A concentração de silte é determinada pela diferença entre a primeira e a segunda leitura, e a concentração de areia pela diferença entre a concentração inicial e a concentração de argila + silte obtida na primeira leitura.

Após as leituras, a areia foi separada da suspensão, por lavagem e peneiramento em malha $0,053 \mathrm{~mm}$, e seca em estufa. As frações foram separadas por peneiramento nas categorias muito grossa $(1-2 \mathrm{~mm})$, grossa $(0,5-1 \mathrm{~mm})$, média $(0,25-0,5 \mathrm{~mm})$, fina $(0,25-0,105 \mathrm{~mm})$ e muito fina $(0,105-0,053 \mathrm{~mm})$.

\subsubsection{Conteúdo de carbono orgânico do solo}

O conteúdo de matéria orgânica do solo, alterado pelos dos tratamentos (principalmente pela aplicação de lodo de esgoto ou composto de lixo), foi acompanhada através da determinação dos teores de carbono oxidável do solo, realizada em amostras coletadas periodicamente na camada entre 0 e $0,20 \mathrm{~m}$ de profundidade. O C-oxidável foi determinado pela sua oxidação em solução $1 \mathrm{~N}$ de dicromato de potássio $\left(\mathrm{K}_{2} \mathrm{Cr}_{2} \mathrm{O}_{7}\right) \mathrm{em}$ meio ácido $\left(\mathrm{H}_{2} \mathrm{SO}_{4}\right.$ concentrado) seguida de titulação com solução padronizada de sulfato ferroso amoniacal $\left[\mathrm{Fe}\left(\mathrm{NH}_{4}\right)_{2}\left(\mathrm{SO}_{4}\right)_{2}\right]$ (adaptado de Walkley \& Black, 1934).

\subsubsection{Avaliação físico-hídrica do solo}

\subsubsection{Coleta e preparo das amostras de solo}

Para o primeiro ano do experimento, a amostragem para a avaliação físico-hídrica do solo foi feita ao final do ciclo da cultura, alguns dias antes da realização da colheita. Foram coletadas amostras deformadas e indeformadas de solo, a uma profundidade média de $0,15 \mathrm{~m}$, próximas ao centro de cada parcela. As amostras indeformadas foram obtidas com dois tipos de cilindros de alumínio, utilizando-se para a coleta um amostrador tipo Uhland. Um destes cilindros tinha cerca de $72 \mathrm{~mm}$ tanto de diâmetro quanto de altura, encaixando-se perfeitamente no amostrador. O outro tinha o mesmo diâmetro, mas apenas um terço da altura, de modo que um conjunto com três cilindros separáveis, que também totalizavam $72 \mathrm{~mm}$ de altura, era encaixado no 
interior do amostrador. Duas amostras nos cilindros maiores foram coletadas em cada parcela para a determinação da condutividade hidráulica do solo saturado e da densidade do solo. Uma amostra no conjunto de cilindros separáveis foi coletada em cada parcela, a qual originaria três sub-amostras para a elaboração da curva de retenção da água no solo. As amostras, todas mantidas com excesso de terra nas bordas, foram individualmente embaladas em papel alumínio e colocadas em sacos plásticos devidamente identificados para serem transportadas.

No preparo das amostras no laboratório, tanto os cilindros maiores quanto os cilindros menores coletados como uma amostra única tiveram os excessos de terra removidos, excessos estes que resultaram nos volumes indeformados de solo que seriam utilizados para a determinação da argila dispersa em água. Após serem submetidas a secagem ao ar, estas amostras com estrutura deformada foram desagregadas e passadas por peneira de malha igual a $2 \mathrm{~mm}$.

Para os cilindros maiores, após a remoção dos excessos de terra das bordas, a face inferior foi protegida por um tecido de náilon preso com elástico, e na face superior foi colocado um outro cilindro que serviria como reservatório de água na realização do ensaio de condutividade hidráulica. Este cilindro "reservatório" foi colado com fita adesiva, o que garantiu uma excelente vedação.

Para a amostra coletada no conjunto de cilindros separáveis, após a remoção dos excessos de terra das bordas, foi feita a separação dos três cilindros utilizando um fio metálico fino. Um disco de papel de filtro Watman 42 foi colado à borda inferior de cada anel, impedindo que houvesse perdas de terra. Este cuidado foi importante devido aos vários processos aos quais cada amostra foi submetida.

No segundo ano do experimento foram obtidas amostras deformadas de solo, compostas por três sub-amostras da camada de 0-0,20 m profundidade. Estas amostras, após serem secas ao ar, desagregadas e passadas por peneira de malha igual a $2 \mathrm{~mm}$, foram utilizadas apenas para a determinação da argila dispersa em água. Coletaram-se também volumes indeformadas de solo em cilindros com $50 \mathrm{~mm}$ tanto de diâmetro quanto de altura, nas camadas 0 a 0,$05 ; 0,05$ a 0,$10 ; 0,10$ a 0,15 e 0,15 a $0,20 \mathrm{~m}$ de profundidade. Os cilindros foram introduzidos ao solo utilizando-se um apoiador 
manual, e as amostras foram utilizadas para a obtenção da densidade do solo e da porosidade total. Estas amostragens foram feitas ao final do ciclo da cultura, alguns dias antes da realização da colheita, próximas ao centro de cada parcela.

\subsubsection{Argila dispersa em água}

O conteúdo de argila dispersa em água foi determinado utilizando-se o mesmo procedimento descrito para a determinação do conteúdo de argila total, exceto que neste caso, para a agitação durante 18 horas, não se utilizou a solução de hexametafosfato de sódio + hidróxido de sódio como meio dispersante da amostra, mas somente água destilada. De maneira idêntica à determinação da argila total, duas horas após a transferência para as provetas de $1000.10^{-6} \mathrm{~m}^{3}$ e a uniformização da suspensão, efetuou-se a leitura da concentração de argila dispersa em água com o densímetro de Bouyoucos.

\subsubsection{Condutividade hidráulica do solo saturado}

Para a determinação da condutividade hidráulica do solo saturado, conforme descrito em Youngs (1991), as amostras preparadas eram colocadas em bandejas e gradualmente embebidas por água até que esta ultrapassasse o limite superior das amostras e levasse à formação de uma lâmina de aproximadamente $10 \mathrm{~mm}$ no cilindro reservatório. Atingida esta condição, esta lâmina de água era elevada para cerca de $40 \mathrm{~mm}$ com o auxílio de uma piceta, e conjuntos com três amostras eram levadas para a determinação, conforme o esquema apresentado na Figura 5. Com o auxílio de um frasco de Mariotte, o nível da água no cilindro reservatório era mantido em cerca de $35 \mathrm{~mm}$.

A massa de água $m_{a}$ (obtida em g e transformada para $\mathrm{kg}$ ) que passava pela amostra em um intervalo de tempo $\Delta t$ (obtido em $\mathrm{s}$ e transformada para $\mathrm{h}$ ) foi determinada até que se tornasse constante. Conhecendo-se $m_{a}$ e assumindo-se a densidade da água $\rho_{a}$ como sendo $1000 \mathrm{~kg} \mathrm{~m}^{-3}$, determinava-se o volume de água

correspondente $V_{a}$ pela equação $V_{a}=\frac{m_{a}}{\rho_{a}}$. Ao mesmo tempo em que se obtinha $m_{a}$, a tomava-se a medida carga hidráulica $c h(\mathrm{~m})$ na face superior da amostra. Conhecendo-se previamente as dimensões dos cilindros (diâmetro $d$ e comprimento $L$, ambos em m), a 
condutividade hidráulica do solo saturado $\mathrm{K}_{0}\left(\mathrm{~mm} \mathrm{~h}^{-1}\right)$ foi determinada a partir da equação de Darcy-Buckingham:

$$
K_{0}=\frac{q}{\operatorname{gradH}}=\frac{V_{a} \cdot L}{A \cdot \Delta t \cdot(c h+L)}
$$

onde $q\left(\mathrm{~mm} \mathrm{~h}^{-1}\right)$ é a densidade de fluxo, $\operatorname{gradH}\left(\mathrm{m} \mathrm{m}^{-1}\right)$ é o gradiente de potencial total e $A\left(\mathrm{~m}^{2}\right)$ é a área da superfície da amostra. Cabe lembrar que $A=\frac{\pi \cdot d^{2}}{4}$.

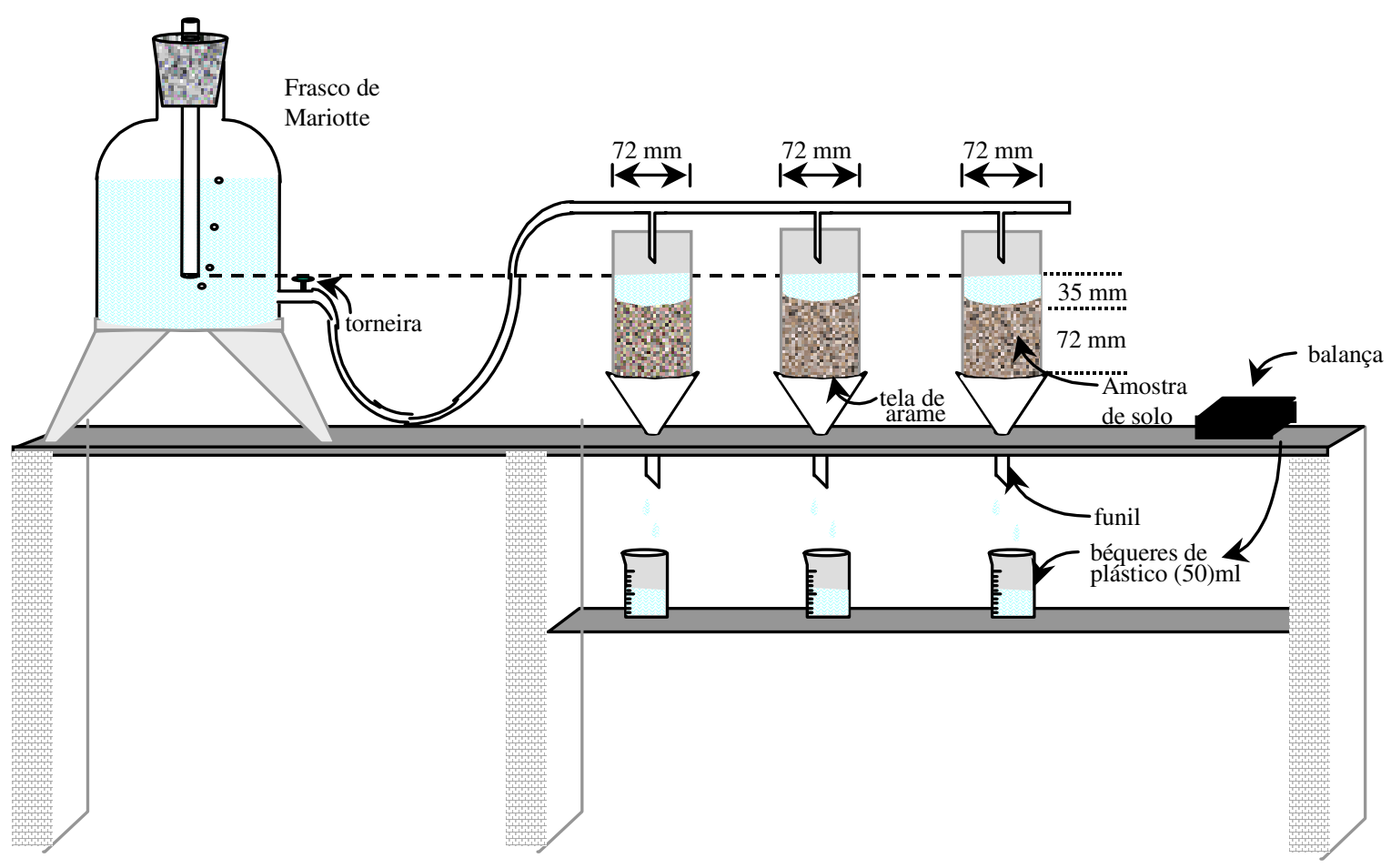

Figura 5: Esquema da determinação da condutividade hidráulica do solo saturado em amostras.

\subsubsection{Densidade e porosidade total do solo}

No primeiro ano, a densidade do solo foi obtida a partir das mesmas amostras utilizadas para determinação da condutividade hidráulica do solo saturado, em cilindros com cerca de $72 \mathrm{~mm}$ de diâmetro e de altura. Após esta determinação, as amostras foram levadas à estufa a $105-110^{\circ} \mathrm{C}$ durante 48 horas, tempo em que se admite massa 
constante $m_{t}(\mathrm{~kg})$. Nesta situação, $m_{t}=m_{s}+m_{c}+m_{p s}$, onde $m_{s}(\mathrm{~kg})$ é a massa do solo seco, $m_{c}(\mathrm{~kg})$ é a massa do cilindro de alumínio e $m_{p s}(\mathrm{~kg})$ é a massa do papel seco que protege a face inferior do cilindro. $\mathrm{O}$ volume da amostra $V\left(\mathrm{~m}^{3}\right)$ foi considerado com sendo igual ao volume interno do cilindro, ou seja, $V=L \pi d^{2} / 4$. A densidade do solo $\rho\left(\mathrm{kg} \mathrm{m}^{-3}\right)$ foi calculada pela equação

$$
\rho=\frac{m_{s}}{V}=\frac{m_{t}-m_{c}-m_{p}}{V}
$$

A porosidade total $P T\left(\mathrm{~m}^{3} \mathrm{~m}^{-3}\right)$ foi calculada utilizando-se a relação existente entre a densidade dos sólidos $\left(\rho_{\mathrm{s}}\right)$ e a densidade do solo, expressa pela equação

$$
P T=1-\frac{\rho}{\rho_{s}}
$$

No segundo ano, estas mesmas equações foram utilizadas para calcular a densidade e a porosidade total do solo. Cabe lembrar, no entanto, que foram utilizados cilindros de dimensões menores que as do primeiro ano $(50 \mathrm{~mm}$ de diâmetro e de altura), e coletados em outras camadas $(0$ a 0,$05 ; 0,05$ a 0,$10 ; 0,10$ a 0,15 e 0,15 a $0,20 \mathrm{~m}$ de profundidade).

\subsubsection{Curva de retenção da água no solo}

As amostras preparadas para a elaboração das curvas de retenção foram colocadas em bandejas e lentamente embebidas com água destilada e deaerada (Moraes, 1991). Para esta embebição utilizou-se um gotejador de Mariotte que demorava cerca de 24 horas para elevar o nível da água na bandeja até a face superior da amostra. As amostras permaneciam embebidas por mais 24 horas para que houvesse a dissolução de ar aprisionado, tentando-se desta forma alcançar uma proximidade da saturação. As amostras eram então levadas aos funis de placa porosa e às câmaras de pressão de Richards, onde eram submetidas às seguintes diferenças de pressão entre a face superior e a face inferior correspondentes aos seguintes potenciais mátricos $\phi_{\mathrm{m}}$ : 0,5, 1, 2, 4, 6, 10, 20, 30, 80, 400 e $1500 \mathrm{kPa}$. Após o equilíbrio (ou seja, após cessada a drenagem), determinava-se a massa total das amostras com solo úmido $m_{u}(\mathrm{~kg})$. Como cada curva foi elaborada a partir de apenas três amostras, até que todos os pontos fossem obtidos, 
elas retornavam à bandeja para serem novamente saturadas e submetidas a novo processo de drenagem. Determinados todos os pontos da curva, as amostras eram levadas à estufa a $105-110^{\circ} \mathrm{C}$ durante 48 horas, para a determinação da massa total com solo seco $m_{t}(\mathrm{~kg})$. A umidade a base de massa $\mathrm{U}\left(\mathrm{kg} \mathrm{kg}^{-1}\right)$ correspondente a cada diferença de potencial utilizada foi calculada pela equação:

$$
U=\frac{m_{u}-m_{t}-m_{a p}}{m_{s}}=\frac{m_{a}}{m_{s}}
$$

onde $m_{a}(\mathrm{~kg})$ é a massa da água retida na amostra, $m_{t}=m_{s}+m_{c}+m_{p s}$, $m_{u}=m_{s}+m_{a}+m_{c}+m_{p u}$ (nesta equação, $m_{p u}(\mathrm{~kg})$ é a massa do papel úmido), e $m_{a p}(\mathrm{~kg})$ é a massa da água retida no papel úmido $\left(m_{a p}=m_{p u}+m_{p s}\right.$, estimada fazendo-se uma curva de retenção para o papel de filtro, para os mesmos potenciais mátricos utilizados na curva de retenção de água no solo). A umidade a base de volume $\theta\left(\mathrm{m}^{3} \mathrm{~m}^{-3}\right)$ foi obtida por

$$
\theta=U \frac{\rho}{\rho_{a}}
$$

Utilizando-se o programa computacional desenvolvido por Dourado Neto \& Jong van Lier (1992), o conjunto de pares $\left(\theta, \phi_{\mathrm{m}}\right)$ obtido para cada parcela foi ajustado ao modelo proposto por Van Genuchten (1980) para a curva de retenção:

$$
\theta=\theta_{r}+\left(\theta_{s}-\theta_{r}\right) \cdot\left[1+\left(\alpha \cdot \phi_{m} \mid\right)^{n}\right]^{m}
$$

onde $\theta_{\mathrm{s}}\left(\mathrm{m}^{3} \mathrm{~m}^{-3}\right)$ é a umidade na saturação, $\theta_{\mathrm{r}}\left(\mathrm{m}^{3} \mathrm{~m}^{-3}\right)$ é umidade residual, e $\alpha\left(\mathrm{kPa}^{-1}\right)$, $m$ e $n$ são parâmetros empíricos de ajuste (estes dois últimos são adimensionais). No ajuste, $\theta_{\mathrm{s}}, \theta_{\mathrm{r}}, \alpha$ e $m$ foram estimados por regressão e $n$ foi considerado dependente de $m\left(n=\frac{1}{1-m}\right)$.

\subsubsection{Condutividade hidráulica obtida pelo método do infiltrômetro de tensão.}

Medidas de infiltração foram feitas no centro das parcelas, aproximadamente entre 0,20 e $0,30 \mathrm{~m}$ de distância da linha de plantio. Foi utilizado um infiltrômetro de 
tensão apresentado na Figura 6 (Perroux \& White, 1988), com área de contato para infiltração circular de raio $r=0,1145 \mathrm{~m}$. As medidas de infiltração foram feitas a 1,00; 0,50; 0,25 e $0 \mathrm{kPa}$ de tensão da água no solo (correspondentes aos potenciais mátricos $-1,00 ;-0,50 ;-0,25$ e $0 \mathrm{kPa}$, respectivamente), sempre nesta ordem e no mesmo local. Devido a irregularidades do terreno e para conseguir um bom contato entre a tecido de náilon e o solo, a superfície do solo era nivelada e recebia uma cobertura com areia de diâmetro $\leq 100 \mu \mathrm{m}$, para que o contato entre o infiltrômetro e o solo fosse adequado. A partir dos valores de fluxo estacionário $\left(q, \mathrm{~mm} \mathrm{~h}^{-1}\right)$ da infiltração tridimensional obtidos para as quatro tensões utilizadas, calculou-se as respectivas condutividades hidráulicas $\left(K, \mathrm{~mm} \mathrm{~h}^{-1}\right)$ utilizando a metodologia apresentada por Ankeny et al. (1991). Para a utilização desta metodologia (detalhada no Apêndice 1) deve-se resolver um sistema com três equações e três incógnitas (equações 7, 8 e 9):

$$
\begin{gathered}
K\left(\tau_{1}\right)=q\left(\tau_{1}\right) /\left(1+\frac{4}{\pi r \alpha}\right) \\
K\left(\tau_{2}\right)=q\left(\tau_{2}\right) /\left(1+\frac{4}{\pi r \alpha}\right) \\
\alpha=\frac{2\left[q\left(\tau_{1}\right)-q\left(\tau_{2}\right)\right]}{\Delta \tau\left[q\left(\tau_{1}\right)+q\left(\tau_{2}\right)\right]}
\end{gathered}
$$

onde $\alpha\left(\mathrm{m}^{-1}\right)$ é uma constante válida para o intervalo $\Delta \tau$ entre duas tensões consecutivas $\tau_{1}$ e $\tau_{2}$ utilizadas nas medidas com o infiltrômetro de tensão (neste cálculo, a unidade utilizada para $\tau$ foi $\mathrm{m}$ de coluna d'água). A partir dos dois valores de fluxo estacionário de infiltração, obtidos para $\tau_{1}$ e $\tau_{2}$, pôde-se calcular $\alpha$ pela equação 9 e $K\left(\tau_{1}\right)$ e $K\left(\tau_{2}\right)$ pelas equações 7 e 8 . Como utilizou-se quatro tensões consecutivas, para cada uma das tensões intermediárias pôde-se obter dois valores de $K(\tau)$, pois dois pares de valores de fluxo puderam ser obtidos para cada uma delas. Estes pares são formados pelo fluxo na tensão considerada e o fluxo obtido para a tensão imediatamente acima ou abaixo desta, respectivamente. Nestes casos, conforme sugere Ankeny et al. (1991), a 
condutividade hidráulica correspondente àquele valor de $\tau$ foi estimada calculando-se a média dos dois valores de $K$ obtidos.

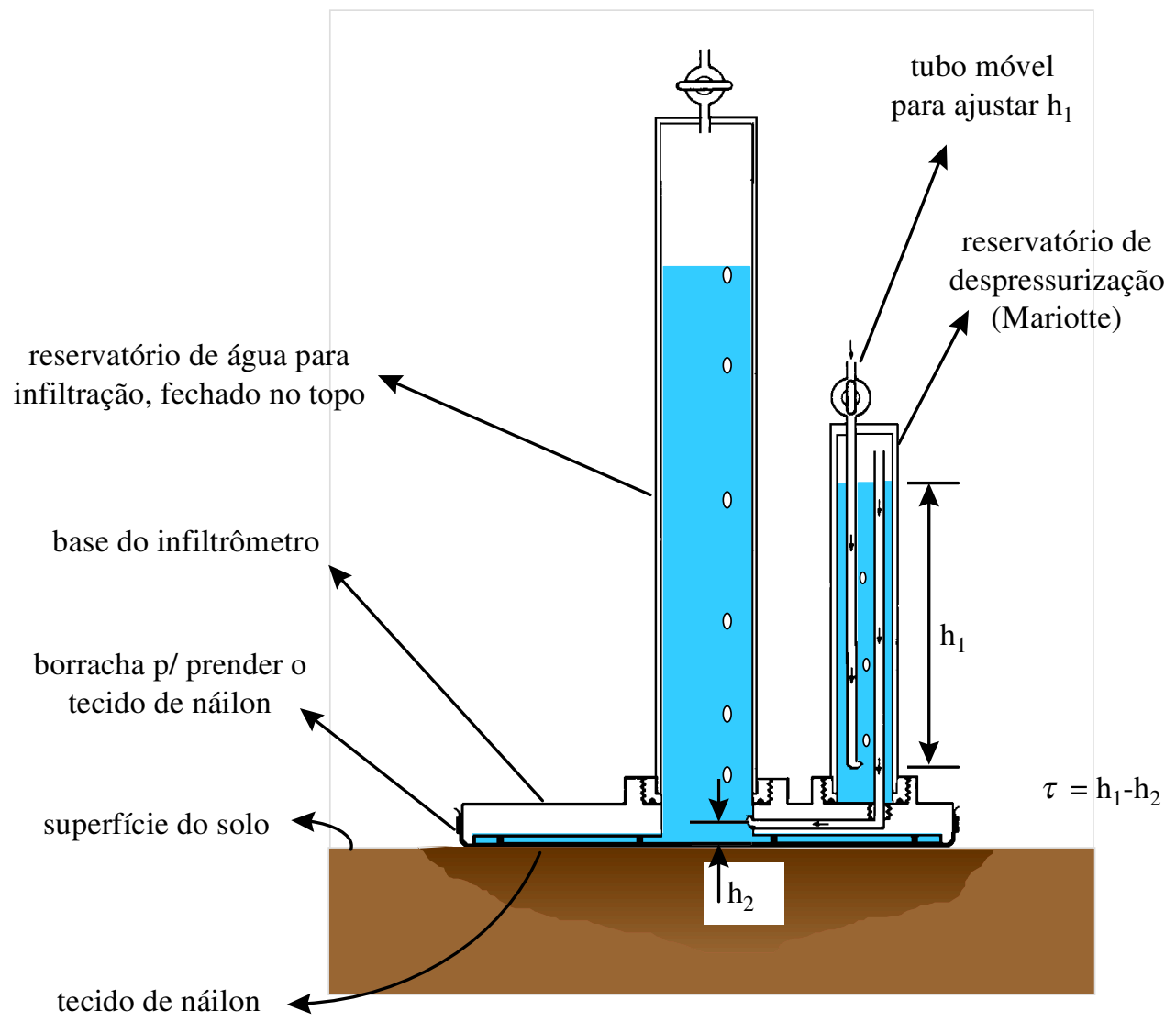

Figura 6. Esquema do infiltrômetro de tensão utilizado.

\subsubsection{Condutividade hidráulica pelo método de Van Genuchten (1980)}

Determinou-se também a condutividade hidráulica relativa $K_{r}\left(\phi_{m}\right)$ em função do potencial mátrico $\phi_{m}$ pelo método de Van Genuchten (1980), que propôs uma equação para a curva de retenção (equação 6) e a combinou ao modelo de Mualem (1976), obtendo-se a expressão apresentada na equação 10,

$$
K_{r}\left(\phi_{m}\right)=\frac{K\left(\phi_{m}\right)}{K_{0}}=\frac{\left\{1-\left(\alpha \cdot\left|\phi_{m}\right|\right)^{n-1}\left[1+\left(\alpha \cdot\left|\phi_{m}\right|\right)^{n}\right]^{n}\right\}^{2}}{\left[1+\left(\alpha \cdot\left|\phi_{m}\right|\right)^{n}\right]^{n / 2}}
$$


onde $\alpha, m$ e $n$ são os parâmetros empíricos de ajuste da equação $6, K_{0}$ é a condutividade hidráulica do solo saturado (obtida conforme item 3.7.3.3) e $K\left(\phi_{m}\right)$ é a condutividade hidráulica efetiva do solo a um dado potencial mátrico $\phi_{m}$. Para estimar $K_{r}\left(\phi_{m}\right)$ por este modelo basta conhecer os parâmetros $\alpha, m$ e $n$, e para estimar $K\left(\phi_{m}\right)$ basta conhecer, além destes parâmetros, a condutividade hidráulica do solo saturado $K_{0}$.

\subsubsection{Tratamento estatístico dos dados}

Para verificar se variações nas propriedades físico-hídricas de interesse (variáveis dependentes) poderiam ser atribuídas às variáveis independentes impostas pelos tratamentos, fez-se a análise de variância de acordo com o esquema apresentado na Tabela 4, aplicando-se o teste $\mathrm{F}$ e assumindo-se como nível de probabilidade de que as diferenças entres os tratamentos sejam devidas ao acaso $\alpha \leq 0,10$. Conforme pode-se observar, os tratamentos foram desdobrados em contrastes ortogonais de interesse, a saber: adubação mineral vs. demais tratamentos; lodo de esgoto vs. composto de lixo; estudo de regressão para doses de lodo de esgoto e estudo de regressão para doses de composto de lixo.

Para os estudos de regressões para doses dos resíduos (que, em virtude dos objetivos deste trabalho, receberam maior ênfase) foram utilizadas equações polinomiais, que embora tenham algumas limitações para representar certos fenômenos, são funções simples e de fácil uso (Pimentel Gomes, 1990). Como utilizaram-se 4 doses, seria possível o ajuste de equações polinomiais de grau 3 (pois tem-se 3 graus de

Tabela 4. Esquema de análise de variância utilizado para os resultados do experimento.

\begin{tabular}{lc}
\hline \hline Causas da variação & Graus de liberdade \\
\hline Blocos & 3 \\
(Tratamentos) & $(8)$ \\
\hline Adubação mineral vs. demais & 1 \\
Lodo vs. Composto & 1 \\
Regressões para doses de lodo & 3 \\
Regressões para doses de composto & 3 \\
\hline Resíduo & 24 \\
\hline Total & 35 \\
\hline \hline
\end{tabular}


liberdade para as regressões). No entanto foram considerados apenas os efeitos linear e quadrático, sendo que a eventual ocorrência de efeito cúbico (ou de grau 3) foi considerado como desvio da regressão.

Por outro lado, para a aplicação sem restrições da análise de variância, além de algumas pressuposições básicas quanto ao modelo matemático (cujos fatores devem ser aditivos) e quanto aos desvios (que devem ser independentes, ter a mesma variância e ter distribuiçãa normal), o experimento deve ter sido conduzido segundo os princípios básicos da experimentação: a repetição, a casualização e, se necessário, o controle local (Pimentel Gomes, 1990). No presente caso, a utilização do delineamento em blocos casualizados com 4 repetições garante a observância de todos estes princípios. Estes cuidados são tomados para garantir que variações anteriores das propriedades de interesse sejam devidas somente ao acaso, não devendo haver covariação destas com relação aos tratamentos a serem implantados. Da mesma forma, outras variáveis independentes que porventura possam interferir nestas propriedades de interesse também devem apresentar variações devidas apenas ao acaso, não covariando com relação aos tratamentos.

Estes cuidados, no entanto, não garantem, por si só, a ausência de covariação (Van Es \& Van Es, 1993). Caso estas covariações ocorram, torna-se possível que as diferenças observadas no atributo de interesse não sejam devidas aos tratamentos, mas sim devidas a variações pré-existentes nas propriedades de interesse ou a variações em outras variáveis independentes que se correlacionam às propriedades de interesse. $\mathrm{O}$ ideal seria sempre a realização de um "ensaio em branco", em que a variação espacial anterior da propriedade de interesse ou outras a ela correlacionadas fossem conhecidas, por exemplo, mediante estudos realizados a luz da geoestatística. Muitas vezes, como no presente caso, este ensaio não é possível de ser realizado, seja pela dificuldade das determinações, seja pelo fato de que a própria implantação do experimento pode levar a modificações nestas propriedades de interesse ou nas outras a elas correlacionadas, consequentemente alterando sua variação espacial. 
Ainda assim, há a possibilidade de que o "ensaio em branco" seja realizado de maneira mais simples, à luz apenas da estatística clássica. Neste caso, uma análise de variância (nos mesmos moldes propostos para verificar os efeitos dos tratamentos sobre as propriedades de interesse) deveria ser realizada para verificar a dependência entre os tratamentos e as propriedades de interesse antes da instalação do experimento, ou entre os tratamentos e outras propriedades que se correlacionam às de interesse. Caso seja verificada a existência de covariação, a casualização dos tratamentos dentro da área experimental ou dos blocos poderia ser refeita, até que esta covariação seja eliminada. No presente caso, estas análises foram feitas entre os tratamentos e a composição granulométrica (conteúdo de areia ou argila), que reconhecidamente se correlaciona às propriedades físico-hídricas de interesse. No entanto, como foram realizadas após a implantação do experimento, uma nova casualização não seria possível. Neste caso, havendo covariação significativa entre tratamento e conteúdo de argila (por exemplo), verificou-se através de análise de regressão linear se o conteúdo de argila de fato se correlacionava à propriedade físico-hídrica em questão. Em caso positivo, lançou-se mão da análise de regressão polinomial múltipla, considerando-se como variável dependente a propriedade físico-hídrica em questão, e como variáveis independentes, as doses dos resíduos e conteúdo de argila (por exemplo). Embora feita com um número reduzido de pontos, esta análise de regressão polinomial múltipla mostrou-se consistente e capaz de elucidar o real efeito dos resíduos. 


\section{RESULTADOS E DISCUSSÃO}

Sabe-se que propriedades físico-hídricas do solo dependem basicamente da composição granulométrica, da estrutura e do conteúdo de matéria orgânica do solo (Kiehl, 1979; Brady, 1989). No presente caso, o conhecimento da variabilidade espacial anterior à implantação do experimento, tanto da estrutura do solo (que poderia ser estudada, por exemplo, em termos da porosidade total e da distribuição dos poros por tamanho) quanto das propriedades físico-hídricas a serem avaliadas, seria pouco relevante, pois tanto a estrutura quanto estas propriedades físico-hídricas são modificadas (e de certa forma uniformizadas) durante a instalação do experimento. Para o conteúdo de matéria orgânica do solo, embora este possa apresentar certa variabilidade ou mesmo covariar com relação aos tratamentos, os próprios tratamentos levam a um aumento considerável nesta propriedade (veja item 3.7.2), tornando as variações anteriores também pouco relevantes. Já para a composição granulométrica do solo, como ela não sofre alterações em consequiência dos tratamentos, o conhecimento de sua variabilidade prévia pode ser importante para verificar a pressuposição de que a variabilidade existente em outras variáveis independentes (que não aquelas induzidas pelos tratamentos do experimento) devam ser devidas somente ao acaso, não devendo haver covariação destas com relação aos tratamentos implantados, conforme anteriormente discutido.

Exceção feita à composição granulométrica e densidade dos sólidos do solo, para a qual fez-se um "ensaio em branco", os demais resultados apresentados a seguir tratam unicamente de avaliar os efeitos dos tratamentos (e consequentemente da alteração do conteúdo de carbono orgânico do solo) sobre as propriedades físico-hídricas do solo. 


\subsection{Composição granulométrica e densidade dos sólidos do solo}

$\mathrm{Na}$ Tabela 5 são apresentados os valores médios por tratamento das frações granulométricas e da densidade dos sólidos do solo, bem como os seus limites de confiança ao nível de probabilidade $\alpha=0,10$ pelo teste $t\left(\mathrm{LC}_{\alpha=0,10}\right)$. Pode-se verificar que os valores de areia total determinados nas peneiras sempre superam aqueles determinados com o densímetro. Isto pode ter ocorrido devido a parte das frações silte e

Tabela 5. Composição granulométrica e densidade dos sólidos do solo na camada de 0 a 0,20 m de profundidade: média por tratamento e respectivo limite de confiança ao nível de probabilidade $\alpha=0,10\left(\mathrm{LC}_{\alpha=0,10}\right)$; valor $\mathrm{F}$ da análise de variância e respectivo nível de probabilidade $\alpha$.

\begin{tabular}{|c|c|c|c|c|c|c|}
\hline \multirow[b]{2}{*}{ Tratamento } & \multirow[b]{2}{*}{$\begin{array}{l}\text { Parâmetro } \\
\text { estatístico }\end{array}$} & \multicolumn{2}{|c|}{ areia } & \multirow[b]{2}{*}{ silte } & \multirow[b]{2}{*}{ argila } & \multirow[b]{2}{*}{$\begin{array}{c}\rho_{\mathrm{s}} \\
\left(\mathrm{Mg} \mathrm{m}^{-3}\right)\end{array}$} \\
\hline & & \multicolumn{2}{|c|}{ - } & & & \\
\hline \multirow[t]{2}{*}{$\operatorname{tr} 1$} & Média & 570,96 & 524,39 & 102,26 & 373,35 & 2,70 \\
\hline & $\mathrm{LC}_{\alpha=0,10}$ & 46,64 & 39,27 & 1,08 & 38,58 & 0,08 \\
\hline \multirow[t]{2}{*}{$\operatorname{tr} 2$} & Média & 550,01 & 512,55 & 91,39 & 396,07 & 2,72 \\
\hline & $\mathrm{LC}_{\alpha=0,10}$ & 66,78 & 78,25 & 13,69 & 88,54 & 0,03 \\
\hline \multirow[t]{2}{*}{$\operatorname{tr} 3$} & Média & 530,91 & 511,23 & 91,68 & 397,09 & 2,78 \\
\hline & $\mathrm{LC}_{\alpha=0,10}$ & 24,23 & 43,08 & 14,14 & 40,42 & 0,07 \\
\hline \multirow[t]{2}{*}{$\operatorname{tr} 4$} & Média & 577,28 & 553,57 & 96,40 & 350,03 & 2,70 \\
\hline & $\mathrm{LC}_{\alpha=0,10}$ & 60,65 & 62,51 & 23,04 & 41,44 & 0,10 \\
\hline \multirow[t]{2}{*}{$\operatorname{tr} 5$} & Média & 586,03 & 567,78 & 101,70 & 330,51 & 2,67 \\
\hline & $\mathrm{LC}_{\alpha=0,10}$ & 28,63 & 22,07 & 0,38 & 22,25 & 0,03 \\
\hline \multirow[t]{2}{*}{$\operatorname{tr} 6$} & Média & 572,63 & 548,03 & 96,52 & 355,45 & 2,73 \\
\hline & $\mathrm{LC}_{\alpha=0,10}$ & 17,44 & 29,10 & 30,14 & 29,59 & 0,02 \\
\hline \multirow[t]{2}{*}{$\operatorname{tr} 7$} & Média & 570,45 & 533,53 & 106,53 & 359,94 & 2,84 \\
\hline & $\mathrm{LC}_{\alpha=0,10}$ & 43,30 & 21,84 & 23,39 & 22,39 & 0,10 \\
\hline \multirow[t]{2}{*}{$\operatorname{tr} 8$} & Média & 509,79 & 464,94 & 91,71 & 443,35 & 2,75 \\
\hline & $\mathrm{LC}_{\alpha=0,10}$ & 46,60 & 41,64 & 13,68 & 41,82 & 0,09 \\
\hline \multirow[t]{4}{*}{$\operatorname{tr} 9$} & Média & 575,87 & 556,71 & 86,58 & 356,71 & 2,70 \\
\hline & $\mathrm{LC}_{\alpha=0,10}$ & 73,01 & 75,25 & 22,81 & 89,43 & 0,04 \\
\hline & valor $\mathrm{F}$ & $1,42^{\text {n.s. }}$ & $1,96^{*}$ & $0,92^{\text {n.s. }}$ & $2,24 *$ & $3,05^{*}$ \\
\hline & $\alpha$ & 0,2371 & 0,0976 & 0,5195 & 0,0603 & 0,0162 \\
\hline
\end{tabular}

*: significativo estatisticamente ao nível de probabilidade $\alpha$ expresso na linha imediatamente abaixo. n.s.: não significativo estatisticamente ao nível de probabilidade $\alpha=0,10$. 
argila não terem sido eliminadas no processo de lavagem e peneiramento, permanecendo junto à fração areia. Na Tabela 5 são apresentados também os valores $\mathrm{F}$ obtidos na análise de variância e seus respectivos níveis de significância. Na Tabela 6, os mesmos parâmetros estatísticos da Tabela 5 são apresentados para as sub-frações da areia.

Tabela 6. Sub-frações da areia na camada de 0 a $0,20 \mathrm{~m}$ de profundidade: média por tratamento e respectivo limite de confiança ao nível de probabilidade $\alpha=0,10$ $\left(\mathrm{LC}_{\alpha=0,10}\right)$; valor $\mathrm{F}$ da análise de variância e respectivo nível de probabilidade $\alpha$.

\begin{tabular}{|c|c|c|c|c|c|c|}
\hline Tratamento & $\begin{array}{l}\text { Parâmetro } \\
\text { estatístico }\end{array}$ & $\begin{array}{c}\text { areia muito } \\
\text { grossa }\end{array}$ & $\begin{array}{c}\text { areia } \\
\text { grossa }\end{array}$ & $\begin{array}{c}\text { areia } \\
\text { média } \\
\left(\mathrm{g} \mathrm{kg}^{-1}\right)--\end{array}$ & $\begin{array}{l}\text { areia } \\
\text { fina }\end{array}$ & $\begin{array}{l}\text { areia muito } \\
\text { fina }\end{array}$ \\
\hline $\operatorname{tr} 1$ & $\begin{array}{l}\text { Média } \\
\mathrm{LC}_{\alpha=0,10}\end{array}$ & $\begin{array}{l}40,03 \\
10,29\end{array}$ & $\begin{array}{l}68,28 \\
17,35\end{array}$ & $\begin{array}{r}107,28 \\
14,68\end{array}$ & $\begin{array}{r}250,98 \\
25,04\end{array}$ & $\begin{array}{r}104,40 \\
4,38\end{array}$ \\
\hline $\operatorname{tr} 2$ & $\begin{array}{l}\text { Média } \\
\mathrm{LC}_{\alpha=0,10}\end{array}$ & $\begin{array}{r}31,73 \\
7,34\end{array}$ & $\begin{array}{l}60,92 \\
14,72\end{array}$ & $\begin{array}{r}103,78 \\
15,74\end{array}$ & $\begin{array}{r}253,35 \\
33,13\end{array}$ & $\begin{array}{r}100,23 \\
5,71\end{array}$ \\
\hline $\operatorname{tr} 3$ & $\begin{array}{l}\text { Média } \\
\mathrm{LC}_{\alpha=0,10}\end{array}$ & $\begin{array}{r}30,14 \\
4,57\end{array}$ & $\begin{array}{r}61,10 \\
1,97\end{array}$ & $\begin{array}{r}102,00 \\
5,01\end{array}$ & $\begin{array}{r}242,13 \\
10,40\end{array}$ & $\begin{array}{l}95,54 \\
10,39\end{array}$ \\
\hline $\operatorname{tr} 4$ & $\begin{array}{l}\text { Média } \\
\qquad \mathrm{LC}_{\alpha=0,10}\end{array}$ & $\begin{array}{l}43,81 \\
17,46\end{array}$ & $\begin{array}{l}72,92 \\
19,99\end{array}$ & $\begin{array}{r}109,04 \\
13,11\end{array}$ & $\begin{array}{r}248,79 \\
17,43\end{array}$ & $\begin{array}{r}102,72 \\
3,40\end{array}$ \\
\hline $\operatorname{tr} 5$ & $\begin{array}{l}\text { Média } \\
\mathrm{LC}_{\alpha=0,10}\end{array}$ & $\begin{array}{l}44,74 \\
14,98\end{array}$ & $\begin{array}{r}72,97 \\
6,74\end{array}$ & $\begin{array}{r}109,38 \\
4,69\end{array}$ & $\begin{array}{r}256,03 \\
20,51\end{array}$ & $\begin{array}{r}102,92 \\
7,77\end{array}$ \\
\hline $\operatorname{tr} 6$ & $\begin{array}{l}\text { Média } \\
\mathrm{LC}_{\alpha=0,10}\end{array}$ & $\begin{array}{r}29,82 \\
6,25\end{array}$ & $\begin{array}{r}60,30 \\
8,54\end{array}$ & $\begin{array}{r}108,33 \\
4,25\end{array}$ & $\begin{array}{r}266,26 \\
9,83\end{array}$ & $\begin{array}{r}107,92 \\
5,93\end{array}$ \\
\hline $\operatorname{tr} 7$ & $\begin{array}{l}\text { Média } \\
\mathrm{LC}_{\alpha=0,10}\end{array}$ & $\begin{array}{l}37,77 \\
14,27\end{array}$ & $\begin{array}{l}76,45 \\
27,96\end{array}$ & $\begin{array}{r}104,33 \\
4,18\end{array}$ & $\begin{array}{r}248,53 \\
10,82\end{array}$ & $\begin{array}{r}103,38 \\
4,62\end{array}$ \\
\hline $\operatorname{tr} 8$ & $\begin{array}{l}\text { Média } \\
\mathrm{LC}_{\alpha=0,10}\end{array}$ & $\begin{array}{r}24,00 \\
4,16\end{array}$ & $\begin{array}{r}55,38 \\
6,89\end{array}$ & $\begin{array}{l}92,97 \\
17,05\end{array}$ & $\begin{array}{r}238,19 \\
20,00\end{array}$ & $\begin{array}{l}99,25 \\
14,92\end{array}$ \\
\hline $\operatorname{tr} 9$ & $\begin{array}{l}\text { Média } \\
\text { LC }_{\alpha=0,10}\end{array}$ & $\begin{array}{l}37,68 \\
11,68 \\
\end{array}$ & $\begin{array}{l}67,99 \\
17,80 \\
\end{array}$ & $\begin{array}{r}110,42 \\
16,39 \\
\end{array}$ & $\begin{array}{r}258,50 \\
29,89 \\
\end{array}$ & $\begin{array}{r}101,27 \\
5,35 \\
\end{array}$ \\
\hline & $\begin{array}{c}\text { valor } \mathrm{F} \\
\alpha\end{array}$ & $\begin{array}{r}2,07 * \\
0,0798\end{array}$ & $\begin{array}{l}1,24^{\text {n.s. }} \\
0,3204\end{array}$ & $\begin{array}{l}1,08^{\text {n.s. }} \\
0,4086\end{array}$ & $\begin{array}{l}0,86^{\text {n.s. }} \\
0,5636\end{array}$ & $\begin{array}{c}1,15^{\text {n.s. }} \\
0,3683\end{array}$ \\
\hline
\end{tabular}

*: significativo estatisticamente ao nível de probabilidade $\alpha$ expresso na linha imediatamente abaixo. n.s.: não significativo estatisticamente ao nível de probabilidade $\alpha=0,10$. 
Sabe-se que a composição granulométrica do solo não pode ser alterada facilmente, a não ser pela adição de grande quantidade de material de determinada fração granulométrica. No presente caso, a adição de material orgânico, mesmo nas maiores doses, não implica em alteração significativa das frações granulométricas do solo. Considerando-se, na maior dose, a incorporação de $211 \mathrm{Mg} \mathrm{ha}^{-1}$ de lodo de esgoto (soma dos dois anos) na camada de 0 a 0,20 m de profundidade, e considerando-se a densidade desta camada $1,5 \mathrm{Mg} \mathrm{m}^{-3}$, verifica-se que esta quantidade de material significa um acréscimo de cerca de $1 \%$ (apenas $10 \mathrm{~kg}$ de resíduo por $\mathrm{Mg}$ de solo).

Presumindo-se que a composição granulométrica do solo não sofra alterações em conseqüência dos tratamentos, fez-se a coleta de amostras antes da implantação do experimento para a realização do "ensaio em branco". No entanto, estas determinações não foram feitas antes da implantação do experimento, de modo que a análise a seguir não serviu para que a casualização dos tratamentos fosse feita de maneira a garantir que não houvesse covariação entre a composição granulométrica do solo e os tratamentos implantados. No entanto, esta análise serviu para verificar a existência ou não desta covariação, pela qual as alterações físico-hídricas estudadas poderiam não ser atribuídas unicamente aos tratamentos. Para esta verificação realizou-se a análise de variância do conteúdo das diferentes frações granulométricas do solo, segundo o esquema apresentado na Tabela 4.

A aplicação do teste $\mathrm{F}$ à análise de variância mostrou haver diferenças estatisticamente significativas entre os tratamentos para as frações argila $(\alpha=0,0603)$, areia total determinada pelo densímetro $(\alpha=0,0976)$ e areia muito grossa $(\alpha=0,0798)$. Neste caso, as alterações físico-hídricas estudadas poderiam não ser atribuídas unicamente aos tratamentos, mas também às diferenças na granulometria do solo. Observou-se também diferenças estatisticamente significativas entre os tratamentos para a densidade dos sólidos do solo $(\alpha=0,0162)$. Nos casos em que se verificou efeito significativo, fez-se o desdobramento da análise estatística conforme os contrastes ortogonais propostos no esquema de análise de variância da Tabela 4, e as funções que se ajustaram significativamente são apresentadas na Figura 7. 

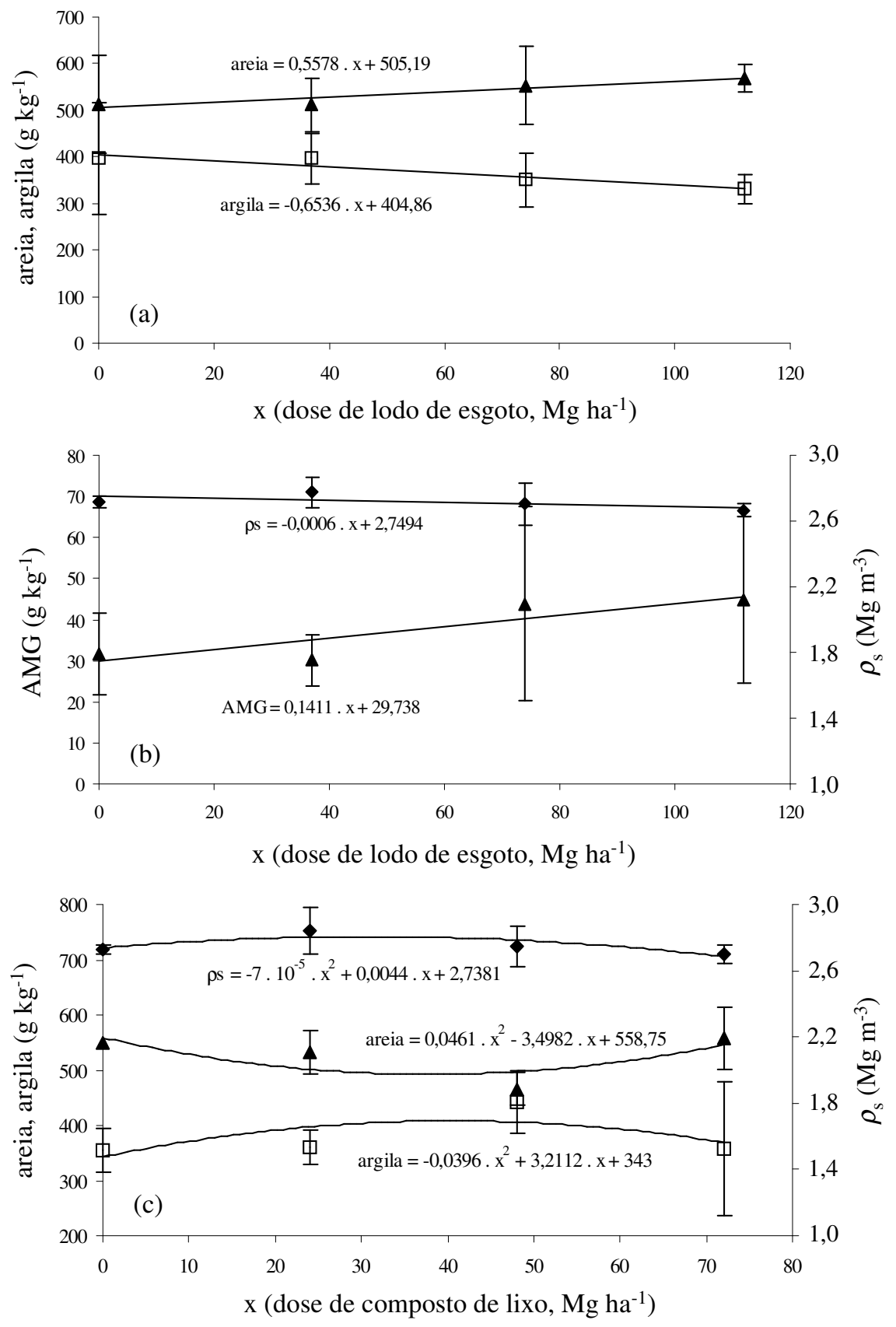

Figura 7. Média por tratamento e limite de confiança ao nível de probabilidade $\alpha=0,10$ e funções ajustadas (obtidas na análise de variância), para a camada 0 a 0,20 m de profundidade, para: (a) areia e argila (obtidas com densímetro) em função das doses de lodo de esgoto; (b) areia muito grossa (AMG) e densidade dos sólidos $\left(\rho_{s}\right)$ em função das doses de lodo de esgoto; (c) areia e argila (obtidas com densímetro) e densidade dos sólidos $\left(\rho_{s}\right)$ em função das doses de composto de lixo. 
Para o lodo de esgoto, observou-se efeito linear significativo tanto do conteúdo de areia $(\alpha=0,0501)$ quanto do conteúdo de argila $(\alpha=0,0237)$ com relação às doses aplicadas, sendo a correlação positiva para a areia e negativa para a argila (efeitos complementares). A fração areia muito grossa apresentou comportamento semelhante à areia total, sendo o efeito linear significativo $(\alpha=0,0233)$ com correlação positiva. Para o composto de lixo, novamente houve a complementação entre as frações areia e argila. O conteúdo de areia apresentou efeito quadrático significativo $(\alpha=0,0270)$ com relação às doses aplicadas, de forma que inicialmente ocorre o seu decréscimo e ao final um acréscimo. $\mathrm{O}$ conteúdo de argila também apresentou efeito quadrático $(\alpha=0,0548)$, porém com comportamento inverso (ou seja, no início ocorre o seu aumento e ao final um diminuição de seu conteúdo). Tanto a areia quanto a argila, no entanto, apresentaram também efeito cúbico, considerados como desvios da regressão.

O desdobramento da análise estatística para a densidade dos sólidos revelou que esta foi significativamente menor $(\alpha=0,0919)$ para o lodo de esgoto que para o composto de lixo. Quanto ao lodo de esgoto, pôde-se observar que houve efeito linear significativo $(\alpha=0,0896)$ com relação às doses aplicadas, sendo a correlação negativa. Para o composto de lixo, verificou-se efeito quadrático $(\alpha=0,0115)$ com relação às doses aplicadas, inicialmente ocorrendo aumento e ao final uma diminuição da densidade dos sólidos.

A análise anterior é importante para se confirmar o pressuposto assumido na análise de variância de que não deve haver covariação entre os tratamentos e as propriedades de interesse antes do experimento ou as propriedades a elas correlacionadas. Como no presente caso os referidos pressupostos não se confirmaram, para a análise do efeito dos tratamentos sobre determinada propriedade físico-hídrica deve-se considerar que parte deste efeito pode ser devido às diferenças na composição granulométrica do solo. Embora isto possa dificultar a interpretação dos resultados, lançou-se mão da análise de regressão polinomial múltipla, incluindo como variáveis independentes os tratamentos e o conteúdo de uma das frações granulométricas (areia ou argila), sempre que estas reconhecidamente se correlacionam à propriedade 
físico-hídrica em questão. Além de sua utilização no "ensaio em branco", a determinação dos valores da densidade dos sólidos do solo se justificam pela sua utilização nos cálculos da porosidade total (conforme descrito no item 3.7.3.4).

\subsection{Conteúdo de carbono orgânico}

Para avaliação do conteúdo de carbono orgânico foram feitas diversas amostragens de solo na camada de 0 a $0,20 \mathrm{~m}$ de profundidade, realizadas aos 15,30 , 60, 90, 150, 210, 270 e 360 dias após a incorporação da primeira dose dos resíduos, e aos 30, 60, 90, 150, 210, 270 e 330 dias após a incorporação da segunda dose. Os valores médios de cada tratamento obtidos para cada amostragem realizada durante o primeiro ano do experimento são apresentados na Tabela 7. A Tabela apresenta ainda os limites de confiança da média ao nível de probabilidade $\alpha=0,10$ pelo teste $t\left(\operatorname{LC}_{\alpha=0,10}\right)$. A Tabela 8 traz os mesmos parâmetros estatísticos apresentados na Tabela 7, porém obtidos para o segundo ano do experimento.

Embora não seja objetivo deste trabalho discutir a dinâmica da mineralização da matéria orgânica adicionada ao solo, como as propriedades físico-hídricas do solo são estreitamente relacionadas ao conteúdo de carbono orgânico, fez-se a análise de variância para todas as amostragens (independentemente para cada uma delas). Para os dois anos do experimento, o teste $\mathrm{F}$ aplicado à análise de variância mostrou que em todas as amostragens houve diferenças estatisticamente significativas entre os tratamentos. Assim fez-se o desdobramento dos tratamentos segundo os contrastes ortogonais apresentados na Tabela 4, obtendo-se os valores $\mathrm{F}$ e respectivos níveis de probabilidade $\alpha$ apresentados na Tabela 9 (primeiro ano do experimento) e na Tabela 10 (segundo ano do experimento).

$\mathrm{Na}$ análise estatística dos contrastes, pode-se verificar que, para todas as amostragens, o conteúdo de carbono orgânico do solo nas parcelas do tratamento tr1 (que recebeu calagem e adubação mineral) foi sempre estatisticamente inferior à média dos demais tratamentos. Comparando-se as parcelas dos tratamentos tr2, tr $3, \operatorname{tr} 4$ e $\operatorname{tr} 5$ (referentes às doses de lodo de esgoto) com as parcelas dos tratamentos tr6, tr7, tr8 e tr9 (referentes às doses de composto de lixo), o comportamento foi diferente entre as 
amostragens. Para a maioria delas, nenhuma diferença significativa foi detectada. No entanto, para as amostragens realizadas 15 dias após a incorporação da primeira dose e 90 e 330 dias após a incorporação da segunda dose dos resíduos, verificou-se que nas parcelas referentes às doses de lodo de esgoto o conteúdo de carbono orgânico do solo foi significativamente inferior ao das parcelas referentes às doses de composto de lixo.

Tendo em vista que quantidades equivalentes de carbono orgânico foram aplicadas para ambos os resíduos, estas diferenças entre lodo e composto de lixo

Tabela 7. Conteúdo de carbono orgânico do solo na camada de 0 a 0,20 m de profundidade para as diversas amostragens realizadas no primeiro ano do experimento: média por tratamento e respectivo limite de confiança ao nível de probabilidade $\alpha=0,10\left(\mathrm{LC}_{\alpha=0,10}\right)$.

\begin{tabular}{|c|c|c|c|c|c|c|c|c|c|}
\hline \multirow{2}{*}{ Tratamento } & \multirow{2}{*}{$\begin{array}{l}\text { Parâmetro } \\
\text { Estatístico }\end{array}$} & \multicolumn{8}{|c|}{ Conteúdo de carbono orgânico do solo $\left(\mathrm{g} \mathrm{kg}^{-1}\right)$} \\
\hline & & $\begin{array}{c}15 \\
\text { dias } \\
\end{array}$ & $\begin{array}{c}30 \\
\text { dias }\end{array}$ & $\begin{array}{c}60 \\
\text { dias } \\
\end{array}$ & $\begin{array}{c}90 \\
\text { dias } \\
\end{array}$ & $\begin{array}{l}150 \\
\text { dias } \\
\end{array}$ & $\begin{array}{l}210 \\
\text { dias } \\
\end{array}$ & $\begin{array}{r}270 \\
\text { dias } \\
\end{array}$ & $\begin{array}{l}360 \\
\text { dias } \\
\end{array}$ \\
\hline \multirow[t]{2}{*}{$\operatorname{tr} 1$} & Média & 6,81 & 5,62 & 6,87 & 7,16 & 8,26 & 7,62 & 8,05 & 8,43 \\
\hline & $\mathrm{LC}_{\alpha=0,10}$ & 0,91 & 0,43 & 0,27 & 0,35 & 0,67 & 0,57 & 0,31 & 0,29 \\
\hline \multirow[t]{2}{*}{$\operatorname{tr} 2$} & Média & 7,26 & 5,79 & 7,17 & 7,83 & 8,92 & 8,90 & 8,69 & 9,10 \\
\hline & $\mathrm{LC}_{\alpha=0,10}$ & 0,70 & 0,57 & 0,43 & 0,47 & 0,75 & 0,45 & 1,23 & 0,79 \\
\hline \multirow[t]{2}{*}{$\operatorname{tr} 3$} & Média & 7,99 & 6,85 & 8,29 & 9,01 & 10,61 & 9,89 & 9,95 & 10,04 \\
\hline & $\mathrm{LC}_{\alpha}=0,10$ & 0,74 & 0,72 & 1,16 & 0,82 & 0,48 & 0,15 & 0,39 & 0,55 \\
\hline \multirow[t]{2}{*}{$\operatorname{tr} 4$} & Média & 8,59 & 7,07 & 8,84 & 9,61 & 10,39 & 9,87 & 9,96 & 10,17 \\
\hline & $\mathrm{LC}_{\alpha=0,10}$ & 1,14 & 0,88 & 0,49 & 0,57 & 1,34 & 0,45 & 0,55 & 0,47 \\
\hline \multirow[t]{2}{*}{$\operatorname{tr} 5$} & Média & 9,19 & 8,66 & 9,61 & 11,92 & 11,70 & 10,34 & 10,31 & 10,26 \\
\hline & $\mathrm{LC}_{\alpha=0,10}$ & 0,63 & 1,31 & 0,59 & 0,41 & 0,46 & 0,62 & 0,78 & 1,54 \\
\hline \multirow[t]{2}{*}{ tr6 } & Média & 6,81 & 5,73 & 6,70 & 7,32 & 8,55 & 7,87 & 8,28 & 8,62 \\
\hline & $\mathrm{LC}_{\alpha=0,10}$ & 1,13 & 0,32 & 0,40 & 0,39 & 0,38 & 0,59 & 0,84 & 0,25 \\
\hline \multirow[t]{2}{*}{$\operatorname{tr} 7$} & Média & 7,96 & 6,10 & 7,60 & 9,51 & 9,70 & 8,97 & 9,45 & 9,37 \\
\hline & $\mathrm{LC}_{\alpha=0,10}$ & 0,98 & 0,51 & 0,43 & 0,82 & 0,34 & 0,54 & 0,11 & 0,75 \\
\hline \multirow[t]{2}{*}{$\operatorname{tr} 8$} & Média & 10,03 & 8,42 & 8,48 & 10,52 & 11,00 & 9,78 & 10,01 & 10,37 \\
\hline & $\mathrm{LC}_{\alpha=0,10}$ & 1,57 & 1,22 & 1,23 & 0,98 & 1,57 & 1,14 & 0,69 & 1,76 \\
\hline \multirow[t]{2}{*}{$\operatorname{tr} 9$} & Média & 10,42 & 9,57 & 9,08 & 11,30 & 11,87 & 11,07 & 9,96 & 10,91 \\
\hline & $\mathrm{LC}_{\alpha}=0,10$ & 1,17 & 0,92 & 0,89 & 1,13 & 1,00 & 1,24 & 0,64 & 0,73 \\
\hline
\end{tabular}


poderiam ser atribuídas a uma maior taxa de mineralização da matéria orgânica do lodo, uma vez que sua relação $\mathrm{C} / \mathrm{N}$ é bastante inferior a do composto. No entanto, esta explicação não pode ser aceita, pois estas diferenças se verificaram em amostragens isoladas, e não em amostragens consecutivas. Além disso, para o primeiro ano do experimento, o comportamento verificado aos 15 dias após a incorporação dos resíduos se inverteu aos 60 dias, quando o conteúdo de carbono orgânico do solo passou a ser significativamente inferior nas parcelas referentes às doses de composto de lixo.

Tabela 8. Conteúdo de carbono orgânico do solo na camada de 0 a 0,20 m de profundidade para as diversas amostragens realizadas no segundo ano do experimento: média por tratamento e respectivo limite de confiança ao nível de probabilidade $\alpha=0,10\left(\mathrm{LC}_{\alpha=0,10}\right)$.

\begin{tabular}{|c|c|c|c|c|c|c|c|c|}
\hline \multirow{2}{*}{ Tratamentc } & \multirow{2}{*}{$\begin{array}{l}\text { Parâmetro } \\
\text { Estatístico }\end{array}$} & \multicolumn{7}{|c|}{ Conteúdo de carbono orgânico do solo $\left(\mathrm{g} \mathrm{kg}^{-1}\right)$} \\
\hline & & $\begin{array}{c}30 \\
\text { dias }\end{array}$ & $\begin{array}{c}60 \\
\text { dias }\end{array}$ & $\begin{array}{c}90 \\
\text { dias }\end{array}$ & $\begin{array}{l}150 \\
\text { dias }\end{array}$ & $\begin{array}{l}210 \\
\text { dias }\end{array}$ & $\begin{array}{l}270 \\
\text { dias }\end{array}$ & $\begin{array}{l}330 \\
\text { dias }\end{array}$ \\
\hline \multirow[t]{2}{*}{$\operatorname{tr} 1$} & Média & 8,42 & 7,98 & 8,27 & 8,69 & 9,15 & 9,51 & 9,86 \\
\hline & $\mathrm{LC}_{\alpha=0,10}$ & 0,59 & 0,76 & 0,59 & 0,68 & 0,69 & 0,77 & 1,01 \\
\hline \multirow[t]{2}{*}{$\operatorname{tr} 2$} & Média & 9,11 & 8,88 & 9,07 & 9,06 & 9,12 & 9,47 & 9,62 \\
\hline & $\mathrm{LC}_{\alpha=0,10}$ & 0,82 & 0,82 & 0,75 & 0,86 & 0,60 & 0,50 & 0,47 \\
\hline \multirow[t]{2}{*}{$\operatorname{tr} 3$} & Média & 11,75 & 10,90 & 11,07 & 11,55 & 11,43 & 11,65 & 11,21 \\
\hline & $\mathrm{LC}_{\alpha=0,10}$ & 0,52 & 0,80 & 0,59 & 0,81 & 1,35 & 0,80 & 0,99 \\
\hline \multirow[t]{2}{*}{$\operatorname{tr} 4$} & Média & 11,68 & 11,43 & 11,31 & 11,36 & 11,72 & 12,14 & 12,30 \\
\hline & $\mathrm{LC}_{\alpha=0,10}$ & 0,80 & 0,50 & 2,00 & 0,93 & 0,65 & 0,74 & 0,94 \\
\hline \multirow[t]{2}{*}{$\operatorname{tr} 5$} & Média & 14,22 & 14,10 & 13,51 & 14,01 & 14,22 & 13,95 & 13,64 \\
\hline & $\mathrm{LC}_{\alpha=0,10}$ & 1,56 & 1,25 & 1,84 & 1,27 & 1,62 & 1,46 & 1,09 \\
\hline \multirow[t]{2}{*}{$\operatorname{tr} 6$} & Média & 8,62 & 8,30 & 8,66 & 8,91 & 8,86 & 9,36 & 9,64 \\
\hline & $\mathrm{LC}_{\alpha=0,10}$ & 0,69 & 0,63 & 0,61 & 0,38 & 0,79 & 0,38 & 0,49 \\
\hline \multirow[t]{2}{*}{$\operatorname{tr} 7$} & Média & 11,80 & 11,06 & 11,51 & 10,90 & 11,06 & 11,29 & 11,94 \\
\hline & $\mathrm{LC}_{\alpha=0,10}$ & 1,56 & 0,94 & 1,16 & 0,89 & 0,41 & 0,75 & 0,64 \\
\hline \multirow[t]{2}{*}{$\operatorname{tr} 8$} & Média & 13,43 & 13,69 & 12,53 & 11,83 & 12,29 & 12,71 & 12,00 \\
\hline & $\mathrm{LC}_{\alpha=0,10}$ & 1,51 & 0,76 & 1,91 & 0,95 & 0,96 & 0,29 & 0,99 \\
\hline \multirow[t]{2}{*}{$\operatorname{tr} 9$} & Média & 14,16 & 13,87 & 15,53 & 16,37 & 15,51 & 14,32 & 14,89 \\
\hline & $\mathrm{LC}_{\alpha}=0,10$ & 1,48 & 0,57 & 0,31 & 1,01 & 1,36 & 0,49 & 1,11 \\
\hline
\end{tabular}


Tabela 9. Valores $\mathrm{F}$ e respectivos níveis de probabilidade $\alpha$ obtidos na análise de variância dos tratamentos e em seu desdobramento em contrastes ortogonais, para o conteúdo de carbono orgânico do solo na camada de 0 a 0,20 m de profundidade no primeiro ano do experimento.

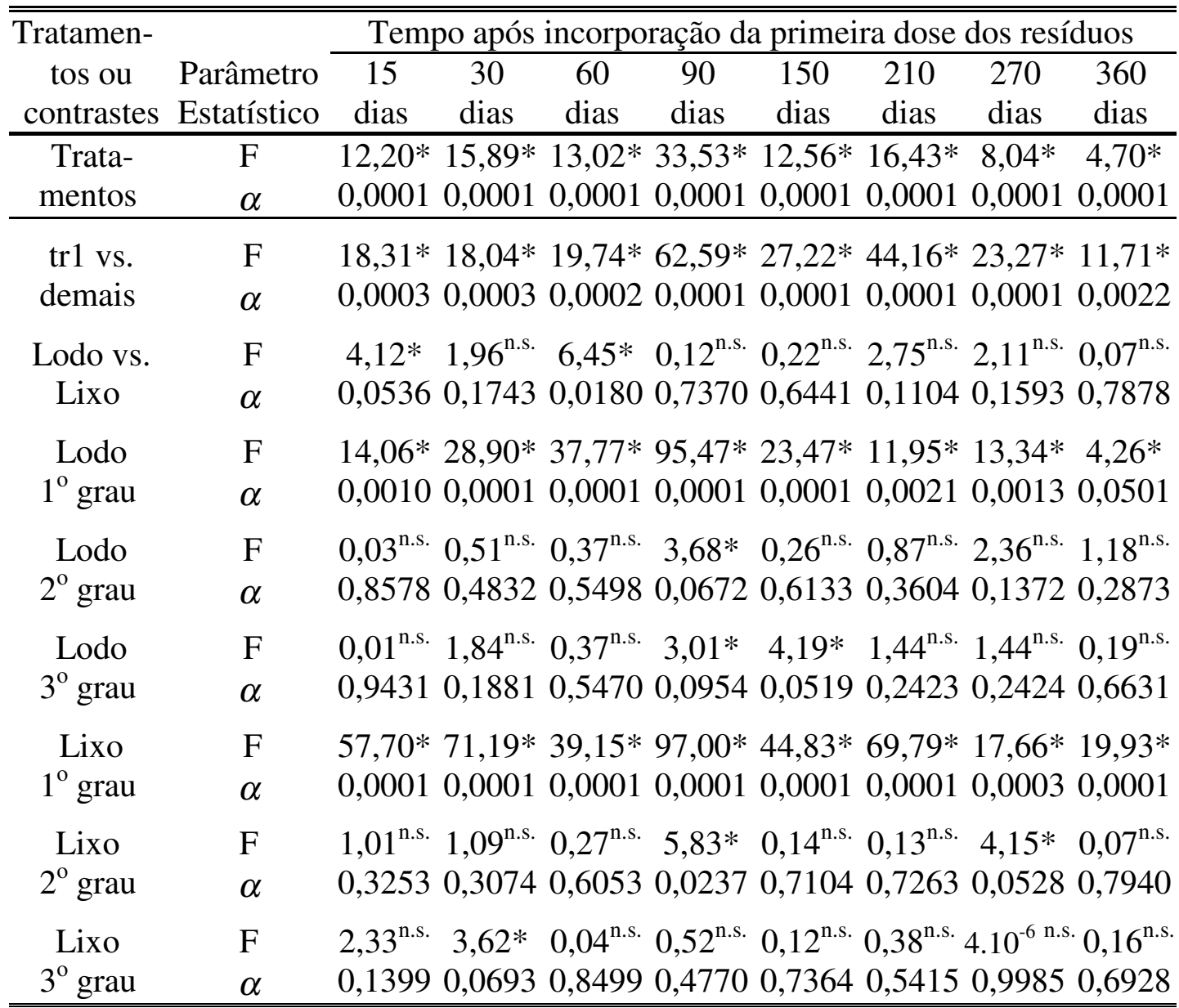

*: significativo estatisticamente ao nível de probabilidade $\alpha$ expresso na linha imediatamente abaixo. n.s.: não significativo estatisticamente ao nível de probabilidade $\alpha=0,10$.

Quanto à análise de regressão, em todas as amostragens, verifica-se que houve efeito linear estatisticamente significativo, tanto para as doses de lodo de esgoto quanto de composto de lixo. Este efeito foi no sentido da elevação do conteúdo de carbono orgânico do solo em função do aumento da dose do resíduo. No entanto, para a primeira amostragem realizada após cada aplicação, este efeito já foi bem menos acentuado do que se poderia esperar caso todo o carbono orgânico aplicado fosse recuperado na determinação. Conhecendo-se o conteúdo de carbono orgânico de cada resíduo e as 
Tabela 10. Valores $\mathrm{F}$ e respectivos níveis de probabilidade $\alpha$ obtidos na análise de variância dos tratamentos e em seu desdobramento em contrastes ortogonais, para o conteúdo de carbono orgânico do solo na camada de 0 a 0,20 m de profundidade no segundo ano do experimento.

\begin{tabular}{|c|c|c|c|c|c|c|c|c|}
\hline \multirow{3}{*}{$\begin{array}{c}\text { Tratamen- } \\
\text { tos ou } \\
\text { contrastes }\end{array}$} & \multirow{3}{*}{$\begin{array}{l}\text { Parâmetro } \\
\text { Estatístico }\end{array}$} & \multicolumn{7}{|c|}{ Tempo após incorporação da primeira dose dos resíduos } \\
\hline & & 30 & 60 & 90 & 150 & 210 & 270 & 330 \\
\hline & & dias & dias & dias & dias & dias & dias & dias \\
\hline Trata- & $\mathrm{F}$ & $21,38 *$ & $48,72 *$ & $21,28^{*}$ & $52,80^{*}$ & $28,77 *$ & $34,89 *$ & $35,55^{*}$ \\
\hline Mentos & $\alpha$ & 0,0001 & 0,0001 & 0,0001 & 0,0001 & 0,0001 & 0,0001 & 0,0001 \\
\hline $\operatorname{tr} 1 \mathrm{vs}$. & $\mathrm{F}$ & $42,52 *$ & $94,68 *$ & $37,95^{*}$ & $68,91 *$ & $33,28 *$ & $48,33^{*}$ & $39,65^{*}$ \\
\hline Demais & $\alpha$ & 0,0001 & 0,0001 & 0,0001 & 0,0001 & 0,0001 & 0,0001 & 0,0001 \\
\hline Lodo vs. & F & $0,79^{\text {n.s. }}$ & $2,77^{\text {n.s. }}$ & $5,08 *$ & $4,29 *$ & $1,03^{\text {n.s. }}$ & $0,27^{\text {n.s. }}$ & $3,86^{*}$ \\
\hline Lixo & $\alpha$ & 0,3834 & 0,1090 & 0,0336 & 0,0492 & 0,3209 & 0,6075 & 0,0611 \\
\hline Lodo & $\mathrm{F}$ & $47,70 *$ & $111,10^{*}$ & $34,37^{*}$ & $88,98 *$ & $65,75^{*}$ & $95,07 *$ & $92,46^{*}$ \\
\hline $1^{\circ}$ grau & $\alpha$ & 0,0001 & 0,0001 & 0,0001 & 0,0001 & 0,0001 & 0,0001 & 0,0001 \\
\hline Lodo & $\mathrm{F}$ & $0,01^{\text {n.s. }}$ & $0,89^{\text {n.s. }}$ & $0,04^{\text {n.s. }}$ & $0,05^{\text {n.s. }}$ & $0,04^{\text {n.s. }}$ & $0,35^{\text {n.s. }}$ & $0,17^{\text {n.s. }}$ \\
\hline $2^{\circ} \mathrm{grau}$ & $\alpha$ & 0,9203 & 0,3553 & 0,8464 & 0,8310 & 0,8404 & 0,5599 & 0,6839 \\
\hline Lodo & $\mathrm{F}$ & $5,81 *$ & $5,56^{*}$ & $2,59^{\text {n.s. }}$ & $12,65^{*}$ & $4,84^{*}$ & $4,44^{*}$ & $0,29^{\text {n.s. }}$ \\
\hline $3^{\circ}$ grau & $\alpha$ & 0,0239 & 0,0269 & 0,1209 & 0,0016 & 0,0377 & 0,0458 & 0,5978 \\
\hline Lixo & $\mathrm{F}$ & $67,95^{*}$ & $158,41 *$ & $87,48^{*}$ & $225,04 *$ & $121,39 *$ & $130,19 *$ & $133,45^{*}$ \\
\hline $1^{\mathrm{o}} \mathrm{grau}$ & $\alpha$ & 0,0001 & 0,0001 & 0,0001 & 0,0001 & 0,0001 & 0,0001 & 0,0001 \\
\hline Lixo & F & $6,14 *$ & $14,10 *$ & $0,02^{\text {n.s. }}$ & $13,43^{*}$ & $1,40^{\text {n.s. }}$ & $0,25^{\text {n.s. }}$ & $0,93^{\text {n.s. }}$ \\
\hline $2^{\circ}$ grau & $\alpha$ & 0,0206 & 0,0010 & 0,8877 & 0,0012 & 0,2482 & 0,6236 & 0,3451 \\
\hline Lixo & $\mathrm{F}$ & $0,09^{\text {n.s. }}$ & $2,25^{\text {n.s. }}$ & $2,71^{\text {n.s. }}$ & $9,07 *$ & $2,40^{\text {n.s. }}$ & $0,24^{\text {n.s. }}$ & $13,59 *$ \\
\hline $3^{\circ} \mathrm{grau}$ & $\alpha$ & 0,7672 & 0,1465 & 0,1126 & 0,0060 & 0,1345 & 0,6297 & 0,0012 \\
\hline
\end{tabular}

*: significativo estatisticamente ao nível de probabilidade $\alpha$ expresso na linha imediatamente abaixo. n.s.: não significativo estatisticamente ao nível de probabilidade $\alpha=0,10$.

doses aplicadas, e presumindo-se a densidade do solo como $1,5 \mathrm{Mg} \mathrm{m}^{-3} \mathrm{e}$ a profundidade de incorporação como $0,20 \mathrm{~m}$, a diferença entre níveis de aplicação consecutivos no primeiro ano deveria ser da ordem de $2,28 \mathrm{~g} \mathrm{~kg}^{-1}$. Neste sentido, a diferença entre a dose máxima de cada resíduo e a testemunha deveria ser de $6,85 \mathrm{~g} \mathrm{~kg}^{-1}$. No entanto, apenas 15 dias após a incorporação desta primeira dose, esta diferença era de $1,93 \mathrm{~g} \mathrm{~kg}^{-1}$ para o lodo de esgoto e de $3,61 \mathrm{~g} \mathrm{~kg}^{-1}$ para o composto de lixo. Isto significa uma recuperação média de $30 \%$ e $58 \%$ para o lodo de esgoto e para o 
composto de lixo, respectivamente. Para o segundo ano, em cada nível de resíduo, a diferença entre a primeira amostragem (30 dias após a incorporação) e o valor anterior à aplicação (obtido na última amostragem do primeiro ano) deveria ser de $2,27 \mathrm{~g} \mathrm{~kg}^{-1}$ para os tratamentos tr3 e tr 7 , de $4,54 \mathrm{~g} \mathrm{~kg}^{-1}$ para os tratamentos tr4 e tr8, e $6,81 \mathrm{~g} \mathrm{~kg}^{-1}$ para os tratamentos tr5 e tr9 (caso todo o carbono orgânico aplicado fosse recuperado). No entanto, os valores obtidos foram, respectivamente, $1,71 \mathrm{~g} \mathrm{~kg}^{-1}$ e $2,43 \mathrm{~g} \mathrm{~kg}^{-1}$ para os tratamentos tr3 e tr7; $1,51 \mathrm{~g} \mathrm{~kg}^{-1}$ e $3,06 \mathrm{~g} \mathrm{~kg}^{-1}$ para os tratamentos tr4 e tr8; e 3,96 $\mathrm{g} \mathrm{kg}^{-1}$ e $3,25 \mathrm{~g} \mathrm{~kg}^{-1}$ para os tratamentos tr5 e tr9. Ou seja, uma recuperação média de $55 \%$ e $70 \%$ para o lodo de esgoto e para o composto de lixo, respectivamente.

Embora a diferença entre a quantidade de carbono orgânico adicionada e a quantidade recuperada na primeira amostragem pudesse ser atribuída a uma elevada taxa de mineralização inicial dos resíduos, outras explicações plausíveis para este fato seriam a dificuldade de aplicação e incorporação dos resíduos de maneira uniforme, a dificuldade de se amostrar representativamente o solo e as limitações do método de determinação de Walkley \& Black (1934) (a respirometria, embora mais trabalhosa, provavelmente levaria a uma maior recuperação de carbono orgânico). Além disso, a observação dos valores de conteúdo de carbono orgânico após a primeira amostragem de cada ano revela que a degradação no decorrer do ano foi inexpressiva. Para o primeiro ano, houve uma aparente elevação do conteúdo de carbono orgânico ao longo do tempo, o que provavelmente pode ser atribuído ao desenvolvimento do sistema radicular da cana-de-açúcar e à dificuldade de controle de plantas invasoras, além dos baixos valores de precipitação pluvial verificados naquele ano, que diminuem a taxa de mineralização da matéria orgânica.

Em alguns casos o efeito quadrático também foi estatisticamente significativo, embora com níveis de significância bastante inferiores aos obtidos para o efeito linear. Isto pôde ser verificado para as doses de lodo de esgoto na amostragem realizada 90 dias após a incorporação da primeira aplicação, e para as doses de composto de lixo nas amostragens realizadas 90 e 150 dias após a incorporação da primeira e 30, 60 e 150 dias após a incorporação da segunda aplicação dos resíduos. Em outros casos verificou-se também efeito cúbico estatisticamente significativo (embora também com 
níveis de significância bastante inferiores aos obtidos para o efeito linear), o que pode ter ocorrido devido a algum fator não controlado e que aqui consideramos simplesmente como sendo desvios da regressão. Para o composto de lixo isto ocorreu apenas em três amostragens (30 dias após a incorporação da primeira dose e 150 e 330 dias após a incorporação da segunda dose dos resíduos). Já para o lodo de esgoto, principalmente no segundo ano do experimento, este efeito foi mais permanente. No primeiro ano ocorreu apenas aos 90 e 150 dias após a incorporação, porém no segundo ano só não ocorreu para as amostragens realizadas aos 90 e aos 330 dias após a incorporação dos resíduos.

Como as propriedades físico-hídricas do solo são estreitamente relacionadas ao conteúdo de carbono orgânico, quando necessário estes resultados serão considerados para discutir o efeito das doses dos resíduos sobre a densidade e porosidade total do solo, a argila dispersa em água, a curva de retenção da água no solo, a condutividade hidráulica do solo saturado e a relação entre a condutividade hidráulica e potencial mátrico.

\subsection{Argila dispersa em água}

A Tabela 11 apresenta os valores médios do conteúdo de argila dispersa em água, bem como os seus limites de confiança ao nível de probabilidade $\alpha=0,10$ pelo teste $t\left(\mathrm{LC}_{\alpha=0,10}\right)$, obtidos para a camada de 0 a $0,20 \mathrm{~m}$ de profundidade nos dois anos de condução do experimento. Apresenta ainda os valores $\mathrm{F}$ obtidos na análise de variância e seus respectivos níveis de significância. Pelo valor $F$ inferiu-se que no primeiro ano do experimento não houve efeito dos tratamentos sobre a argila dispersa em água ou sobre a fração argila total dispersa em água. No segundo ano, no entanto, o valor F obtido na análise de variância do conteúdo de argila dispersa em água revela haver efeito significativo dos tratamentos sobre esta propriedade $(\alpha=0,0688)$.

Desdobrando-se os tratamentos conforme os contrastes ortogonais propostos na Tabela 4, obteve-se significância na regressão linear para as doses de lodo de esgoto (Figura 8). Por esta Figura constatou-se a redução da argila dispersa em água com o aumento da dose aplicada. No entanto, embora a análise estatística tenha mostrado que 
Tabela 11. Argila dispersa em água nos dois anos do experimento: média por tratamento e respectivo limite de confiança ao nível de probabilidade $\alpha=0,10$ $\left(\mathrm{LC}_{\alpha=0,10}\right)$; valor $\mathrm{F}$ da análise de variância e respectivo nível de probabilidade $\alpha$.

\begin{tabular}{|c|c|c|c|}
\hline \multirow[b]{2}{*}{ Tratamento } & \multirow{2}{*}{$\begin{array}{l}\text { Parâmetro } \\
\text { Estatístico }\end{array}$} & \multicolumn{2}{|c|}{ "Argila dispersa em água $\left(\mathrm{g} \mathrm{kg}^{-1}\right)$} \\
\hline & & $1^{\circ}$ ano & $2^{\circ}$ ano \\
\hline \multirow[t]{2}{*}{$\operatorname{tr} 1$} & Média & 283,63 & 295,68 \\
\hline & $\mathrm{LC}_{\alpha=0,10}$ & 55,12 & 33,70 \\
\hline \multirow[t]{2}{*}{$\operatorname{tr} 2$} & Média & 252,09 & 284,57 \\
\hline & $\mathrm{LC}_{\alpha=0,10}$ & 24,50 & 47,43 \\
\hline \multirow[t]{2}{*}{$\operatorname{tr} 3$} & Média & 278,51 & 301,65 \\
\hline & $\mathrm{LC}_{\alpha=0,10}$ & 20,87 & 10,19 \\
\hline \multirow[t]{2}{*}{$\operatorname{tr} 4$} & Média & 278,86 & 265,75 \\
\hline & $\mathrm{LC}_{\alpha=0,10}$ & 32,43 & 33,32 \\
\hline \multirow[t]{2}{*}{$\operatorname{tr} 5$} & Média & 248,70 & 234,25 \\
\hline & $\mathrm{LC}_{\alpha=0,10}$ & 63,76 & 29,92 \\
\hline \multirow[t]{2}{*}{$\operatorname{tr} 6$} & Média & 261,41 & 270,67 \\
\hline & $\mathrm{LC}_{\alpha=0,10}$ & 29,41 & 15,58 \\
\hline \multirow[t]{2}{*}{$\operatorname{tr} 7$} & Média & 268,91 & 278,56 \\
\hline & $\mathrm{LC}_{\alpha=0,10}$ & 34,73 & 44,92 \\
\hline \multirow[t]{2}{*}{$\operatorname{tr} 8$} & Média & 289,66 & 299,83 \\
\hline & $\mathrm{LC}_{\alpha=0,10}$ & 25,27 & 27,57 \\
\hline \multirow[t]{4}{*}{$\operatorname{tr} 9$} & Média & 276,19 & 284,77 \\
\hline & $\mathrm{LC}_{\alpha=0,10}$ & 24,10 & 45,07 \\
\hline & Valor F & $0,82^{\text {n.s. }}$ & $2,16^{*}$ \\
\hline & $\alpha$ & 0,5963 & 0,0688 \\
\hline
\end{tabular}

*: significativo estatisticamente ao nível de probabilidade $\alpha$ expresso na linha imediatamente abaixo. n.s.: não significativo estatisticamente ao nível de probabilidade $\alpha=0,10$.

este efeito foi significativo, esta redução pode não necessariamente ter ocorrido em função do aumento das doses de lodo de esgoto, mas sim pode estar associada à diminuição do conteúdo de argila total que se verificou para as doses de lodo de esgoto (Figura 7 - a). Desta forma, foi possível ajustar, para as parcelas dos tratamentos tr2, tr3, tr4 e tr5, uma equação linear que relaciona o conteúdo de argila dispersa em água e o conteúdo de argila total (Figura 9). Portanto, matematicamente, a redução do conteúdo 


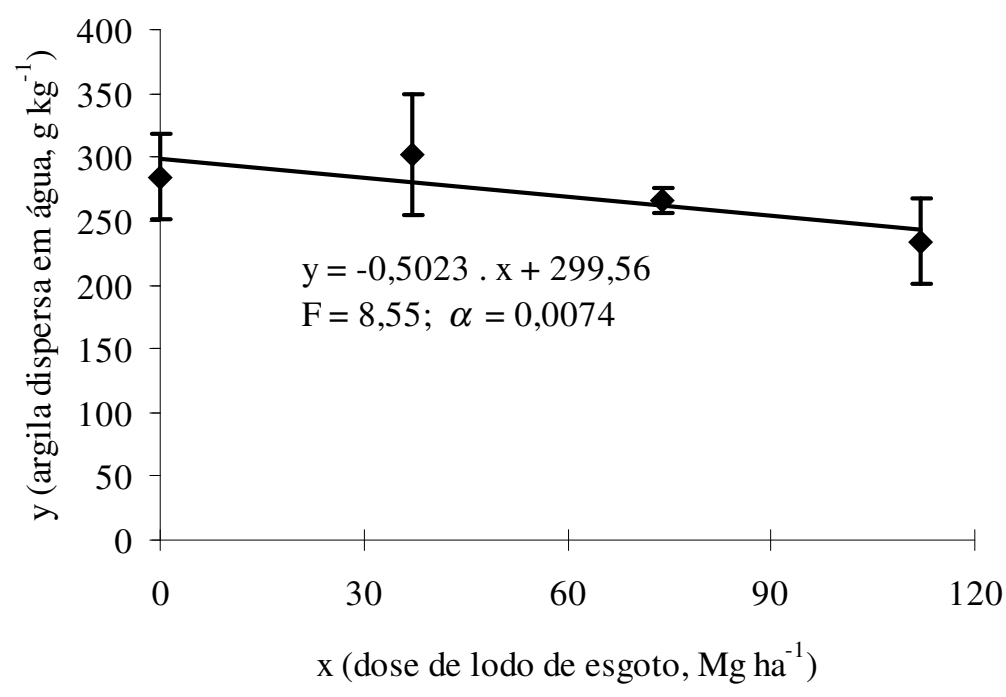

Figura 8. Médias e respectivos limites de confiança ao nível de probabilidade $\alpha=0,10$ pelo teste $t$, e função ajustada obtida na análise de variância para conteúdo de argila dispersa em água do solo em função das doses de lodo de esgoto (com valor $\mathrm{F}$ e nível de probabilidade $\alpha$ ) no segundo ano do experimento, para a camada 0 a $0,20 \mathrm{~m}$ de profundidade.

de argila dispersa em água pode ser explicada tanto pelo aumento das doses de lodo de esgoto quanto pela diminuição do conteúdo de argila total.

Numa tentativa de elucidar esta questão, realizou-se uma análise de regressão linear múltipla relacionando o conteúdo de argila dispersa em água (y) com o conteúdo de argila total $\left(\mathrm{x}_{1}\right)$ e com as doses de lodo $\left(\mathrm{x}_{2}\right)$, a qual revelou uma equação significativa $\left(\mathrm{y}=0,3528 . \mathrm{x}_{1}-0,5846 . \mathrm{x}_{2}+174,15 ; \mathrm{F}=9,70 ; \alpha=0,0026\right)$. Nesta equação, tanto o coeficiente angular relacionado à argila total $\left(\mathrm{x}_{1}\right)$ quanto aquele relacionado às doses de lodo $\left(\mathrm{x}_{2}\right)$ foram significativos pelo teste $t$ (para 0,3528, $\alpha \leq 0,0157$; e para 0,5846, $\alpha \leq 0,0018$ ). Como ambos os coeficientes angulares foram significativos, verifica-se que o conteúdo de argila dispersa em água realmente diminui com as doses de lodo de esgoto, mas o seu valor pode ser melhor previsto por um modelo que inclui também o conteúdo de argila total. O coeficiente de correlação entre os valores de argila dispersa observados e os valores previstos utilizando-se a equação de regressão múltipla (que relaciona argila dispersa com doses de lodo e com argila total) é de 0,79 , enquanto a utilização da equação de regressão simples (que relaciona argila dispersa com doses de lodo) fornece um coeficiente de correlação de 0,60. Abu-Sarar (1993), trabalhando em 


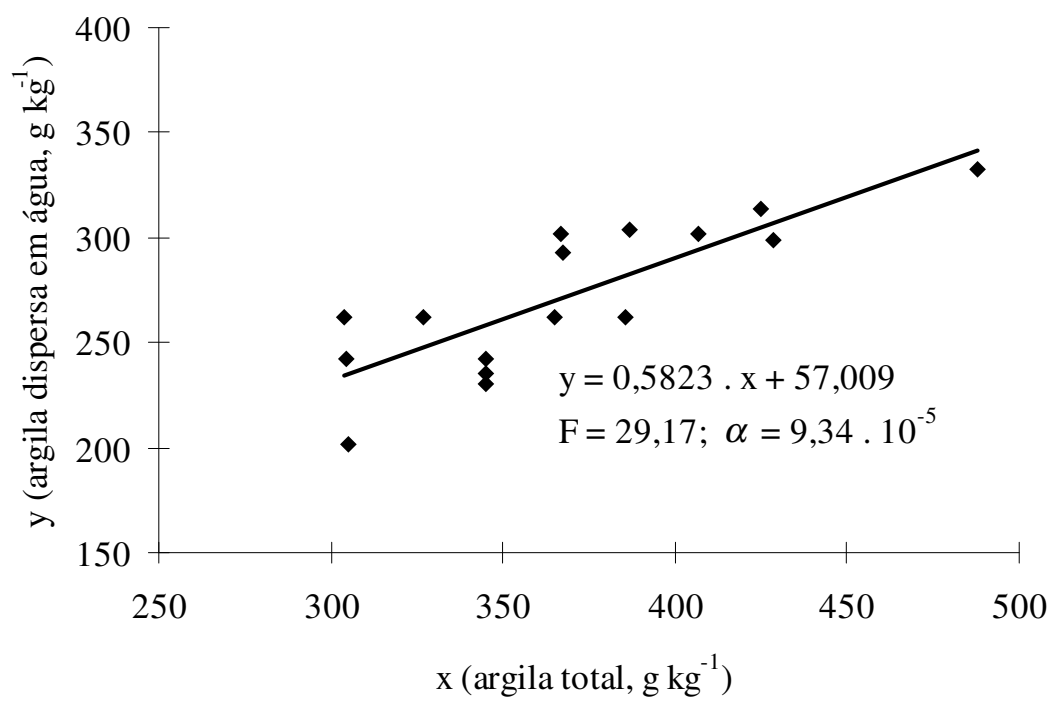

Figura 9. Valores observados e função ajustada para conteúdo de argila dispersa em água do solo $(\rho)$ em função do conteúdo de argila total (com valor F e nível de probabilidade $\alpha$ ) no segundo ano do experimento, para a camada 0 a $0,20 \mathrm{~m}$ de profundidade das parcelas dos tratamentos tr2, $\operatorname{tr} 3, \operatorname{tr} 4$ e tr5.

solos com diversos valores de RAS (razão de saturação por sódio), também verificaram que, em concentrações eletrolíticas baixas, a dispersão de argila foi mais baixa e a estabilidade de agregados mais elevada nas amostras tratadas $8 \%$ de lodo. $\mathrm{O}$ autor salienta que os resultados obtidos sustentam a hipótese de que a dispersão de argila ocorre no último estágio do enfraquecimento da estrutura do agregado.

\subsection{Densidade do solo e porosidade total}

A Tabela 12 apresenta os valores médios de densidade do solo, bem como os seus limites de confiança ao nível de probabilidade $\alpha=0,10$ pelo teste $t\left(\operatorname{LC}_{\alpha=0,10}\right)$, obtidos para os dois anos de condução do experimento para as profundidades indicadas. Apresenta ainda os valores F obtidos na análise de variância e seus respectivos níveis de significância, pelos quais inferiu-se a existência ou não de efeitos dos tratamentos. A Tabela 13 traz, para a porosidade total do solo calculada por $\left(P T=1-\rho / \rho_{\mathrm{s}}\right)$, os mesmos parâmetros estatísticos apresentados na Tabela 12, obtidos também nos dois anos do experimento para as profundidades indicadas. Uma outra maneira de se estimar a porosidade total do solo é pelo conteúdo de água na saturação, obtido na determinação da curva de retenção. No entanto, como a curva de retenção foi feita somente para o 
Tabela 12. Densidade do solo na camada superficial para os dois anos do experimento: média por tratamento e respectivo limite de confiança ao nível de probabilidade $\alpha=0,10$ ( $\mathrm{LC}_{\alpha=0,10}$ ); valor $\mathrm{F}$ da análise de variância e respectivo nível de probabilidade $\alpha$.

\begin{tabular}{|c|c|c|c|c|c|c|}
\hline \multirow[b]{3}{*}{ Tratamento } & \multirow{3}{*}{$\begin{array}{l}\text { Parâmetro } \\
\text { Estatístico }\end{array}$} & \multicolumn{5}{|c|}{ Densidade do solo $\left(\mathrm{Mg} \mathrm{m}^{-3}\right)$} \\
\hline & & \multirow{2}{*}{$\begin{array}{c}1^{\mathrm{o}} \text { ano } \\
(0,114 \mathrm{a} \\
0,186 \mathrm{~m})\end{array}$} & \multicolumn{4}{|c|}{$2^{\circ}$ ano } \\
\hline & & & $\begin{array}{c}(0 \mathrm{a} \\
0,05 \mathrm{~m})\end{array}$ & $\begin{array}{c}(0,05 \mathrm{a} \\
0,10 \mathrm{~m})\end{array}$ & $\begin{array}{c}(0,10 \mathrm{a} \\
0,15 \mathrm{~m})\end{array}$ & $\begin{array}{c}(0,15 \mathrm{a} \\
0,20 \mathrm{~m})\end{array}$ \\
\hline \multirow[t]{2}{*}{$\operatorname{tr} 1$} & Média & 1,425 & 1,223 & 1,368 & 1,418 & 1,434 \\
\hline & $\mathrm{LC}_{\alpha=0,10}$ & 0,022 & 0,031 & 0,055 & 0,030 & 0,071 \\
\hline \multirow[t]{2}{*}{$\operatorname{tr} 2$} & Média & 1,408 & 1,233 & 1,446 & 1,550 & 1,506 \\
\hline & $\mathrm{LC}_{\alpha=0,10}$ & 0,071 & 0,088 & 0,113 & 0,078 & 0,041 \\
\hline \multirow[t]{2}{*}{$\operatorname{tr} 3$} & Média & 1,369 & 1,226 & 1,417 & 1,455 & 1,452 \\
\hline & $\mathrm{LC}_{\alpha=0,10}$ & 0,048 & 0,074 & 0,097 & 0,075 & 0,081 \\
\hline \multirow[t]{2}{*}{$\operatorname{tr} 4$} & Média & 1,457 & 1,116 & 1,284 & 1,391 & 1,425 \\
\hline & $\mathrm{LC}_{\alpha=0,10}$ & 0,107 & 0,091 & 0,197 & 0,107 & 0,055 \\
\hline \multirow[t]{2}{*}{$\operatorname{tr} 5$} & Média & 1,359 & 1,074 & 1,179 & 1,317 & 1,457 \\
\hline & $\mathrm{LC}_{\alpha=0,10}$ & 0,127 & 0,141 & 0,088 & 0,092 & 0,092 \\
\hline \multirow[t]{2}{*}{$\operatorname{tr} 6$} & Média & 1,459 & 1,242 & 1,473 & 1,546 & 1,480 \\
\hline & $\mathrm{LC}_{\alpha=0,10}$ & 0,102 & 0,072 & 0,028 & 0,063 & 0,079 \\
\hline \multirow[t]{2}{*}{$\operatorname{tr} 7$} & Média & 1,484 & 1,225 & 1,370 & 1,469 & 1,497 \\
\hline & $\mathrm{LC}_{\alpha=0,10}$ & 0,064 & 0,017 & 0,046 & 0,074 & 0,044 \\
\hline \multirow[t]{2}{*}{$\operatorname{tr} 8$} & Média & 1,416 & 1,153 & 1,260 & 1,366 & 1,430 \\
\hline & $\mathrm{LC}_{\alpha=0,10}$ & 0,043 & 0,060 & 0,062 & 0,060 & 0,080 \\
\hline \multirow[t]{4}{*}{$\operatorname{tr} 9$} & Média & 1,471 & 1,076 & 1,215 & 1,274 & 1,406 \\
\hline & $\mathrm{LC}_{\alpha=0,10}$ & 0,118 & 0,094 & 0,089 & 0,060 & 0,039 \\
\hline & valor $\mathrm{F}$ & $1,50^{\text {n.s. }}$ & $4,42^{*}$ & $6,87^{*}$ & $9,78^{*}$ & $1,46^{\text {n.s. }}$ \\
\hline & $\alpha$ & 0,2078 & 0,0022 & 0,0001 & 0,0001 & 0,2239 \\
\hline
\end{tabular}

*: significativo estatisticamente ao nível de probabilidade $\alpha$ expresso na linha imediatamente abaixo. n.s.: não significativo estatisticamente ao nível de probabilidade $\alpha=0,10$.

primeiro ano do experimento, optou-se neste capítulo por trabalhar apenas com a porosidade total do solo calculada. $\mathrm{O}$ valor estimado pelo conteúdo de água na saturação será posteriormente analisado no capítulo sobre retenção de água (item 4.5)

Embora tenham sido verificadas diferenças significativas da densidade dos sólidos do solo entre os tratamentos (Figura 7), estas diferenças foram pequenas e 
Tabela 13. Porosidade total do solo na camada superficial para os dois anos do experimento: média por tratamento e respectivo limite de confiança ao nível de probabilidade $\alpha=0,10\left(\mathrm{LC}_{\alpha=0,10}\right)$; valor $\mathrm{F}$ da análise de variância e respectivo nível de probabilidade $\alpha$.

\begin{tabular}{|c|c|c|c|c|c|c|}
\hline \multirow[b]{3}{*}{ Tratamento } & \multirow{3}{*}{$\begin{array}{l}\text { Parâmetro } \\
\text { estatístico }\end{array}$} & \multicolumn{5}{|c|}{ Porosidade total do solo $\left(\mathrm{m}^{3} \mathrm{~m}^{-3}\right)$} \\
\hline & & \multirow{2}{*}{$\begin{array}{c}1^{\mathrm{o}} \text { ano } \\
(0,114 \mathrm{a} \\
0,186 \mathrm{~m})\end{array}$} & \multicolumn{4}{|c|}{$2^{\circ}$ ano } \\
\hline & & & $\begin{array}{c}(0 \mathrm{a} \\
0,05 \mathrm{~m})\end{array}$ & $\begin{array}{l}(0,05 \mathrm{a} \\
0,10 \mathrm{~m})\end{array}$ & $\begin{array}{l}(0,10 \mathrm{a} \\
0,15 \mathrm{~m})\end{array}$ & $\begin{array}{c}(0,15 \text { a } \\
0,20 \mathrm{~m})\end{array}$ \\
\hline \multirow[t]{2}{*}{$\operatorname{tr} 1$} & Média & 0,472 & 0,547 & 0,493 & 0,474 & 0,468 \\
\hline & $\mathrm{LC}_{\alpha=0,10}$ & 0,019 & 0,018 & 0,016 & 0,015 & 0,039 \\
\hline \multirow[t]{2}{*}{$\operatorname{tr} 2$} & Média & 0,482 & 0,546 & 0,468 & 0,429 & 0,445 \\
\hline & $\mathrm{LC}_{\alpha=0,10}$ & 0,027 & 0,035 & 0,047 & 0,034 & 0,021 \\
\hline \multirow[t]{2}{*}{$\operatorname{tr} 3$} & Média & 0,507 & 0,558 & 0,490 & 0,476 & 0,477 \\
\hline & $\mathrm{LC}_{\alpha=0,10}$ & 0,016 & 0,036 & 0,024 & 0,035 & 0,033 \\
\hline \multirow[t]{2}{*}{$\operatorname{tr} 4$} & Média & 0,461 & 0,586 & 0,523 & 0,485 & 0,473 \\
\hline & $\mathrm{LC}_{\alpha=0,10}$ & 0,033 & 0,044 & 0,088 & 0,033 & 0,019 \\
\hline \multirow[t]{2}{*}{$\operatorname{tr} 5$} & Média & 0,490 & 0,597 & 0,558 & 0,506 & 0,454 \\
\hline & $\mathrm{LC}_{\alpha=0,10}$ & 0,051 & 0,052 & 0,033 & 0,034 & 0,034 \\
\hline \multirow[t]{2}{*}{$\operatorname{tr} 6$} & Média & 0,465 & 0,544 & 0,460 & 0,433 & 0,457 \\
\hline & $\mathrm{LC}_{\alpha=0,10}$ & 0,040 & 0,027 & 0,013 & 0,021 & 0,032 \\
\hline \multirow[t]{2}{*}{$\operatorname{tr} 7$} & Média & 0,477 & 0,568 & 0,517 & 0,482 & 0,473 \\
\hline & $\mathrm{LC}_{\alpha=0,10}$ & 0,033 & 0,014 & 0,025 & 0,034 & 0,024 \\
\hline \multirow[t]{2}{*}{$\operatorname{tr} 8$} & Média & 0,484 & 0,580 & 0,541 & 0,502 & 0,479 \\
\hline & $\mathrm{LC}_{\alpha=0,10}$ & 0,023 & 0,030 & 0,036 & 0,031 & 0,016 \\
\hline \multirow[t]{4}{*}{$\operatorname{tr} 9$} & Média & 0,455 & 0,601 & 0,550 & 0,528 & 0,479 \\
\hline & $\mathrm{LC}_{\alpha=0,10}$ & 0,048 & 0,035 & 0,029 & 0,017 & 0,010 \\
\hline & Valor F & $1,27^{\text {n.s. }}$ & $2,38^{*}$ & $4,41^{*}$ & $7,75^{*}$ & $1,31^{\text {n.s. }}$ \\
\hline & $\alpha$ & 0,3063 & 0,0477 & 0,022 & 0,0001 & 0,2836 \\
\hline
\end{tabular}

*: significativo estatisticamente ao nível de probabilidade $\alpha$ expresso na linha imediatamente abaixo. n.s.: não significativo estatisticamente ao nível de probabilidade $\alpha=0,10$.

insuficientes para provocar alterações consideráveis na porosidade total calculada $\left(\mathrm{PT}=1-\rho / \rho_{\mathrm{s}}\right)$. Assim, uma vez que análises de regressão múltipla mostraram que os coeficientes angulares referentes à densidade das partícula não foram significativos, utilizou-se o esquema de análise de variância apresentado na Tabela 4. 
Para o primeiro ano, quando foi amostrada somente a camada de 0,114 a 0,186 m de profundidade, a análise estatística dos dados mostrou que não houve efeito significativo dos tratamentos sobre a densidade ou a porosidade total. Já para o segundo ano do experimento, quando a amostragem foi feita em quatro camadas distintas, verificou-se que o efeito foi diferente dependendo da profundidade considerada. Nas camadas mais superficiais ( 0 a 0,$05 ; 0,05$ a 0,10 e 0,10 a $0,15 \mathrm{~m}$ de profundidade), houve efeito estatisticamente significativo dos tratamentos sobre ambas as propriedades. Para a camada mais profunda ( 0,15 a $0,20 \mathrm{~m}$ de profundidade), no entanto, nenhum efeito significativo foi observado.

Onde houve efeito significativo, fez-se o desdobramento dos tratamentos conforme os contrastes ortogonais propostos no esquema de análise de variância (Tabela 4). Pôde-se verificar que, para ambos os resíduos, houve efeito linear significativo tanto sobre a densidade do solo (Figura 10) como sobre a porosidade total (Figura 11). Com o aumento da dose aplicada houve redução da densidade e aumento da porosidade total. Inúmeros autores também verificaram que aplicações de resíduos levaram a diminuições na densidade do solo (Gupta et al., 1977; Wei et al., 1985; Mbagwu \& Piccolo, 1990; Martens \& Frankenberger Jr., 1992; Felton, 1995; Logan \& Harrison, 1995; Logan et al., 1996) e a incrementos na porosidade total (Wei et al., 1985; Logan \& Harrison, 1995; Logan, 1996). Gupta et al. (1977) obtiveram a equação linear $(\rho=1,4975-0,0875 \mathrm{MO})$ relacionando a densidade do solo $\left(\rho, \mathrm{em} \mathrm{Mg} \mathrm{m}^{-3}\right)$ e o conteúdo de matéria orgânica do solo (MO, em \%). No presente caso, a adequação dos dados às unidades utilizadas por Gupta et al. (1977) forneceram as seguintes equações: $\rho=1,4451-0,1322 \mathrm{MO}$ para a camada 0 a $0,05 \mathrm{~m}$ de profundidade; $\rho=1,8043-0,2293 \mathrm{MO}$ para a camada 0,05 a 0,10 ; e $\rho=1,8624-0,2175 \mathrm{MO}$ para a camada 0,10 a $0,15 \mathrm{~m}$. Khaleel et al. (1981) deduziram uma equação de regressão linear $(\Delta \rho=3,99+6,99 \Delta \mathrm{CO})$ entre a redução percentual relativa na densidade do solo $(\Delta \rho)$ e o incremento percentual relativo no carbono orgânico do solo $(\Delta \mathrm{CO})$. Novamente adaptando os presentes dados às unidades deste autor, obtemos as equações $\Delta \rho=1,24+0,19 \Delta \mathrm{CO}$ para a camada 0 a $0,05 \mathrm{~m}$ de profundidade; 

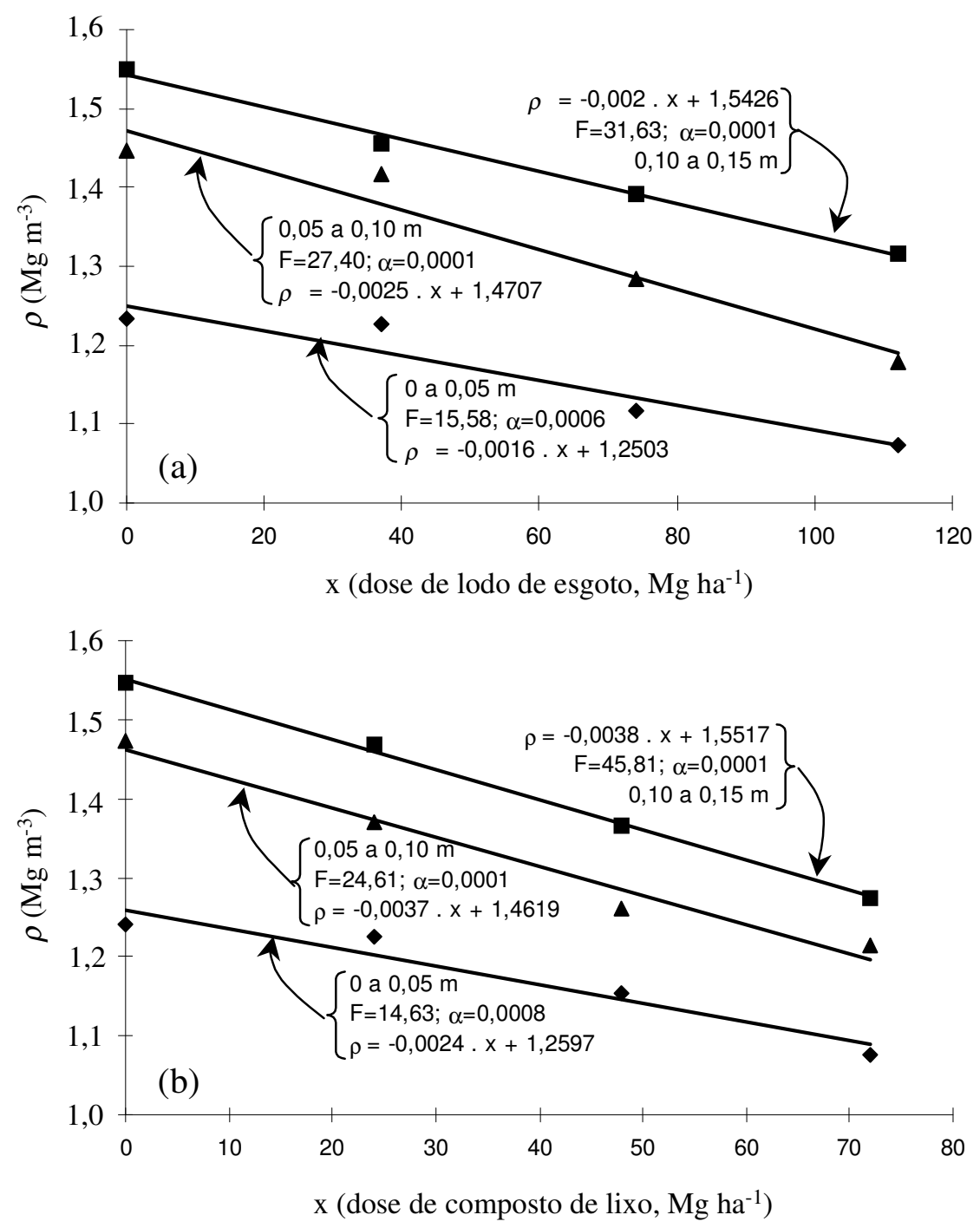

Figura 10. Médias e funções ajustadas (obtidas na análise de variância) para densidade do solo $(\rho)$ em função das doses dos resíduos (com valor $\mathrm{F}$ e nível de probabilidade $\alpha$ ) no segundo ano do experimento, para as camadas 0 a 0,05 ; 0,05 a 0,10 e 0,10 a 0,15 m de profundidade: (a) lodo de esgoto; (b) composto de lixo.

$\Delta \rho=1,74+0,30 \Delta \mathrm{CO}$ para a camada 0,05 a $0,10 \mathrm{~m}$ e $\Delta \rho=0,66+0,28 \Delta \mathrm{CO}$ para a camada 0,10 a $0,15 \mathrm{~m}$. Portanto este efeito é devido à atuação da matéria orgânica incorporada, que atua como agente cimentante das partículas do solo, dando-lhe maior estabilidade estrutural e diminuindo sua susceptibilidade aos fatores que induzem a reacomodação das partículas após o revolvimento. 

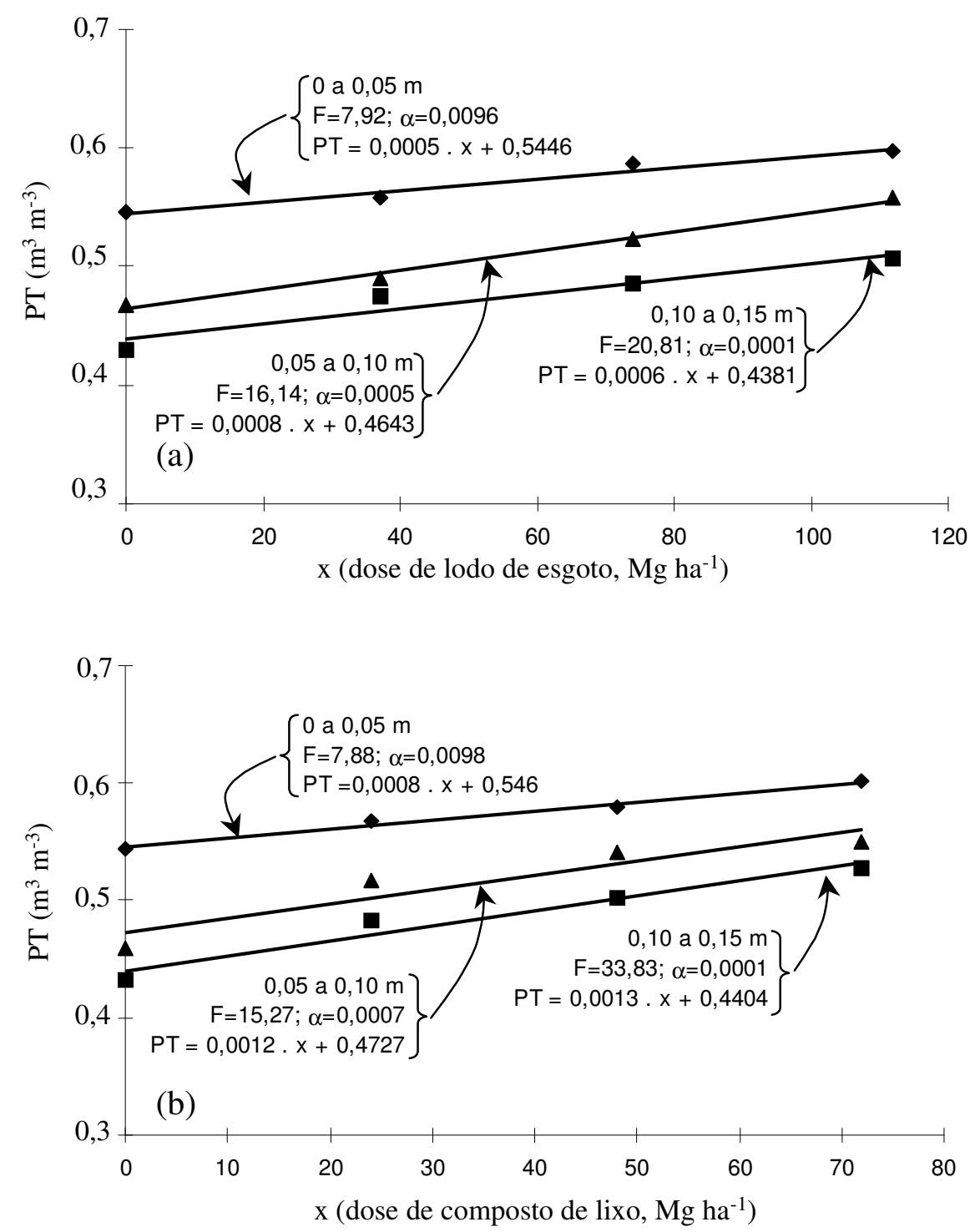

Figura 11. Médias e funções ajustadas (obtidas na análise de variância) para porosidade total do solo $(P T)$ em função das doses dos resíduos (com valor $\mathrm{F}$ e nível de probabilidade $\alpha$ ) no segundo ano do experimento, para as camadas 0 a 0,05 ; 0,05 a 0,10 e 0,10 a 0,15 m de profundidade: (a) lodo de esgoto e (b) composto de lixo

A ausência de efeito na camada de 0,15 a $0,20 \mathrm{~m}$ de profundidade pode ter ocorrido devido ao equipamento utilizado para incorporação do resíduo (uma enxada rotativa, mostrada na Figura 4 b e 4c) não ter atingido de fato esta profundidade. Além disso, como a sobrecarga das partículas das camadas mais superficiais é maior, a reacomodação do solo ocorre de maneira mais intensa nesta camada, ainda que parte da 
matéria orgânica tenha sido aí incorporada. Com relação ao primeiro ano, cabe ressaltar que a amostragem foi realizada com um cilindro maior que aquele do segundo ano, e na camada de 0,114 a 0,186 m de profundidade (ou seja, metade da amostra foi proveniente da camada de 0,15 a 0,20 m). Neste caso, para a ausência de efeitos significativos podem ser utilizadas as mesmas justificativas acima. Além disso, um outro fator que deve ter contribuído para um maior efeito maior no segundo ano do que no primeiro foi o efeito cumulativo do carbono orgânico, comprovado pelos maiores conteúdos observados na Tabela 8 em relação à Tabela 7 .

\subsection{Curva de retenção de água}

Na Tabela 14 são apresentados, para o primeiro ano do experimento, os valores médios de conteúdo de água e seus respectivos limites de confiança ao nível de probabilidade $\alpha=0,10\left(\mathrm{LC}_{\alpha=0,10}\right)$, para cada potencial mátrico utilizado na elaboração da curva de retenção. A Tabela traz ainda, para cada valor de potencial, os valores F obtidos na análise de variância e seus respectivos níveis de significância, pelos quais inferiu-se a existência ou não de efeitos dos tratamentos. Os valores médios de conteúdo de água e os limites de confiança $\left(\mathrm{LC}_{\alpha=0,10}\right)$ da Tabela 14 são reapresentados na forma de gráficos específicos para cada tratamento na Figura 12. De maneira geral, pode-se dizer que, comparativamente às testemunhas e ao tratamento que recebeu adubação mineral, a aplicação dos resíduos levou ao aumento da variabilidade do conteúdo de água, principalmente para os potenciais mátricos próximos à saturação. Isto pode ser evidenciado comparando-se os limites de confiança na Figura 12 (barras verticais no corpo dos gráficos), e pode ser justificado pelos poros maiores serem mais afetados pelas alterações estruturais do que os poros menores. A Figura 12 traz também o ajuste das médias de cada tratamento ao modelo expresso pela equação 6 (Van Genuchten, 1980), que serão posteriormente utilizados na estimativa da condutividade hidráulica relativa do solo. Os parâmetros de ajuste destas funções são apresentados na Tabela 15. Além do ajuste para as médias, fez-se também um ajuste para cada repetição, para que tanto os parâmetros das equações quanto outros obtidos a partir destas funções pudessem sofrer tratamento estatístico. 
Tabela 14. Conteúdo de água correspondente a cada valor de potencial mátrico utilizado para a elaboração da curva de retenção no primeiro ano do experimento: média por tratamento e respectivo limite de confiança ao nível de probabilidade $\alpha=0,10\left(\mathrm{LC}_{\alpha=0,10}\right)$; valor $\mathrm{F}$ da análise de variância e respectivo nível de probabilidade $\alpha$.

\begin{tabular}{|c|c|c|c|c|c|c|c|c|c|c|c|c|}
\hline \multirow[b]{3}{*}{ Tratamento } & \multirow{3}{*}{$\begin{array}{l}\text { Parâmetro } \\
\text { estatístico }\end{array}$} & \multicolumn{11}{|c|}{ Potenciais mátricos utilizados $(\mathrm{kPa})$} \\
\hline & & $-0,5$ & -1 & -2 & -4 & -6 & -10 & -20 & -30 & -80 & -400 & -1500 \\
\hline & & \multicolumn{11}{|c|}{ Conteúdo de água do solo $\left(\mathrm{m}^{3} \mathrm{~m}^{-3}\right)$} \\
\hline \multirow[t]{2}{*}{$\operatorname{tr} 1$} & Média & 0,446 & 0,428 & 0,403 & 0,348 & 0,300 & 0,268 & 0,216 & 0,205 & 0,186 & 0,169 & 0,154 \\
\hline & $\mathrm{LC}_{\alpha=0,10}$ & 0,017 & 0,021 & 0,035 & 0,039 & 0,018 & 0,014 & 0,013 & 0,014 & 0,014 & 0,024 & $+0,030$ \\
\hline \multirow[t]{2}{*}{$\operatorname{tr} 2$} & Média & 0,421 & 0,416 & 0,397 & 0,341 & 0,304 & 0,273 & 0,224 & 0,213 & 0,191 & 0,166 & 50,149 \\
\hline & $\mathrm{LC}_{\alpha=0,10}$ & 0,017 & 0,025 & 0,014 & 0,023 & 0,022 & 0,022 & 0,017 & 0,015 & 0,015 & 0,019 & 0,022 \\
\hline \multirow[t]{2}{*}{$\operatorname{tr} 3$} & Média & 0,452 & 0,439 & 0,404 & 0,349 & 0,308 & 0,280 & 0,236 & 0,225 & 0,210 & 0,181 & 0,151 \\
\hline & $\mathrm{LC}_{\alpha=0,10}$ & 0,074 & 0,069 & 0,050 & 0,029 & 0,017 & 0,010 & 0,006 & 0,007 & 0,024 & $+0,010$ & 0,014 \\
\hline \multirow[t]{2}{*}{$\operatorname{tr} 4$} & Média & 0,405 & 0,400 & 0,379 & 0,350 & 0,306 & 0,278 & 0,238 & 0,224 & 0,201 & 0,168 & 0,149 \\
\hline & $\mathrm{LC}_{\alpha=0,10}$ & 0,054 & 0,056 & 0,041 & 0,036 & 0,027 & 0,017 & 0,018 & 0,022 & 0,023 & 0,020 & 0,021 \\
\hline \multirow[t]{2}{*}{$\operatorname{tr} 5$} & Média & 0,399 & 0,400 & 0,377 & 0,325 & 0,287 & 0,258 & 0,226 & 0,210 & 0,194 & 0,164 & $+0,143$ \\
\hline & $\mathrm{LC}_{\alpha=0,10}$ & 0,057 & 0,057 & 0,052 & 0,048 & 0,044 & 0,037 & 0,029 & 0,027 & 0,026 & 0,025 & 0,030 \\
\hline \multirow[t]{2}{*}{$\operatorname{tr} 6$} & Média & 0,422 & 0,418 & 0,400 & 0,347 & 0,305 & 0,271 & 0,227 & 0,215 & 0,193 & 0,165 & 0,148 \\
\hline & $\mathrm{LC}_{\alpha=0,10}$ & 0,040 & 0,044 & 0,039 & 0,027 & 0,018 & 0,011 & 0,007 & 0,009 & 0,009 & 0,012 & 20,015 \\
\hline \multirow[t]{2}{*}{$\operatorname{tr} 7$} & Média & 0,433 & 0,422 & 0,395 & 0,347 & 0,316 & 0,287 & 0,240 & 0,226 & 0,204 & 0,179 & 0,158 \\
\hline & $\mathrm{LC}_{\alpha=0,10}$ & 0,080 & 0,062 & 0,066 & 0,045 & 0,032 & 0,023 & 0,017 & 0,026 & 0,014 & 0,019 & 0,023 \\
\hline \multirow[t]{2}{*}{$\operatorname{tr} 8$} & Média & 0,403 & 0,399 & 0,387 & 0,354 & 0,324 & 0,294 & 0,276 & 0,249 & 0,219 & 0,197 & 70,170 \\
\hline & $\mathrm{LC}_{\alpha=0,10}$ & 0,013 & 0,018 & 0,018 & 0,023 & 0,018 & 0,017 & 0,058 & 0,024 & 0,010 & 0,026 & 50,026 \\
\hline \multirow[t]{4}{*}{$\operatorname{tr} 9$} & Média & 0,409 & 0,408 & 0,385 & 0,337 & 0,299 & 0,267 & 0,245 & 0,229 & 0,211 & 0,172 & 0,152 \\
\hline & $\mathrm{LC}_{\alpha=0,10}$ & 0,074 & 0,073 & 0,055 & 0,039 & 0,030 & 0,020 & 0,026 & 0,018 & 0,024 & 0,007 & 7 0,008 \\
\hline & valor $\mathrm{F}$ & $0,75^{\text {n.s. }}$ & $0,44^{\text {n.S. }}$ & $0,35^{\text {n.s. }}$ & $0,36^{\text {n.s. }}$ & $0,82^{\text {n.s. }}$ & $1,52^{\text {n.s. }}$ & $2,64 *$ & $2,75^{*}$ & $2,31^{*}$ & $2,16^{*}$ & $0,77^{\text {n.s. }}$ \\
\hline & $\alpha$ & 0,6476 & 0,8828 & 0,9385 & 0,9314 & 0,5930 & 0,2026 & 0,0313 & 0,0262 & 0,0535 & 0,0692 & 20,1272 \\
\hline
\end{tabular}

*: significativo estatisticamente ao nível de probabilidade $\alpha$ expresso na linha imediatamente abaixo.

n.s.: não significativo estatisticamente ao nível de probabilidade $\alpha=0,10$.

Inicialmente aplicou-se a análise de variância aos conteúdos de água correspondentes a cada valor de potencial mátrico utilizado, e pelos valores $\mathrm{F}$ obtidos observou-se que não houve efeito significativo dos tratamentos para os valores de potencial mátrico mais próximos à saturação, possivelmente pela maior variabilidade verificada para esta faixa. Efeitos significativos foram observados somente para os 

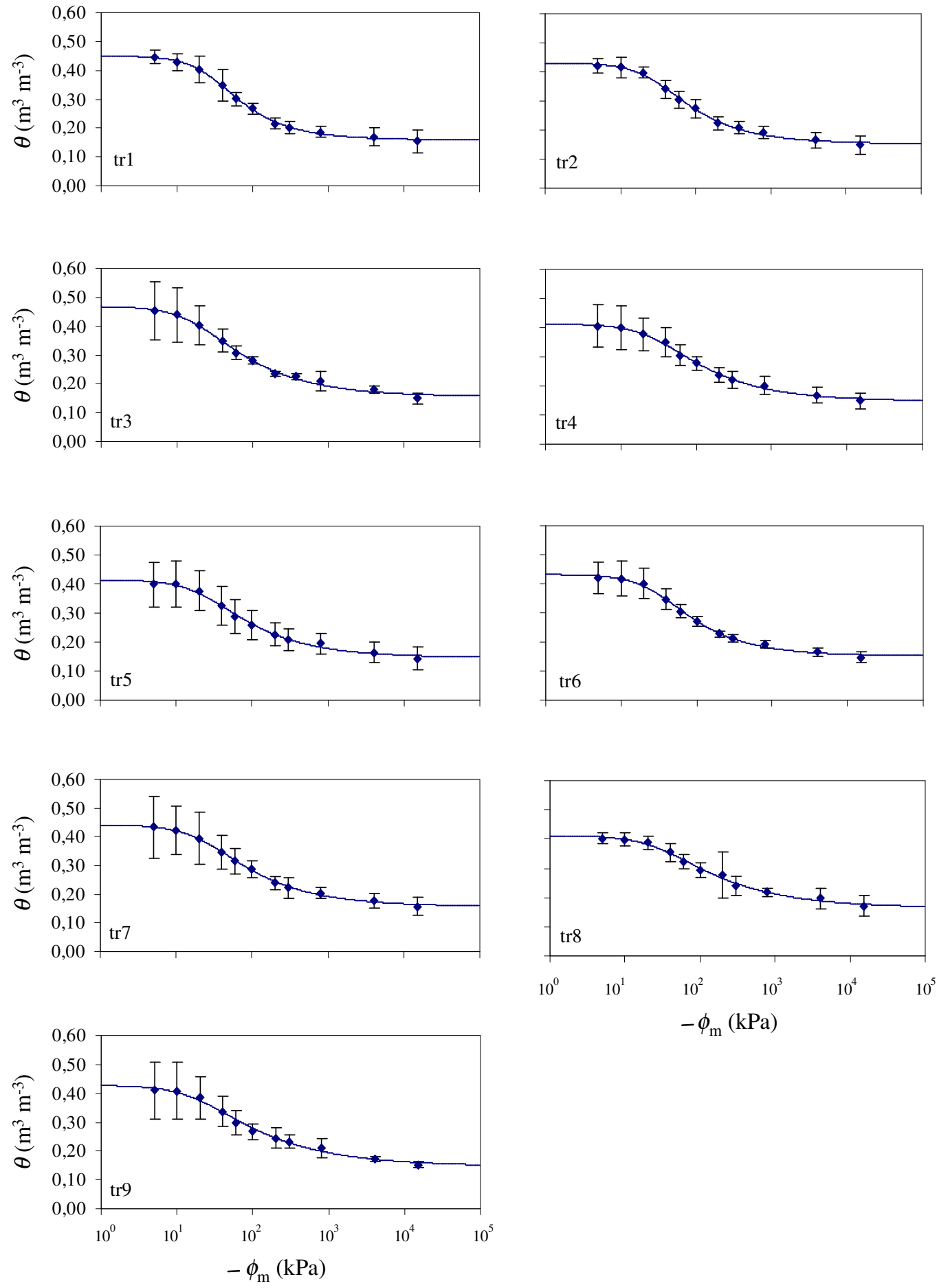

Figura 12. Valores médios e limites de confiança ao nível de probabilidade $\alpha=0,10$ do conteúdo de água do $\operatorname{solo}(\theta)$ em função do potencial mátrico, e funções ajustadas ao modelo de Van Genuchten (1980), para cada tratamento, no primeiro ano do experimento. 
Tabela 15. Parâmetros do ajuste dos valores médios do conteúdo de água correspondente a cada valor de potencial mátrico da curva de retenção ao modelo de Van Genuchten (1980), no primeiro ano do experimento.

\begin{tabular}{cccccc}
\hline \hline Tratamento & $\alpha\left(\mathrm{kPa}^{-1}\right)$ & $\mathrm{m}$ & $\mathrm{n}$ & $\theta_{\mathrm{r}}\left(\mathrm{m}^{3} \mathrm{~m}^{-3}\right)$ & $\theta_{\mathrm{s}}\left(\mathrm{m}^{3} \mathrm{~m}^{-3}\right)$ \\
\hline $\operatorname{tr} 1$ & 0,3390 & 0,4446 & 1,8004 & 0,159 & 0,449 \\
$\operatorname{tr} 2$ & 0,3260 & 0,4059 & 1,6833 & 0,153 & 0,431 \\
$\operatorname{tr} 3$ & 0,5180 & 0,3517 & 1,5425 & 0,155 & 0,469 \\
$\operatorname{tr} 4$ & 0,3180 & 0,3556 & 1,5518 & 0,147 & 0,413 \\
$\operatorname{tr} 5$ & 0,3960 & 0,3675 & 1,5810 & 0,146 & 0,415 \\
$\operatorname{tr} 6$ & 0,3200 & 0,4057 & 1,6826 & 0,152 & 0,432 \\
$\operatorname{tr} 7$ & 0,3980 & 0,3598 & 1,5620 & 0,157 & 0,442 \\
$\operatorname{tr} 8$ & 0,3140 & 0,3221 & 1,4752 & 0,164 & 0,412 \\
$\operatorname{tr} 9$ & 0,4880 & 0,3135 & 1,4566 & 0,146 & 0,428 \\
\hline \hline
\end{tabular}

potenciais mátricos $-20,-30,-80$ e $-400 \mathrm{kPa}$. No entanto, sabendo-se da literatura que a composição granulométrica do solo influencia na retenção de água (Kiehl, 1979; Brady, 1989) e que, no presente caso, o conteúdo de argila sofre covariação com relação aos tratamentos (Figura 7), deduz-se que estes efeitos podem ter sido provocados pelas diferenças granulométricas, e não necessariamente pelos tratamentos. A adoção do desdobramento da análise de variância segundo os contrastes ortogonais propostos na Tabela 4, sem considerar esta covariação, poderia levar as conclusões equivocadas. Por exemplo, por este desdobramento, o tratamento tr1 (que recebeu adubação mineral) apresentaria conteúdos de água significativamente menores que os demais tratamentos para os potenciais mátricos $-20,-30$ e $-80 \mathrm{kPa}$ (os valores de $\alpha$ seriam 0,$0527 ; 0,0331$ e 0,0345 , respectivamente). Diferenças significativas entre os tratamentos com lodo de esgoto e composto de lixo (incluindo as testemunhas de ambos) seriam verificadas para os potenciais mátricos $-20 \mathrm{kPa}(\alpha=0,0527)$ e $-30 \mathrm{kPa}(\alpha=0,0527)$, sendo que o composto de lixo apresentaria conteúdos de água mais elevados. Efeito das doses crescentes de lodo de esgoto sobre o conteúdo de água seria verificado somente para o potencial mátrico $-80 \mathrm{kPa}$, ajustando-se aos dados uma função quadrática (Figura 13). Para doses crescentes de composto de lixo, também seriam verificados efeitos 


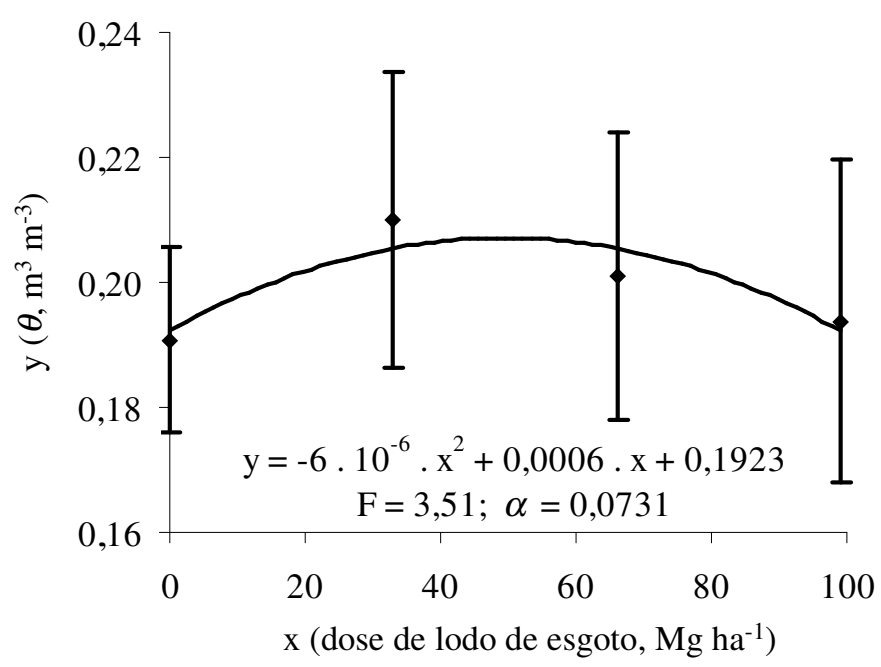

Figura 13. Médias e respectivos limites de confiança ao nível de probabilidade $\alpha=0,10$ pelo teste $t$, e função ajustada (obtida na análise de variância) para conteúdo de água no solo $(\theta)$ no potencial mátrico $\phi_{\mathrm{m}}=-80 \mathrm{kPa}$, em função das doses de lodo de esgoto (com valor $\mathrm{F}$ e nível de probabilidade $\alpha$ ) no primeiro ano do experimento.

significativos para os conteúdos de água nos potenciais mátricos $-20,-30,-80$ e $-400 \mathrm{kPa}$ (Figura 14). Nos potenciais mátricos $-20,-30$ e $-400 \mathrm{kPa}$ o efeito seria semelhante ao descrito anteriormente para o lodo de esgoto a $-30 \mathrm{kPa}$, ou seja, os dados se ajustariam a uma função quadrática. Já para o potencial mátrico $-80 \mathrm{kPa}$ o efeito das doses crescentes de composto de lixo seria uma função linear crescente.

No entanto, para se comprovar se as variações na retenção de água a um dado potencial mátrico podem de fato ser atribuídas a variações na composição granulométrica do solo, fez-se análises de regressão linear entre os valores de conteúdo de água e o respectivo conteúdo de argila de cada parcela. Nas parcelas que receberam doses de lodo de esgoto, para o potencial mátrico $-80 \mathrm{kPa}$, não houve ajuste de uma função que relacionasse o conteúdo de água ao conteúdo de argila da parcela, aceitando-se que as doses de lodo de esgoto realmente influenciaram o conteúdo de água retido ao potencial mátrico $-80 \mathrm{kPa}$ segundo a função expressa na Figura 13. Por outro lado, nas parcelas que receberam doses de composto de lixo, para os potenciais mátricos $-20,-30,-80$ e $-400 \mathrm{kPa}$, houve ajustes significativos de funções lineares relacionando o conteúdo de água ao conteúdo de argila, as quais são apresentadas na 

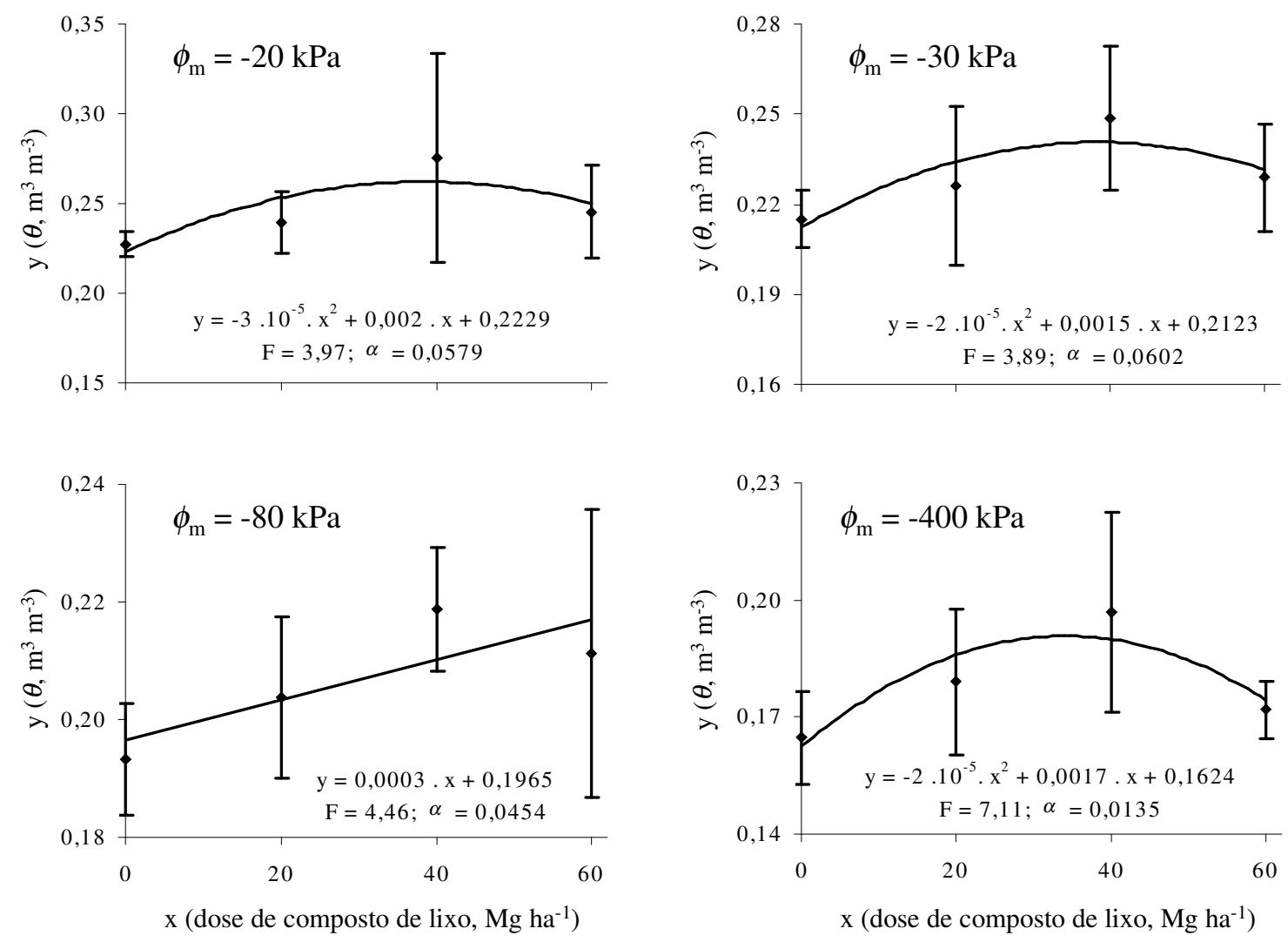

Figura 14. Médias e respectivos limites de confiança ao nível de probabilidade $\alpha=0,10$ pelo teste $t$, e funções ajustadas (obtidas na análise de variância) para conteúdo de água no solo $(\theta)$ em função das doses de composto de lixo (com valor $\mathrm{F}$ e nível de probabilidade $\alpha$ ) no primeiro ano do experimento, para os seguintes potenciais mátricos $\left(\phi_{\mathrm{m}}\right):-20,-30,-80$ e $-400 \mathrm{kPa}$.

Figura 15. A significância destas regressões confirma a possibilidade de que os efeitos descritos anteriormente possam ter sido provocados pelas diferenças granulométricas, e não exclusivamente pelas doses de composto de lixo. Este fato, associado à covariação entre o conteúdo de argila e doses de composto de lixo (Figura 7c), tornam inválida a análise de variância no que diz respeito às equações apresentadas na Figura 14. Nestes casos, fez-se análises de regressão múltipla relacionando o conteúdo de água (y) com o conteúdo de argila total $\left(\mathrm{x}_{1}\right)$ e com as doses de composto de lixo $\left(\mathrm{x}_{2}\right)$, considerando-se a possibilidade de efeito linear para o conteúdo de argila total e de efeito linear ou quadrático para as doses de composto. Assim ajustaram-se dois tipos de equações: 

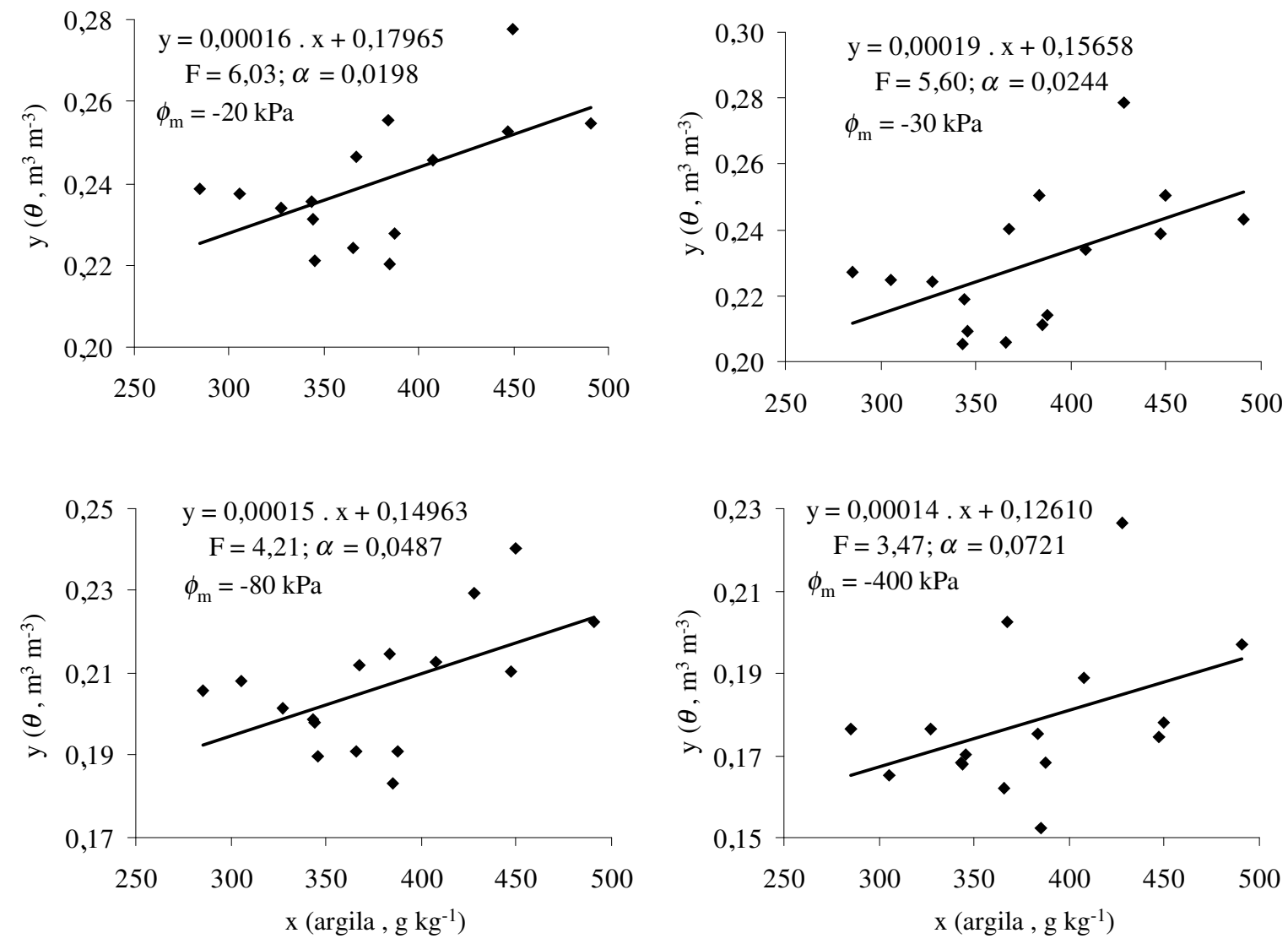

Figura 15. Valores observados e funções ajustadas para conteúdo de água no solo $(\theta)$ em função do conteúdo de argila total (com valor $\mathrm{F}$ e nível de probabilidade $\alpha$ ) no primeiro ano do experimento, para os seguintes potenciais mátricos $\left(\phi_{\mathrm{m}}\right):-20$, $-30,-80$ e $-400 \mathrm{kPa}$.

$$
\mathrm{y}=\mathrm{a} \cdot \mathrm{x}_{1}+\mathrm{b} \cdot \mathrm{x}_{2}+\mathrm{d}
$$

e

$$
y=a \cdot x_{1}+b \cdot x_{2}+c \cdot x_{2}^{2}+d
$$

onde $\underline{\mathrm{a}}, \underline{\mathrm{b}}$ e $\underline{\mathrm{c}}$ são os coeficientes relacionados às variáveis independentes, e $\underline{\mathrm{d}}$ é o coeficiente linear das funções ajustadas. Na Tabela 16 são apresentados os coeficientes obtidos para estas equações ajustadas, os resultados da aplicação do teste $\mathrm{F}$ ao nível de probabilidade $\alpha=0,10$ para verificar a significância destas equações e os resultados 
Tabela 16. Valor F e nível de probabilidade $\alpha$ para as equações 11 e 12 que relacionam o conteúdo de água $\left(\mathrm{y}, \mathrm{m}^{3} \mathrm{~m}^{-3}\right)$ com o conteúdo de argila total $\left(\mathrm{x}_{1}, \mathrm{~g} \mathrm{~kg}^{-3}\right)$ e com as doses de composto de lixo $\left(\mathrm{x}_{2}, \mathrm{Mg} \mathrm{ha}^{-1}\right)$, para os potenciais mátricos -20 , $-30,-80$ e $-400 \mathrm{kPa}$; coeficientes das equações e respectivos valores $t$ e nível de probabilidade $\alpha$

\begin{tabular}{|c|c|c|c|c|c|}
\hline \multirow{2}{*}{$\begin{array}{c}\text { Potencial } \\
\text { mátrico }\end{array}$} & \multirow{2}{*}{$\begin{array}{c}\text { Equação; } \\
\text { F; } \alpha\end{array}$} & \multicolumn{4}{|c|}{ Coeficientes das equações ajustadas; $t ; \alpha$} \\
\hline & & $\mathrm{a}$ & $\mathrm{b}$ & $\mathrm{c}$ & $\mathrm{d}$ \\
\hline \multirow[t]{6}{*}{$-20 \mathrm{kPa}$} & Eq. 11 & $2,4272.10^{-4}$ & $3,4251.10^{-4}$ & - & 0,1448 \\
\hline & $F=6,47$ & $t=1,82^{*}$ & $t=1,07^{\text {n.s. }}$ & - & $t=2,88^{*}$ \\
\hline & $\alpha=0,0059$ & $\alpha=0,0819$ & $\alpha=0,2974$ & - & $\alpha=0,0084$ \\
\hline & Eq. 12 & $1,1920 \cdot 10^{-4}$ & $1,3001 \cdot 10^{-3}$ & $-1,5592 \cdot 10^{-5}$ & 0,1571 \\
\hline & $\mathrm{F}=4,83$ & $t=1,28^{\text {n.s. }}$ & $t=1,03^{\text {n.s. }}$ & $t=-0,79^{\text {n.s. }}$ & $t=2,95^{*}$ \\
\hline & $\alpha=0,0178$ & $\alpha=0,2134$ & $\alpha=0,3138$ & $\alpha=0,4405$ & $\alpha=0,0073$ \\
\hline \multirow[t]{6}{*}{$-30 \mathrm{kPa}$} & Eq. 11 & $1,7493 \cdot 10^{-4}$ & $2,4490.10^{-4}$ & - & 0,1562 \\
\hline & $F=6,05$ & $t=2,17 *$ & $t=1,26^{\mathrm{n} . \mathrm{s} .}$ & - & $t=5,14^{*}$ \\
\hline & $\alpha=0,0077$ & $\alpha=0,0410$ & $\alpha=0,2205$ & - & $\alpha=3,4 \cdot 10^{-5}$ \\
\hline & Eq. 12 & $1,3781 \cdot 10^{-4}$ & $9,4619 \cdot 10^{-4}$ & $-1,1418 \cdot 10^{-5}$ & 0,1652 \\
\hline & $F=4,54$ & $t=1,54^{\text {n.s. }}$ & $t=1,25^{\text {n.s. }}$ & $t=-0,96^{\text {n.s. }}$ & $t=5,18^{*}$ \\
\hline & $\alpha=0,0218$ & $\alpha=0,1383$ & $\alpha=0,2228$ & $\alpha=0,3465$ & $\alpha=2,9.10^{-5}$ \\
\hline \multirow[t]{6}{*}{$-80 \mathrm{kPa}$} & Eq. 11 & $1,2920.10^{-4}$ & $2,8780 \cdot 10^{-4}$ & - & 0,1492 \\
\hline & $F=4,96$ & $t=2,28^{*}$ & $t=2,12^{*}$ & - & $t=7,02 *$ \\
\hline & $\alpha=0,0161$ & $\alpha=0,0316$ & $\alpha=0,0452$ & - & $\alpha=5.10^{-7}$ \\
\hline & Eq. 12 & $1,1421.10^{-4}$ & $5,7084 \cdot 10^{-4}$ & $-4,6084 \cdot 10^{-6}$ & 0,1528 \\
\hline & $F=3,40$ & $t=1,76^{*}$ & $t=1,05^{\text {n.s. }}$ & $t=-0,54^{\text {n.s. }}$ & $t=5,18^{*}$ \\
\hline & $\alpha=0,0511$ & $\alpha=0,0888$ & $\alpha=0,3025$ & $\alpha=0,5935$ & $\alpha=2,9 \cdot 10^{-5}$ \\
\hline \multirow[t]{6}{*}{$-400 \mathrm{kPa}$} & Eq. 11 & $1,2670 \cdot 10^{-4}$ & $1,4128 \cdot 10^{-4}$ & - & 0,1259 \\
\hline & $\mathrm{F}=2,84$ & $t=1,56^{\text {n.s. }}$ & $t=0,72^{\text {n.s. }}$ & - & $t=4,12^{*}$ \\
\hline & $\alpha=0,0791$ & $\alpha=0,1323$ & $\alpha=0,4772$ & - & $\alpha=4,2 \cdot 10^{-4}$ \\
\hline & Eq. 12 & $5,7858 \cdot 10^{-5}$ & $1,4414 \cdot 10^{-3}$ & $-2,1171 \cdot 10^{-5}$ & 0,1426 \\
\hline & $F=3,61$ & $t=0,71^{\text {n.s. }}$ & $t=2,10 *$ & $t=-1,96^{\text {n.s. }}$ & $t=4,93^{*}$ \\
\hline & $\alpha=00432$ & $\alpha=0,4846$ & $\alpha=0,0466$ & $\alpha=0,0617$ & $\alpha=5,5 \cdot 10^{-5}$ \\
\hline
\end{tabular}

*: significativo estatisticamente ao nível de probabilidade $\alpha$ expresso na linha imediatamente abaixo. n.s.: não significativo estatisticamente ao nível de probabilidade $\alpha=0,10$.

do teste $t$ ao mesmo nível probabilidade para verificar a significância de cada um dos coeficientes, tanto aqueles relacionados à argila total $\left(\mathrm{x}_{1}\right)$ quanto aqueles relacionados às doses de lodo $\left(\mathrm{x}_{2}\right)$.

Para os potenciais mátricos -20 e $-30 \mathrm{kPa}$ verificou-se, pelos valores de $t$ da Tabela 16, que não houve significância, ao nível de probabilidade $\alpha=0,10$, para os coeficientes relacionados às doses de composto de lixo. Para estes potenciais houve sim 
significância para os coeficientes relacionados à argila total. Para o potencial mátrico $-80 \mathrm{kPa}$ verificou-se que houve significância tanto para o coeficiente relacionado à argila total quanto para o coeficiente $\underline{b}$ relacionado às doses de composto de lixo. Desta forma, aceita-se que houve efeito linear crescente das doses de composto de lixo sobre a água retida a $-80 \mathrm{kPa}$. Já para o potencial mátrico $-400 \mathrm{kPa}$, o coeficiente relacionado à argila total não foi significativo. Para este potencial verificou-se significância dos coeficientes $\underline{\mathrm{b}} \mathrm{e} \underline{\mathrm{c}}$ relacionados às doses de composto de lixo, havendo um efeito quadrático das doses deste resíduo sobre o conteúdo de água. Outros autores freqüentemente verificaram resultados significativos da aplicação de resíduos, levando ao aumento da capacidade de retenção de água a um dado potencial (Epstein, 1975; Epstein et al., 1976; Gupta et al., 1977; Kumar et al., 1985; Obreza \& Reeder, 1994; Barreto, 1995; Felton, 1995). No presente caso, a elevação do conteúdo de água foi evidenciada apenas para os potenciais mátricos -80 e $-400 \mathrm{kPa}$, nas parcelas tratadas com composto de lixo. Para os demais potenciais, ou mesmo para as parcelas tratadas com lodo de esgoto (em todos os potenciais), não houve qualquer efeito significativo sobre a retenção de água. Além do aumento na variabilidade da retenção de água devido à aplicação dos resíduos, uma outra justificativa para a ausência de efeitos significativos mais evidentes pode ser a profundidade de amostragem $(0,114$ a $0,186 \mathrm{~m})$, que pode ter excedido parcialmente a profundidade de incorporação do resíduo pelo equipamento utilizado (enxada rotativa, Figura 4b e 4c).

Embora pela análise anterior tenha se verificado que houve efeito significativo das doses de composto de lixo sobre o conteúdo de água aos potenciais mátricos -80 e -400 kPa, os valores médios de conteúdo de água no solo na faixa de aplicação dos resíduos estudada sofreram variações máximas da ordem de $0,02 \mathrm{~m}^{3} \mathrm{~m}^{-3}$ (Tabela $14 \mathrm{e}$ Figuras 14 e 15), que podem ser consideradas pouco significativas. Além da água retida a um dado potencial, a análise de variância feita para diversos outros parâmetros, obtidos a partir da curva de retenção, revelou que nenhum destes sofreu alterações estatisticamente significativas ao nível de probabilidade $\alpha=0,10$. Estes parâmetros estudados foram: (a) água retida entre a capacidade de campo (-10 ou $-30 \mathrm{kPa})$ e o ponto de murcha permanente $(-1500 \mathrm{kPa})$; (b) umidade e potencial mátrico no ponto de 
inflexão da curva de retenção (quando representada em escala semi-log); (c) umidade na saturação $\left(\theta_{\mathrm{S}}\right)$ e umidade residual $\left(\theta_{\mathrm{r}}\right)$ estimadas por regressão no ajuste da curva de retenção; (d) porosidade bloqueada $(P B)$ ou não acessível, estimada peta diferença entre a porosidade total e a umidade na saturação $\left(P B=P T-\theta_{\mathrm{s}}\right)$.

\subsection{Condutividade hidráulica em amostras de solo saturadas}

$\mathrm{Na}$ Tabela 17 são apresentados os valores médios de condutividade hidráulica do solo saturado e seus respectivos limites de confiança ao nível de probabilidade $\alpha=0,10\left(\mathrm{LC}_{\alpha=0,10}\right)$ para as amostras indeformadas coletadas no primeiro ano do experimento. A análise estatística mostrou que houve efeito significativo $(\alpha=0,0905)$ dos tratamentos sobre a condutividade hidráulica do solo saturado no primeiro ano do experimento, o que ocorreu a despeito da alta variabilidade dos dados e a despeito da não ocorrência de efeito significativo dos tratamentos sobre a porosidade total do solo e sobre a retenção de água nos potenciais mátricos próximos à saturação. $\mathrm{O}$ desdobramento da análise em contrastes ortogonais revelou efeito significativo para as doses de lodo de esgoto, segundo uma função quadrática (Figura 16). No entanto, pôde-se também verificar efeito cúbico significativo $(\alpha=0,0669)$, o que evidencia variações por causas não controladas e faz com que a dependência quadrática entre a condutividade hidráulica do solo saturado e as doses de lodo de esgoto deva ser vista com cautela. Os problemas metodológicos envolvidos na obtenção desta propriedade, desde a amostragem até a sua determinação em laboratório, bem como a elevada

Tabela 17. Condutividade hidráulica do solo saturado nas amostras coletadas no primeiro ano do experimento: média por tratamento e limite de confiança ao nível de probabilidade $\alpha=0,10\left(\mathrm{LC}_{\alpha=0,10}\right)$; valor $\mathrm{F}$ da análise de variância e respectivo nível de probabilidade $\alpha$.

\begin{tabular}{cccccccccccc}
\hline & \multicolumn{8}{c}{ Condutividade hidráulica do solo saturado $\left(\mathrm{mm} \mathrm{h}^{-1}\right)$} & & \\
Parâmetro & \multicolumn{8}{c}{ Tratamentos } & & & \\
\cline { 2 - 9 } Estatístico & $\operatorname{tr} 1$ & $\operatorname{tr} 2$ & $\operatorname{tr} 3$ & $\operatorname{tr} 4$ & $\operatorname{tr} 5$ & $\operatorname{tr} 6$ & $\operatorname{tr} 7$ & $\operatorname{tr} 8$ & $\operatorname{tr} 9$ & $\mathrm{~F}$ & $\alpha$ \\
\hline Média & 371,4 & 236,3 & 272,1 & 172,3 & 445,0 & 232,4 & 216,0 & 280,8 & 303,5 & $2,00^{*}$ & 0,0905 \\
LC $_{\alpha=0,10}$ & 187,1 & 156,5 & 114,6 & 60,8 & 187,1 & 103,8 & 86,1 & 137,5 & 120,8 & & \\
\hline
\end{tabular}

*: significativo estatisticamente ao nível de probabilidade $\alpha$ expresso imediatamente na célula seguinte. 


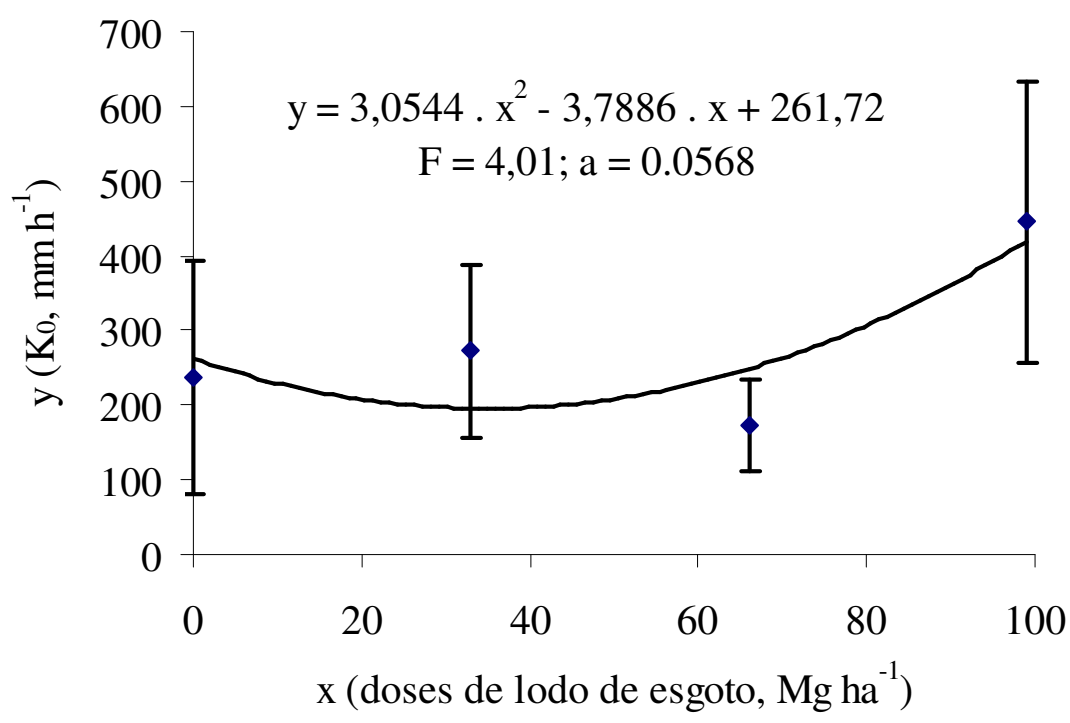

Figura 16. Médias e respectivos limites de confiança ao nível de probabilidade $\alpha=0,10$ pelo teste $t$, e função ajustada (obtida na análise de variância) para condutividade hidráulica do solo saturado $\left(\mathrm{K}_{0}\right)$ em função das doses de lodo de esgoto (com valor $\mathrm{F}$ e nível de probabilidade $\alpha$ ) nas amostras do primeiro ano do experimento.

variabilidade amplamente relatada na literatura (Warrick \& Nielsen, 1980; Khaleel et al., 1981), podem ter sido responsáveis por estes desvios da regressão. Para verificar se a covariação significativa verificada entre composição granulométrica do solo e os tratamentos (Figura 7) interferiram neste resultado, fez-se uma análise de regressão múltipla relacionando a condutividade hidráulica do solo saturado ao conteúdo de areia e às doses de lodo de esgoto. A aplicação do teste $t$ ao nível de probabilidade $\alpha=0,10$ aos coeficientes da equação obtida mostrou que não houve efeito significativo do conteúdo de areia sobre a condutividade hidráulica do solo saturado.

Embora com problemas de variabilidade, a equação ajustada na Figura 16 revela que há elevação da condutividade hidráulica do solo saturado com o aumento das doses de lodo. Os resultados disponíveis na literatura muitas vezes são contraditórios. Trabalhando com amostras de um solo arenoso, Kumar et al. (1985) obtiveram diminuições marcantes na condutividade hidráulica do solo saturado com a adição de doses de resíduos (diminuição $93 \%$ para o lodo industrial, $82 \%$ para o esterco de curral, $78 \%$ para o adubo verde e $62 \%$ para o lodo de esgoto). Este comportamento foi 
justificado pelos autores por se tratar de um solo arenoso. Desta forma, eles não esperariam o mesmo resultado para solos com textura fina, onde a matéria orgânica promove a formação de agregados. Logan et al. (1996), mesmo aplicando 25\% (a base de massa) de lodo de esgoto, não obtiveram efeitos significativos sobre a condutividade hidráulica do solo saturado, independentemente da textura do solo utilizado. Jacobowitz $\&$ Steenhuis (1984), mesmo trabalhando com um solo arenoso, obtiveram aumentos na condutividade hidráulica do solo saturado devidos à adição de composto de lodo. Para solos numa ampla faixa de textura, a condutividade hidráulica do solo saturado nas parcelas tratadas com lodo normalmente é maior do que nas parcelas testemunhas (Epstein, 1975; Gupta et al., 1977; Morel et al., 1978; Chang et al., 1983; Wei et al., 1985).

\subsection{Condutividade hidráulica pelo método do infiltrômetro de tensão}

As determinações foram feitas na superfície do solo, nos dois anos do experimento, utilizando-se o infiltrômetro de tensão (Perroux \& White, 1988) ajustado nos potenciais mátricos $0 ;-0,25 ;-0,50$ e $-1,00 \mathrm{kPa}$. Cabe ressaltar aqui que, durante os testes de infiltração de campo para a obtenção dos valores de fluxo estacionário, pôde-se detectar visualmente que a superfície do solo nas parcelas que receberam resíduos (tanto composto de lixo quanto lodo de esgoto) manifestava certa repelência à água. Constantini et al. (1995) também relataram caráter hidrófobo para três solos tratados com lodo de esgoto. Segundo os autores, esta repelência diminuiu a taxa de infiltração inicial do solo (medida com um infiltrômetro de tensão), porém as taxas de infiltração em equilíbrio dinâmico foram maiores nas parcelas que receberam lodo. Kumar et al. (1985) mediram o ângulo de contato da água $(\beta)$ com o solo tratado com lodo de esgoto, lodo industrial prensado, adubo verde e esterco de curral. Os valores obtidos foram $\beta=33,7^{\circ}$ para a testemunha $(\cos \beta=0,832), \beta=79,2^{\circ}$ para o lodo de esgoto ( $\cos \beta=0,188), \beta=82,0^{\circ}$ para o lodo industrial $(\cos \beta=0,140), \beta=84,4^{\circ}$ para o adubo verde $(\cos \beta=0,097)$ e $\beta=85,1^{\circ}$ para o esterco de curral $(\cos \beta=0,086)$. Tratam-se de alterações consideráveis, uma vez que o ângulo de contato exerce uma importante função na penetração da água no material poroso. 
Na Tabela 18 são apresentados os valores médios de condutividade hidráulica e os respectivos limites de confiança ao nível de probabilidade $\alpha=0,10\left(\operatorname{LC}_{\alpha=0,10}\right)$. A Tabela 18 traz ainda, para cada valor de potencial, os valores $\mathrm{F}$ obtidos na análise de variância e seus respectivos níveis de significância $\alpha$, pelos quais inferiu-se a existência

Tabela 18. Condutividade hidráulica correspondente a cada valor de potencial mátrico utilizado no infiltrômetro de tensão, nos dois anos do experimento: média por tratamento e respectivo limite de confiança ao nível de probabilidade $\alpha=0,10\left(\mathrm{LC}_{\alpha=0,10}\right)$; valor $\mathrm{F}$ da análise de variância e respectivo nível de probabilidade $\alpha$.

\begin{tabular}{|c|c|c|c|c|c|c|c|c|c|}
\hline \multirow[b]{4}{*}{ Tratamento } & \multirow{4}{*}{$\begin{array}{l}\text { Parâmetro } \\
\text { Estatístico }\end{array}$} & \multicolumn{8}{|c|}{ Potenciais mátricos utilizados $(\mathrm{kPa})$} \\
\hline & & \multicolumn{4}{|c|}{$1^{\circ}$ ano } & \multicolumn{4}{|c|}{$2^{\circ}$ ano } \\
\hline & & 0 & 0,25 & 0,50 & 1,00 & 0 & 0,25 & 0,50 & 1,00 \\
\hline & & \multicolumn{8}{|c|}{ Condutividade hidráulica do solo $\left(\mathrm{mm} \mathrm{h}^{-1}\right)$} \\
\hline \multirow[t]{2}{*}{$\operatorname{tr} 1$} & Média & 138,61 & 34,22 & 15,25 & 6,50 & 117,36 & 21,42 & 11,34 & 5,68 \\
\hline & $\mathrm{LC}_{\alpha=0,10}$ & 77,96 & 26,36 & 7,93 & 3,77 & 92,74 & 10,91 & 2,72 & 2,05 \\
\hline \multirow[t]{2}{*}{$\operatorname{tr} 2$} & Média & 153,15 & 26,31 & 13,11 & 7,43 & 49,31 & 15,95 & 6,52 & 4,45 \\
\hline & $\mathrm{LC}_{\alpha=0,10}$ & 67,50 & 5,27 & 2,89 & 1,49 & 23,94 & 2,54 & 3,30 & 2,34 \\
\hline \multirow[t]{2}{*}{$\operatorname{tr} 3$} & Média & 203,35 & 21,70 & 7,67 & 3,21 & 173,35 & 8,98 & 3,36 & 1,62 \\
\hline & $\mathrm{LC}_{\alpha=0,10}$ & 142,79 & 16,24 & 5,83 & 2,48 & 53,51 & 1,85 & 1,46 & 0,96 \\
\hline \multirow[t]{2}{*}{$\operatorname{tr} 4$} & Média & 207,23 & 25,25 & 8,00 & 3,10 & 177,25 & 11,81 & 4,48 & 1,83 \\
\hline & $\mathrm{LC}_{\alpha=0,10}$ & 72,69 & 15,90 & 3,15 & 1,69 & 79,58 & 6,50 & 2,47 & 0,93 \\
\hline \multirow[t]{2}{*}{$\operatorname{tr} 5$} & Média & 361,19 & 19,67 & 6,60 & 2,54 & 200,51 & 13,23 & 2,94 & 1,08 \\
\hline & $\mathrm{LC}_{\alpha=0,10}$ & 335,90 & 16,08 & 6,22 & 2,47 & 118,95 & 9,93 & 1,11 & 0,18 \\
\hline \multirow[t]{2}{*}{$\operatorname{tr} 6$} & Média & 111,66 & 24,59 & 11,28 & 5,65 & 49,31 & 15,95 & 6,52 & 5,41 \\
\hline & $\mathrm{LC}_{\alpha=0,10}$ & 45,54 & 3,72 & 3,82 & 3,20 & 23,94 & 2,54 & 3,30 & 1,43 \\
\hline \multirow[t]{2}{*}{$\operatorname{tr} 7$} & Média & 211,13 & 21,91 & 8,13 & 3,76 & 80,07 & 5,09 & 1,78 & 0,65 \\
\hline & $\mathrm{LC}_{\alpha=0,10}$ & 22,75 & 10,48 & 1,37 & 0,26 & 68,84 & 2,97 & 1,02 & 0,26 \\
\hline \multirow[t]{2}{*}{$\operatorname{tr} 8$} & Média & 157,82 & 14,16 & 6,69 & 2,90 & 245,91 & 6,04 & 1,73 & 0,62 \\
\hline & $\mathrm{LC}_{\alpha=0,10}$ & 148,05 & 9,22 & 3,82 & 1,44 & 163,46 & 2,53 & 0,77 & 0,23 \\
\hline \multirow[t]{4}{*}{$\operatorname{tr} 9$} & Média & 268,10 & 15,44 & 6,44 & 3,20 & 155,41 & 5,70 & 1,82 & 0,56 \\
\hline & $\mathrm{LC}_{\alpha=0,10}$ & 271,29 & 15,54 & 4,56 & 0,46 & 71,21 & 1,07 & 1,17 & 0,26 \\
\hline & valor F & $1,29^{\text {n.s. }}$ & $1,28^{\text {n.s. }}$ & $3,55^{*}$ & $4,51 *$ & $4,15^{*}$ & $6,04 *$ & $11,33^{*}$ & $5,18^{*}$ \\
\hline & $\alpha$ & 0,2978 & 0,3031 & 0,0081 & 0,0026 & 0,0031 & 0,0003 & 0,0001 & 0,0008 \\
\hline
\end{tabular}

*: significativo estatisticamente ao nível de probabilidade $\alpha$ expresso na linha imediatamente abaixo. n.s.: não significativo estatisticamente ao nível de probabilidade $\alpha=0,10$. 
ou não de efeitos dos tratamentos. Para o primeiro ano do experimento, a análise estatística dos dados mostrou que houve efeito significativo dos tratamentos sobre a condutividade hidráulica apenas nos potenciais mátricos $-0,50$ e -1,00 kPa. Já para o segundo ano, verificou-se que o efeito foi significativo para todos os potenciais mátricos estudados $(0 ;-0,25 ;-0,50$ e $-1,00 \mathrm{kPa})$. Nestes casos de efeito significativo dos tratamentos, fez-se o desdobramento da análise estatística conforme os contrastes ortogonais propostos no esquema de análise de variância (Tabela 4).

Pelos contrastes ortogonais, pôde-se verificar que a condutividade hidráulica do solo nas parcelas do tratamento tr1 (que recebeu calagem e adubação mineral) foi estatisticamente superior à média dos demais tratamentos, para os potenciais mátricos $-0,50 \mathrm{kPa}(\alpha=0,0011)$ e $-1,00 \mathrm{kPa}(\alpha=0,0096)$ no primeiro ano, e para os potenciais $-0,25 \mathrm{kPa}(\alpha=0,0001) ;-0,50 \mathrm{kPa}(\alpha=0,0001)$ e $-1,00 \mathrm{kPa}(\alpha=0,0001)$, no segundo ano. Comparando-se as parcelas dos tratamentos tr $2, \operatorname{tr} 3, \operatorname{tr} 4$ e tr5 (referentes às doses de lodo de esgoto) com as parcelas dos tratamentos tr6, tr7, tr8 e tr9 (referentes às doses de composto de lixo), pôde-se observar que, no segundo ano, as primeiros apresentaram condutividade hidráulica superior a das últimas, para os potenciais mátricos $-0,25 \mathrm{kPa}$ $(\alpha=0,0136)$ e $-0,50 \mathrm{kPa}(\alpha=0,0530)$. Para os demais casos esta diferença significativa não se manifestou.

Para as doses dos resíduos, os contrastes revelaram que, no primeiro ano, a condutividade hidráulica foi afetada significativamente tanto pelo lodo de esgoto quanto pelo composto de lixo, para os potenciais $-0,50$ e $-1,00 \mathrm{kPa}$, conforme as funções apresentadas na Figura 17. Para o segundo ano, a condutividade hidráulica também foi afetada significativamente por ambos os resíduos, para todos os potenciais mátricos estudados $(0 ;-0,25 ;-0,50$ e $-1,00 \mathrm{kPa})$, conforme as funções apresentadas na Figura 18. Observando-se as funções das Figuras 17 e 18, verifica-se que o efeito das doses de ambos os resíduos foi sempre depressivo para condutividade hidráulica, exceto na saturação (ou seja, exceto para $\phi_{\mathrm{m}}=0 \mathrm{kPa}$; veja os dois gráficos correspondentes na parte superior da Figura 18), para a qual a condutividade hidráulica demonstrou sofrer incrementos significativos. 

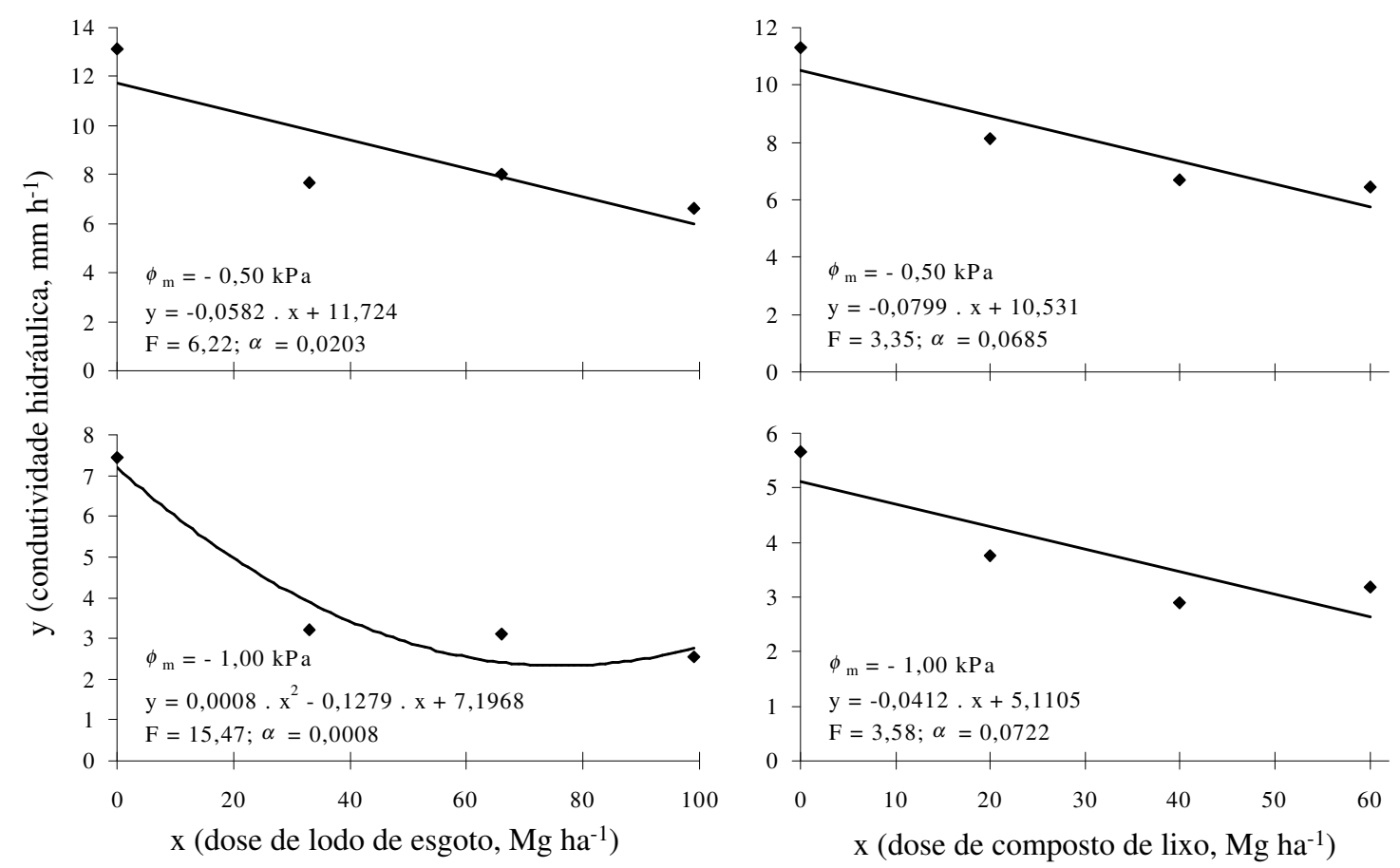

Figura 17. Valores médios e funções ajustadas (obtidas na análise de variância) entre a condutividade hidráulica $(\mathrm{K})$ e as doses de lodo de esgoto e de composto de lixo (com valor $\mathrm{F}$ e nível de probabilidade $\alpha$ ), para os potenciais mátricos onde houve significância, no primeiro ano do experimento.

Os valores médios da condutividade hidráulica em função do potencial mátrico são apresentados na Figura 19, para os diversos tratamentos e para os dois anos do experimento. Nestes gráficos, para cada tratamento, fez-se a interpolação da condutividade hidráulica entre potenciais consecutivos por meio de uma linha reta. Isto significa assumir uma relação logarítmica entre a condutividade hidráulica e o potencial mátrico (uma vez que o eixo que representa a condutividade hidráulica está em escala logarítmica). Embora para o primeiro ano do experimento a análise estatística não tenha revelado efeito significativo dos tratamentos para os potenciais mátricos 0 e $-0,25 \mathrm{kPa}$, a Figura 19 dá consistência à afirmação de que, na faixa de potencial mátrico estudada, a adição de ambos os resíduos levam ao aumento da condutividade hidráulica do solo próximo à saturação e à sua redução a medida que o solo se afasta da saturação. Assim, em cada gráfico pode-se distingüir claramente dois grupos. Um deles, formado pelos tratamentos que receberam resíduos (tr3, tr4 e tr5 ou tr7, $\operatorname{tr} 8$ e $\operatorname{tr} 9)$, tem a condutividade 

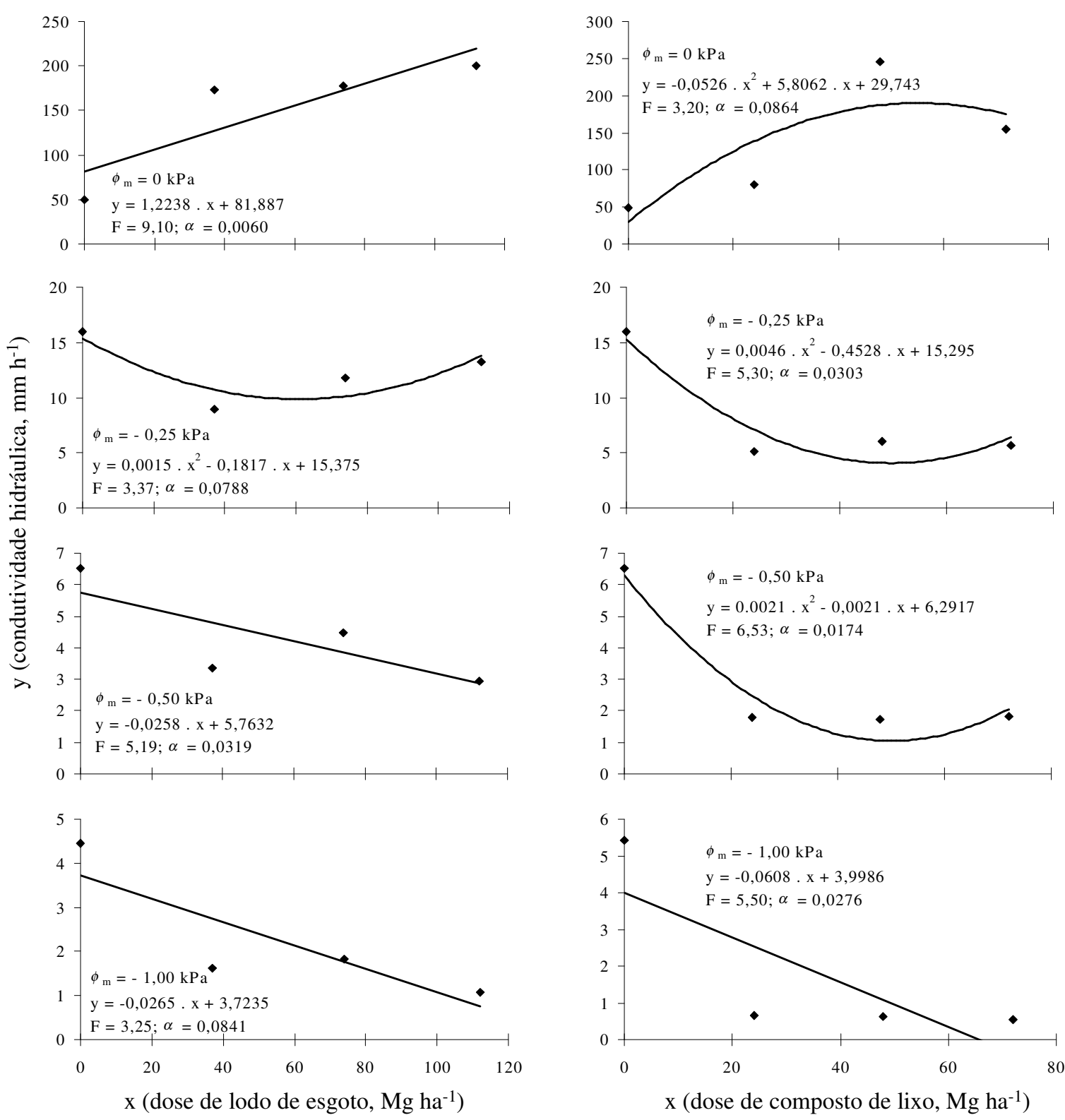

Figura 18. Valores médios e funções ajustadas (obtidas na análise de variância) para condutividade hidráulica $(\mathrm{K})$ em função das doses de lodo de esgoto e de composto de lixo (com valor $\mathrm{F}$ e nível de probabilidade $\alpha$ ), para os potenciais mátricos onde houve significância, no segundo ano do experimento.

hidráulica do solo saturado maior, porém com um decréscimo acentuado ao se afastar da saturação. O outro, formado pelos tratamentos testemunha e adubação mineral, que não receberam resíduos (tr1 e tr2 ou tr1 e tr6), tem maior condutividade hidráulica do solo saturado, porém um menor decréscimo ao se afastar da saturação. 

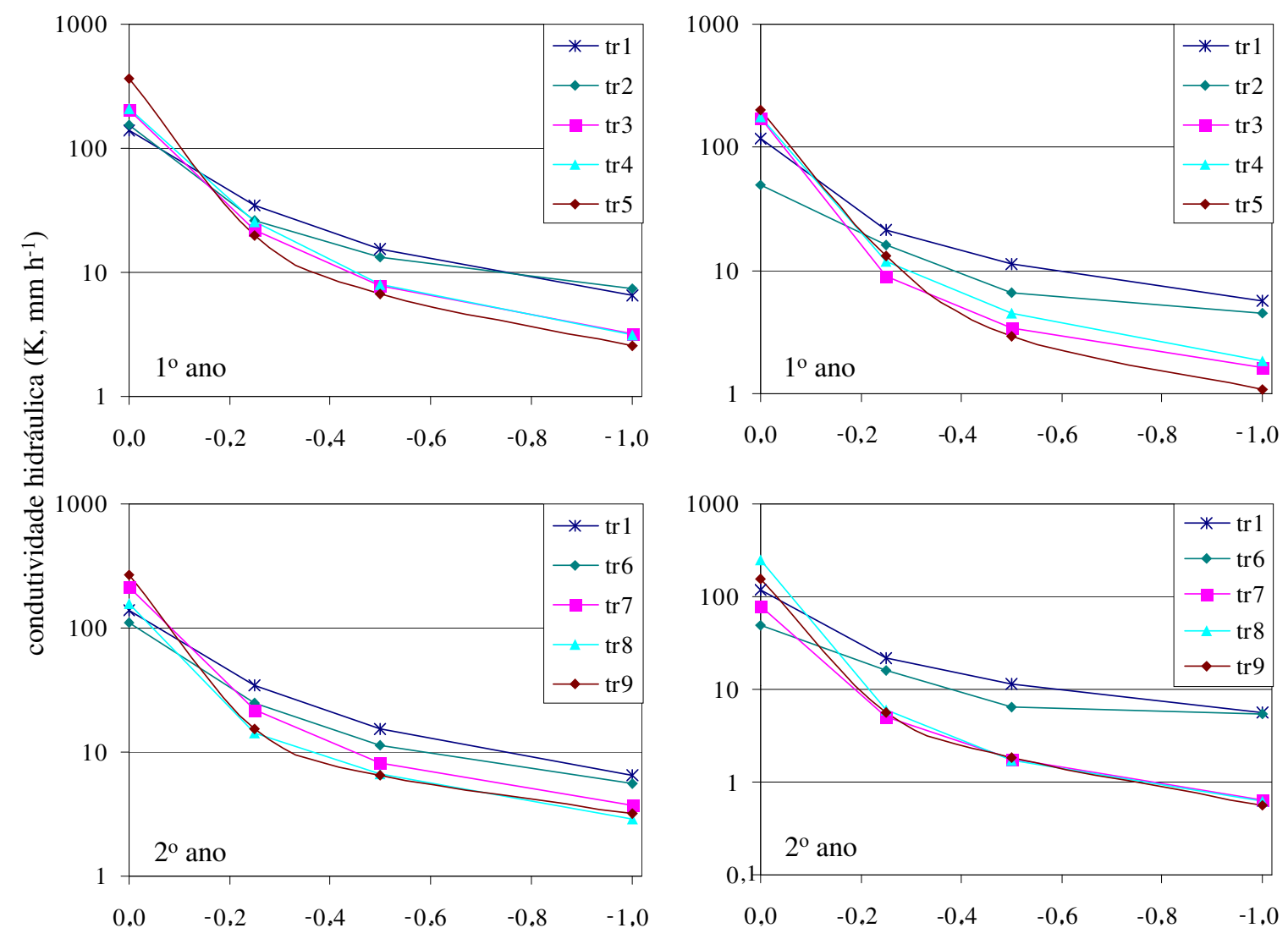

Potencial mátrico $\left(\phi_{\mathrm{m}}, \mathrm{kPa}\right)$

Figura 19. Valores médios de condutividade hidráulica $(\mathrm{K})$ em função do potencial mátrico, nos dois anos do experimento, para os tratamentos tr1, tr2, tr3, $\operatorname{tr} 4 \mathrm{e}$ tr5 (referentes à adubação mineral e às doses de lodo de esgoto) e tr1, tr6, tr7, tr8 e tr9 (referentes à adubação mineral e às doses de composto de lixo).

Jacobowitz \& Steenhuis (1984), trabalhando em um solo arenoso, obtiveram aumentos tanto na condutividade hidráulica do solo saturado quanto na condutividade hidráulica do solo não saturado (faixa de potencial mátrico de 0 a $-100 \mathrm{kPa}$ ) devido à adição de composto de lodo. Embora haja alguns outros relatos como este, na literatura há o amplo predomínio de resultados semelhantes aos obtidos no presente experimento. Ou seja, a condutividade hidráulica do solo saturado em parcelas tratadas com resíduos normalmente é maior do que nas parcelas testemunhas (Epstein, 1975; Gupta et al., 1977; Morel et al., 1978; Chang et al., 1983; Wei et al., 1985), enquanto a condutividade hidráulica do solo não saturado geralmente diminui com o aumento das 
doses (Gupta et al., 1977; Martens \& Frankenberger Jr., 1992; Abu-Sarar; 1996). Este comportamento pode ser justificado da forma descrita a seguir. Após o revolvimento para a incorporação do resíduo, o solo passa a ter uma estabilidade estrutural maior do que aquele onde nenhum resíduo foi incorporado. Desta forma, a reacomodação do solo após o revolvimento ocorre de maneira menos intensa do que no solo sem resíduo, e o solo mantém uma maior porosidade total, principalmente causada pela maior proporção de poros grandes. Este maior volume de poros grandes é que é responsável pela elevação da condutividade hidráulica do solo próximo à saturação. No entanto, à medida que o potencial mátrico se afasta da saturação, estes poros grandes se esvaziam e a umidade diminui mais acentuadamente no solo que recebeu resíduo. Estes poros grandes esvaziados, associados a uma possível diminuição do volume de microporos, tornam-se barreiras ao movimento da água. Ocorre a redução da área diponível ao fluxo e o aumento na tortuosidade do filme de água que recobre as partículas do solo. Portanto, ocorre diminuição da condutividade intrínseca do solo e, conseqüentemente, da condutividade hidráulica do solo não saturado.

Para o primeiro ano do experimento, as diferenças significativas na condutividade hidráulica foram verificadas a despeito da não ocorrência de efeitos significativos na densidade do solo, na porosidade total do solo e na retenção de água aos potenciais mátricos próximos à saturação. No entanto, cabe ressaltar que pequenas variações na porosidade do solo (eventualmente não significativa numa análise estatística) podem levar a variações expressivas na condutividade hidráulica (por vezes significativas numa análise estatística). Além disso, o possível aumento da atividade biológica no solo devido à aplicação dos resíduos pode levar a formação de caminhos de fluxo preferencial que, ainda que alterem pouco a porosidade total ou a retenção da água, afetariam de maneira mais pronunciada a transmissão da água no solo. Ressalta-se ainda que, enquanto a densidade, a porosidade total e a retenção de água foram determinadas em amostras coletadas na camada de 0,114 a 0,186 $\mathrm{m}$ de profundidade, a condutividade hidráulica foi medida com o infiltrômetro de tensão na superfície, onde a reacomodação estrutural do solo após o revolvimento é menos intenso, dando margem a que efeitos mais pronunciados se manifestem. 
No segundo ano do experimento houve efeito significativo dos tratamentos sobre a condutividade hidráulica para todos os potenciais mátricos estudados, enquanto no primeiro ano esta significância se verificou somente para os potenciais mátricos -0,50 e -1,00 kPa. Esta intensificação dos efeitos dos tratamentos é indício de ocorrência do efeito cumulativo da matéria orgânica, evidenciado pelos maiores conteúdos de carbono orgânico no segundo ano em relação ao primeiro (Tabelas 7 e 8). No entanto, comparando-se a condutividade hidráulica obtida para cada potencial mátrico nos dois anos do experimento, verifica-se que os valores médios no segundo ano foram sistematicamente menores que no primeiro, inclusive na saturação (Tabela 18). Além disso, os valores de condutividade hidráulica de cada parcela obtidos nos dois anos do experimento apresentam baixos coeficientes de correlação para todos os potenciais mátricos estudados $(0,31 ; 0,13 ; 0,57$ e 0,72 , respectivamente para os potenciais mátricos $0 ;-0,25 ;-0,50$ e -1,00 kPa). A variabilidade da condutividade geralmente é maior para o solo saturado que para o solo não saturado, o que justifica que os coeficientes de correlação para os potenciais mátricos mais próximos à saturação $(0 ;-0,25 \mathrm{kPa})$ sejam menores que aqueles dos potenciais mais afastados da saturação (-0,50 e -1,00 kPa).

Ainda que tenham sido obtidos em profundidades diferentes, cabe ressaltar que os valores de condutividade hidráulica determinados com o infiltrômetro de tensão nos dois anos para o potencial mátrico $0 \mathrm{kPa}$ (ou seja, na saturação) são consideravelmente menores que aqueles obtidos para as amostras coletadas no primeiro ano. Verifica-se também uma fraca correlação $(0,33)$ entre os valores condutividade hidráulica de cada parcela obtidos pelos dois métodos no primeiro ano do experimento.

\subsection{Condutividade hidráulica pelo método de Van Genuchten (1980)}

Para o primeiro ano do experimento, a condutividade hidráulica relativa $K_{r}$ foi estimada pela equação 10 (Van Genuchten, 1980). Embora seja possível a sua obtenção para toda a faixa de potencial mátrico utilizada na curva de retenção, optou-se por restringir sua estimativa à mesma faixa de potencial utilizada para o infiltrômetro de tensão (ou seja, 0 a $-1,0 \mathrm{kPa}$ ). Os resultados para os diversos tratamentos são apresentados na Figura 20. Nos gráficos desta Figura pode-se distinguir os mesmos dois 
grupos de condutividade hidráulica observados para o infiltrômetro de tensão, embora não tenham sido determinados na mesma profundidade. $\mathrm{O}$ grupo formado pelos tratamentos que receberam doses de resíduos $(\operatorname{tr} 3, \operatorname{tr} 4$ e tr5 ou tr7, tr8 e tr9) tem um decaimento de $K_{r}$ inicialmente mais acentuado que o grupo formado pelos tratamentos que não receberam resíduos (tr1 e tr2 ou tr1 e tr6). Da mesma forma que para a condutividade hidráulica medida com o infiltrômetro de tensão no primeiro ano, estas diferenças na condutividade hidráulica relativa foram verificadas a despeito da não ocorrência de efeitos significativos na densidade do solo, na porosidade total do solo e na retenção de água aos potenciais mátricos próximos à saturação. Desta forma, as mesmas justificativas apresentadas para a ocorrência de diferenças significativas na condutividade com o infiltrômetro de tensão são válidas para a condutividade relativa.

Outro aspecto é que, embora tenha sido possível a distinção dos mesmos dois grupos de dependência entre condutividade hidráulica e potencial mátrico por ambos os métodos, o decréscimo da condutividade hidráulica com a diminuição do potencial mátrico previsto pelo método de Van Genuchten (1980) é menos acentuado quando comparado ao decréscimo previsto pelo método do infiltrômetro de tensão. Para a faixa de potencial mátrico estudada, a redução da condutividade hidráulica por

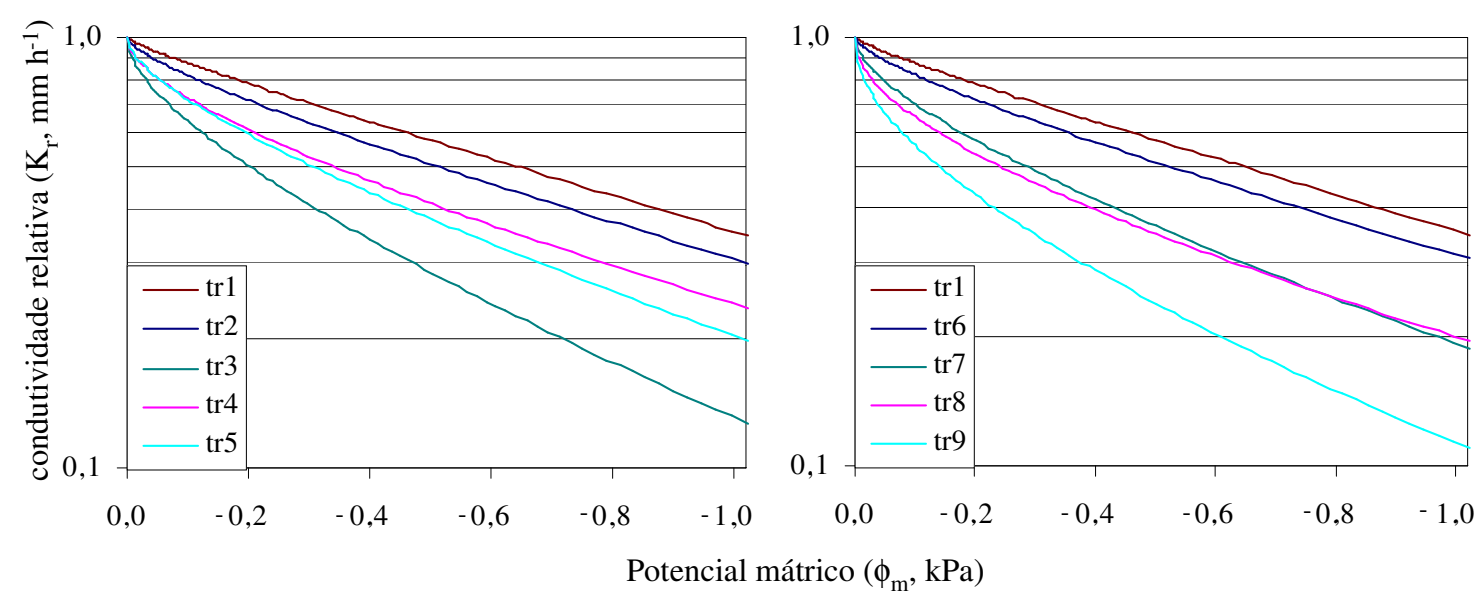

Figura 20. Condutividade hidráulica relativa $\left(K_{r}\right)$ estimada pelo modelo de Van Genuchten (1980) em função do potencial mátrico, no primeiro ano do experimento, para os tratamentos $\operatorname{tr} 1, \operatorname{tr} 2, \operatorname{tr} 3, \operatorname{tr} 4$ e tr5 (referentes à adubação mineral e às doses de lodo de esgoto) e tr $1, \operatorname{tr} 6, \operatorname{tr} 7, \operatorname{tr} 8$ e tr9 (referentes à adubação mineral e às doses de composto de lixo). 
Van Genuchten (1980) foi inferior a uma ordem de grandeza (menor que 10 vezes), enquanto pelo infiltrômetro de tensão foi de aproximadamente duas ordens de grandeza (cerca de 100 vezes). Além de terem sido determinadas em profundidades distintas, duas outras explicações para estas diferenças podem ser dadas. A primeira é que, como no presente caso apenas dois pontos da curva de retenção foram medidos na faixa de potencial mátrico entre 0 a $-1,0 \mathrm{kPa}$, tanto a curva de retenção ajustada quanto os valores de condutividade hidráulica dela obtidos são sujeitos a erros relativamente grandes. A segunda seria as limitações próprias do modelo de Van Genuchten (1980), que por ser baseado na curva de retenção, não teria sensibilidade suficiente para detectar diferenças devidas, por exemplo, a existência de caminhos de fluxo preferencial. Estes caminhos geralmente representam uma fração muito reduzida da porosidade total, sendo portanto pouco relevantes para a retenção de água. No entanto, quando se refere à condutividade hidráulica, sua importância pode ser muito maior.

A substituição dos valores de condutividade hidráulica do solo saturado $K_{0}$ obtidos nas amostras na equação 10 permitiria a obtenção da condutividade hidráulica efetiva do solo em função do potencial mátrico. No entanto, devido aos diversos problemas de variabilidade discutidos no item 4.6, optou-se pela não determinação desta função, uma vez que estes problemas seriam propagados e os resultados não seriam esclarecedores. 


\section{CONCLUSÕES}

Os principais resultados obtidos foram:

- a densidade do solo diminui e a porosidade total aumenta com o aumento das doses dos resíduos, para a camada de 0 a $0,15 \mathrm{~m}$ de profundidade, no segundo ano de aplicação;

- para a faixa de potencial mátrico de 0 a $1 \mathrm{kPa}$, a condutividade hidráulica do solo determinada com o infiltrômetro de tensão em parcelas que recebem aplicações de ambos os resíduos é maior que nas parcelas testemunhas quando próximo à saturação e menor que nas testemunhas à medida que o solo se afasta da saturação;

- a condutividade hidráulica relativa, determinada pelo modelo de Van Genuchten (1980), diminui com a umidade, mais acentuadamente em parcelas que recebem aplicações de ambos os resíduos do que naquelas que não recebem resíduos;

- diferenças na retenção de água e no conteúdo de argila dispersa em água, que seriam atribuídas exclusivamente aos tratamentos pela análise de variância convencional, de fato foram parcial ou totalmente devidas a variações não casuais na composição granulométrica do solo (verificado através de análises de regressão múltipla).

Com base nestes resultados pôde-se concluir que a incorporação de resíduos urbanos ao solo leva a modificações de propriedades como a densidade do solo, a porosidade total, a condutividade hidráulica do solo saturado e a condutividade hidráulica do solo não saturado, podendo-se aceitar a hipótese formulada. Concluiu-se também que a casualização dos tratamentos na área experimental não garante a ausência de covariação entre eles e outras variáveis independentes que possam interferir nas propriedades de interesse (variáveis dependentes), sendo recomendado a realização de um "ensaio em branco" para verificar a eficiência desta casualização. 


\section{REFERÊNCIAS BIBLIOGRÁFICAS}

ABU-SARAR, T.H. Effects of sewage sludge treatments on aggregate slaking, clay dispersion and hydraulic condutivity of a semi-arid soil sample. Geoderma, v.59, p.327-343, 1993.

ABU-SARAR, T.H. Modification of hydraulic properties of a semiarid soil in ralation to seasonal applications of sewage sludge and electrolyte-producing compounds. Soil Technology, v.9, p.1-13, 1996.

ANKENY, M.D.; AHMED, M.; KASPAR, T.C.; HORTON, R. Simple field method for determining unsatured hydraulic condutivity. Soil Science Society of America Journal, v.55, p.467-470, 1991.

BARRETO, M.C. de V. Degradação da fração orgânica de diferentes resíduos e efeitos em algumas propriedades químicas e físicas de dois solos. Piracicaba, 1995. 106p. Tese (Doutorado) - Escola Superior de Agricultura 'Luiz de Queiroz"/ Universidade de São Paulo.

BERTON, R.S. Potencial agrícola do composto de lixo urbano In: CONGRESSO LATINO-AMERICANO DE CIÊNCIA DO SOLO, 13., Águas de Lindóia, 1996, Anais. 1996. Campinas: Sociedade Brasileira de Ciência do Solo, 1996. (Compact disk).

BERTON, R.S.; VALADARES, J.M.A.S. Potencial agrícola do composto de lixo urbano no Estado de São Paulo. O Agronômico, v.4, p.87-93, 1991.

BOUYOUCOS, G.J. Efect of organic matter on de water-holding capacity and the wilting point of mineral soils. Soil Science, v.47, p.377-383, 1939.

BRADY, N.C. The Nature and properties of soils. 10.ed. New York: Macmillan Publishing Company, 1990. 621p.

BROWN, L.C.; WEST, L.T.; BEASLEY, D.B.; FOSTER, G.R. Rill erosion one year after incorporation of crop residue. Transactions of the ASAE, v.33, p.1531-1540, 1990. 
CAMARGO, O.A. Compactação do solo e desenvolvimento de plantas. Campinas: Fundação Cargill, 1983. 41p.

CASTRO, O. M. de. Preparo do solo para a cultura do milho. Campinas: Fundação Cargill, 1989. 41p.

CENTRO NACIONAL DE REFERÊNCIA EM GESTÃO AMBIENTAL URBANA. Utilização agrícola do lodo de esgoto como fertilizante. http://www.bsi.com.br/unilivre/centro/experiencias/015.html. (04 Nov 1998).

CHANG, A.C.; PAGE, A.L.; VARNEKE, J.E. Soil conditioning effects of municipal sludge compost. Journal of Environmental Engeneering, v.109, p.574-583, 1983.

CLAPP, C.E.; STARK, S.A.; CLAY, D.E.; LARSON, W.E. Sewage sludge organic matter ando soil properties. In: Chen; Y.; Avnimelech, Y. (Ed.). The role of organic matter in modern agriculture. Boston: Martinus Nijhoff Publ. 1986. cap.10, p.209-253. (Developments in plant and soil sciences, v.25).

COMPANHIA DE SANEAMENTO DO PARANÁ Publicações. http://www.sanepar.pr.gov.br/ publicação.html. (04 Nov 1998).

CONSTANTINI, A.; LOCH, R.J.; GLANVILLE, S.F.; ORANGE, D.N. Evaluation of the potential to dispose of sewage sludge. I. Soil hydraulic and overland flow properties of Pinus plantations in Queensland Australian Journal of Soil Research, v.33, p.1041-1052, 1995.

DIAS JÚNIOR, M. de S.; PIERCE, F.J. O processo de compactação do solo e sua modelagem. Revista Brasileira de Ciência do Solo, v.20, p.175-182, 1996.

DOURADO NETO, D.; JONG VAN LIER, Q. de. Curvaret: programa computacional. Piracicaba, Depto. de Agricultura/ESALQ/USP, 1992. (Disquete).

EPSTEIN, E. Effects of sewage sludge on some soil physical properties. Journal of Environmental Quality, v.4, p.139-142, 1975.

EPSTEIN, E; TAYLOR, J.M.; CHANEY, R.L. Effects of swage sludge compost applied to soil on some physical and chemical properties. Journal of Enviromental Quality, Madison, v.5, p.422-426, 1976. 
FELTON, G.K. Temporal variation of soil hydraulic properties on municipal solid waste amended mine soils. Transactions of the ASAE, v.38, p.775-782, 1995.

GALLARDO-LARA, F.; NOGALES, R. Effect of the application of town refuse compost on the soil-plant system: a review. Biological Wastes, v.19, p.35-62, 1987.

GEE, G.W.; BAUDER, J.C. Particle size anasysis. In: KLUTE, A. (Ed.) Methods of soil analysis: physical and mineralogical methods. 2.ed. Madison: American Society of Agronomy / Soil Science Society of America, 1986. cap.15, p.383-411.

GERARD, C.J. The influence of soil moisture, sois texture, drying conditions, and exchangeable cations on soil strength. Soil Science Society of America Proceedings, v.29, p.641-645, 1965.

GLÓRIA, N.A. da. Uso agronômico de resíduos. In: REUNIÃO BRASILEIRA DE FERTILIDADE DO SOLO E NUTRIÇÃO DE PLANTAS, 22., Piracicaba, 1992, Anais. Campinas: Fundação Cargill, 1992. p.195-212.

GUPTA, S.C.; DOWDY, R.H.; LARSON, W.E. Hidraulic and thermal properties of a sandy soil as influenced by incorporation of swage sludge. Soil Science Society of America Journal, v.41, p.601-605, 1977.

HERNANDEZ, T; COSTA, F.; LAX, A.; CEGARRA, J.; ROIG, A., MORENO, J.I. Transformations of carbon and nitrogen in a Calciorthid soil amended with a range of organic residues. Plant and Soil, v.105, p.205-211, 1988.

HILL, R.L.; JAMES, B.R. The influence of waste amendments on soil properties. In: RECHCIGL, J.E. (Ed.). Soil amendments and environmental quality. Boca Raton: Lewis Publishers, 1995. cap.8, p.311-325.

JACOBOWITZ. L.A.; STEENHUIS, T.S. Compost impact on soil moisture and temperature. Biocycle, v.25, p.56-60, 1984.

KHALEEL, R; REDDY, K.R.; OVERCASH, M.R. Journal of Enviromental Quality, v.10, p.133-141, 1981.

KIEHL, E.J. Manual de edafologia: relações solo planta. São Paulo: Ceres, 1979. $264 p$. 
KLADIVKO, E.J.; NELSON, D.W. Changes in the soil properties from application of anaerobic sludge. Journal of Water Pollution Control Fed., v.51, p.325-332, 1979.

KLEIN; V.A. Densidade do solo em área com plantio direto submetido a diferentes manejos. In: CONGRESSO LATINO AMERICANO DE CIÊNCIA DO SOLO "SOLO-SUELO 96", 13. Anais. Águas de Lindóia-SP, 1996. Campinas: Sociedade Brasileira de Ciência do Solo, 1996. (Compact Disc).

KLUTE, A. \& JACOB, W.C. Physical properties of sassafras silt loam as affected by long-time organic matter additions. Soil Science Society of America Proceedings, Madison, v.14, p.24-28, 1949.

KUMAR, S.; MALIK, R.S.; DAHIYA, I.S. Influence of different organic wastes upon water retention, transmission and contact characteristics of a sandy soil. Australian Journal of Soil Reserch, v.23, p.131-136, 1985.

LIMA, J.S.; LICHTIG, J.; OLIVEIRA, E. de; MENK, J.R.F. Composto feito de lixo pode contaminar hortaliças. Ciência Hoje, v.24, p.57-59, 1998.

LOGAN, T.J.; HARRISON, B.J. Physical characteristics of alkaline stabilized sewage sludge (N-ViroSoil) and their effects on soil physical properties. Jounal of Environmental Quality, v.24, p.153-164, 1995.

LOGAN, T.J.; HARRISON, B.J.; McAVOY, D.C.; GREFF, J.A. Effects of olestra in sewage sludge on soil physical properties. Jounal of Environmental Quality, v.25, p.153-161, 1996.

MARTENS, D.A.; FRANKENBERGER JR., W.T. Modification of infiltration rates in a organic-amended irrigated soil. Agronomy Journal, v.84, p.707-717, 1992.

MATTIAZZO-PREZZOTTO, M.E. Química ambiental e Agronomia. In: REUNIÃO BRASILEIRA DE FERTILIDADE DO SOLO E NUTRIÇÃO DE PLANTAS, 22., Piracicaba, 1992, Anais. Campinas: Fundação Cargill, 1992. p.157-178.

MBAGWU, J.S.C. \& PICCOLO, A. Some physical properties of structural aggregates separated from organic waste-amended soils. Biological Wastes, v.33, p.107-121, 1990. 
METZGER, L. \& YARON, B. Influence of sludge organic matter on soil physical properties. Advances in Soil Science, v.7, p.141-163, 1987.

MORAES, S.O. Heterogeneidade hidráulica de uma terra roxa estruturada. Piracicaba, 1991. 141p. Tese (Doutorado) - Escola Superior de Agricultura 'Luiz de Queiroz'/ Universidade de São Paulo.

MOREL, J.L.; GUCKERT, A.; SEDOGO, M. Effets de l' épandage des boues résiduaires urbaines sur l' état physique du sol.Bull. ENSAIA, v.20, p.13-19, 1978.

MUALEM, Y. A new model for predicting the hydraulic condutivity of unsaturated porus media. Water Resource Research, v.12, p.513-522, 1976.

OBREZA, T.A. \& REEDER, R.K. Municipal solid waste compost use in tomato/watermelon successional cropping. Soil and Crop Science Society of Florida, v.53, p.13-19, 1994.

OLIVEIRA, F.C. Metais pesados e formas nitrogenadas em solos tratados com lodo de esgoto. Piracicaba, 1995. 106p. Dissertação (Mestrado) - Escola Superior de Agricultura 'Luiz de Queiroz’/Universidade de São Paulo.

PERROUX, K.M.; WHITE, I. Designs for disc permeameters. Soil Science Society of America Journal, v.52, p.1205-1215, 1988.

PIMENTEL GOMES, F. Curso de estatística experimental. 13.ed. Piracicaba: Nobel, 1990. 467p.

RENGASAMY, P.; OADES, J.M.; HANCOCK, T.W. Improvement of soil structure and plant growth by addition alum sludge. Communications in Soil Science and Plant Analysis, v.11, p.533-545, 1980.

SETZER, J. Atlas climático e ecológico do Estado de São Paulo. São Paulo: Comissão Interestadual da Bacia Paraná-Uruguai, 1966. 61p. 
SPIRONELlO, A.; RAIJ, B. van; PENATTI, C.P.; CANTARELLA, H.; MORELLI, J.L.; ORLANDO FILHO, J.; LANDELL, M.G.A.; ROSSETTO, R.; Cana-de-açúcar. In: RAIJ, B. van; CANTARELLA, H.; QUAGGIO, J.A.; FURLANI, A.M.C. (Ed.). Recomendações de adubação e calagem para o Estado de São Paulo. Campinas: IAC, 1996. p.237-239.

TERRY, R.E.; NELSON, D.W.; SOMMERS, L.E. Carbon cycling during sewage sludge decomposition in soils. Soil Science Society of America Journal, v.54, p.827-831, 1979 .

VAN GENUCHTEN, M.T. A closed form equation for predicting the hidraulic condutivity of unsaturated soil. Soil Science Society of America Journal, v.44, p.892-897, 1980.

VAN ES, H.M.; VAN ES, C.L. Spatial nature of randomization and its effect on the outcome of field experiments. Agronomy Journal, v.85, p.420-428, 1993.

WALKLEY, A.; BLACK, I.A. An examination of the Degtjareff method for determining soil organic matter and a proposed modification of the chromic acid titration method. Soil Science, v.37, p.29-38, 1934.

WALLACE, A.; WALLACE, G.A. A possible flaw in EPA' 1993 new sludge rule due to heavy metal interactions. Communications in Soil Science and Plant Analysis, v.25, p.129-135, 1994.

WARRICK, A.W.; NIELSEN, D.R. Spatial Variability of Soil Physical Properties in the field. In: HILLEL, D. (Ed.) Aplications of Soil Physics. New York, Academic Press, 1980. p.319-344.

WEI, Q.F.; LOWERY, B.; PETERSON, A.E. Effect of sludge application on physical properties of a silty clay loam soil. Journal of Environmental Quality, v.14, p.178-180, 1985 .

WEST, L.T.; MILLER, W.P.; BRUCE, R..R; LANGDALE, G.W.; LAFLEN, J.M.; THOMAS, A.W. Crooping system and consolidation effects on rill erosion in the Georgia piedmont. Soil Science Society of America Journal, v.56, p.1238-1243, 1992 
WOODING, R.A. Steady infiltration from a shallow circular pond. Water Resource Research, v.4, p.1259-1273, 1968.

YOUNGS, E.G. Hidraulic condutivity of saturated soils. In: SMITH, K.A; MULLINS, C.E. (Ed.) Soil analysis: physical methods. New York: Marcel Dekker, 1991. cap.4,p.161-207. 


\section{APÊNDICE}

\section{Determinação da condutividade hidráulica a partir de medidas com infiltrômetro de tensão, pelo método de Ankeny et al. (1991)}

A partir dos valores de fluxo estacionário $\left(q, \mathrm{~m} \mathrm{dia}^{-1}\right)$ da infiltração tridimensional medida com o infiltrômetro de tensão, obtidos para dois diferentes valores de potencial mátrico ou tensão da água no solo $(\tau)$, Ankeny et al. (1991) propuseram uma metodologia para cálculo das condutividades hidráulicas $\left(K, \mathrm{~m} \mathrm{dia}^{-1}\right)$. Esta metodologia é baseada na expressão algébrica simplificada proposta por Wooding (1968)

$$
q(\tau)=K(\tau)+\frac{4 \phi(\tau)}{\pi r}
$$

onde $q, K$ e $\phi$ (chamado potencial de fluxo mátrico, $\mathrm{em} \mathrm{m}^{2} \mathrm{~s}^{-1}$ ) são funções da tensão da água no solo. O potencial de fluxo mátrico $\phi$ é definido como

$$
\phi(\tau)=\int_{\tau_{i}}^{\tau_{1}} K(\tau) d \tau
$$

sendo $\tau_{i}$ uma tensão inicial da água no solo e $\tau_{1}$ a tensão final, utilizada no infiltrômetro de tensão. Assumindo que a relação entre $K(\tau)$ e $\phi_{(\tau)}$ entre duas tensões $\tau_{1}$ e $\tau_{2}$ é uma constante $\alpha$, obtemos que

$$
\phi\left(\tau_{1}\right)=K\left(\tau_{1}\right) / \alpha
$$

$\mathrm{e}$

$$
\phi\left(\tau_{2}\right)=K\left(\tau_{2}\right) / \alpha
$$

que substituídas na equação [A1] fornecem

$$
q\left(\tau_{1}\right)=\left(1+\frac{4}{\pi r \alpha}\right) K\left(\tau_{1}\right)
$$




$$
q\left(\tau_{2}\right)=\left(1+\frac{4}{\pi r \alpha}\right) K\left(\tau_{2}\right)
$$

Estas duas equações têm três incógnitas $(q, K$ e $\alpha)$, e é preciso obter mais uma equação para que se possa calcular os valores dessas incógnitas. Obtendo-se a diferença $\phi\left(\tau_{1}\right)-\phi\left(\tau_{2}\right)$ das equações [A3] e [A4], tem-se

$$
\phi\left(\tau_{1}\right)-\phi\left(\tau_{2}\right)=\frac{K\left(\tau_{1}\right)-K\left(\tau_{2}\right)}{\alpha}
$$

Esta mesma diferença $\phi\left(\tau_{1}\right)-\phi\left(\tau_{2}\right)$ obtida por aproximação numérica a partir da equação [A2], fornece

$$
\phi\left(\tau_{1}\right)-\phi\left(\tau_{2}\right)=\Delta \tau\left[\frac{K\left(\tau_{1}\right)+K\left(\tau_{2}\right)}{2}\right]
$$

Das equações [A7] e [A8] obtém-se

$$
\frac{K\left(\tau_{1}\right)-K\left(\tau_{2}\right)}{\alpha}=\Delta \tau\left[\frac{K\left(\tau_{1}\right)+K\left(\tau_{2}\right)}{2}\right]
$$

As equações [A5], [A6] e [A9] formam um sistema com três equações e três incógnitas. Para sua resolução, deve-se explicitar $K\left(\tau_{1}\right)$ na equação [A5], $K\left(\tau_{2}\right)$ na equação [A6] e $\alpha$ na equação [A9], obtendo-se

$$
\begin{aligned}
& K\left(\tau_{1}\right)=q\left(\tau_{1}\right) /\left(1+\frac{4}{\pi r \alpha}\right) \\
& K\left(\tau_{2}\right)=q\left(\tau_{2}\right) /\left(1+\frac{4}{\pi r \alpha}\right)
\end{aligned}
$$

$\mathrm{e}$ 


$$
\alpha=\frac{2\left[K\left(\tau_{1}\right)-K\left(\tau_{2}\right)\right]}{\Delta \tau\left[K\left(\tau_{1}\right)+K\left(\tau_{2}\right)\right]}
$$

Substituindo-se as equações [A10] e [A11] na equação [A12], obtém-se

$$
\alpha=\frac{2\left[q\left(\tau_{1}\right)-q\left(\tau_{2}\right)\right]}{\Delta \tau\left[q\left(\tau_{1}\right)+q\left(\tau_{2}\right)\right]}
$$

As equações 10, 11 e 13 formam o mesmo sistema citado anteriormente, com três equações e três incógnitas, porém apresentando explicitados $K\left(\tau_{1}\right), K\left(\tau_{2}\right)$ e $\alpha$. A partir de dois pares de fluxo estacionário de infiltração e tensão, podemos calcular $\alpha$ pela equação 13 e $K\left(\tau_{1}\right)$ e $K\left(\tau_{2}\right)$ pelas equações 10 e 11 . 